ESCOLA DE ENFERMAGEM DA

UNIVERSIDADE DE SÃO PAULO

CRISTINA HELENA COSTANTI SETTERVALL

INTERVENÇÕES PARA ADESÃO TERAPÊUTICA

MEDICAMENTOSA DE PACIENTES COM EPILEPSIA

SÃo PAULO

2014 
CRISTINA HELENA COSTANTI SETTERVALL

\section{INTERVENÇÕES PARA ADESÃO TERAPÊUTICA MEDICAMENTOSA DE PACIENTES COM EPILEPSIA}

Tese apresentada ao Programa de Pósgraduação em Enfermagem na Saúde do Adulto (PROESA) da Escola de Enfermagem da Universidade de São Paulo para obtenção de título de Doutor em Ciências.

Área de Concentração: Enfermagem na Saúde do Adulto

Orientadora: $\operatorname{Prof}^{\mathrm{a}} \operatorname{Dr}^{\mathrm{a}}$ Regina Marcia Cardoso de Sousa

Versão Corrigida. O exemplar original se encontra na Biblioteca da Escola de Enfermagem da Universidade de São Paulo.

\section{SÃo PAULO}


AUTORIZO A REPRODUÇÃO E DIVULGAÇÃO TOTAL OU PARCIAL DESTE TRABALHO, POR QUALQUER MEIO CONVENCIONAL OU ELETRÔNICO, PARA FINS DE ESTUDO E PESQUISA, DESDE QUE CITADA A FONTE.

Assinatura:

Data:

Catalogação na Publicação (CIP)

Biblioteca "Wanda de Aguiar Horta"

Escola de Enfermagem da Universidade de São Paulo

Settervall, Cristina Helena Costanti

Intervenções para adesão terapêutica medicamentosa de pacientes com epilepsia. -- São Paulo, 2014.

$129 \mathrm{p}$.

Tese (Doutorado) - Escola de Enfermagem da Universidade de São Paulo.

Orientadora: Profa. Dra. Regina Marcia Cardoso de Sousa Área de concentração: Enfermagem na Saúde do Adulto

1. Adesão à medicação. 2. Assistência ambulatorial. 3. Epilepsia. 4. Terapêutica. I. Título. 


\section{Nome: Cristina Helena Costanti Settervall}

Título: Intervenções para adesão terapêutica medicamentosa de pacientes com epilepsia.

Tese apresentada ao Programa de Pós-graduação em Enfermagem na Saúde do Adulto da Escola de Enfermagem da Universidade de São Paulo para obtenção de título de Doutor em Ciências.

Aprovado em:

Banca Examinadora:

Nome:

Instituição:

Julgamento:

Assinatura:

Nome:

Instituição:

Julgamento:

Assinatura:

Nome:

Instituição:

Julgamento:

Assinatura:

Nome:

Instituição:

Julgamento:

Assinatura:

Nome:

Instituição:

Julgamento:

Assinatura: 


\section{DEDICATÓRIA}

Aos meus pais Alexandre e Cecília, pelo apoio e incentivo incondicional que recebi e recebo em toda minha vida. Dedico a vocês todas minhas conquistas.

Ao meu marido Ricardo, pelo amor, compreensão e apoio, na construção desse projeto e da nossa nova família.

Aos meus irmãos Ingrid e Alexandre, que compreenderam minhas ausências e foram sempre porto seguro para mim.

Às minhas sobrinhas Amanda e Alice que, mesmo longe, me trazem inspiração para acreditar sempre. 


\section{AGRADECIMENTOS}

À Regina Marcia Cardoso de Sousa, pela experiência, sabedoria, dedicação, profissionalismo e amizade construída ao longo desses anos.

À Carla Maria Maluf Ferrari, pela amizade, exemplo e oportunidade de encarar novos desafios. Sem você, nada disso seria possivel.

Ao Dr. Luiz Henrique Martins Castro, pela oportunidade, disponibilidade e confiança na realização deste projeto.

À Daniela Bezerra da Silva Costa e ao Jorge Getzoff, pela alegria e apoio na coleta de dados. Vocês me trouxeram forças para perseverar.

À Prof ${ }^{a}$. Dra ${ }^{a}$. Angela Maria Geraldo Pierin, pelas valiosas contribuições no exame de qualificação.

Aos Doutores Rosa Maria Figueredo Valério, Carmen Lisa Jorge, Inah Carolina G. F. Proença e Valmir Passarelli, pelas contribuições e auxílio durante toda coleta de dados.

Aos queridos Márcia, Antônio e Aparecida, pela companhia agradável e exemplo de dedicação.

Aos pacientes participantes da pesquisa, pela fonte de inspiração.

À equipe da Secretaria e Serviço de Enfermagem do Ambulatório de Neurologia do HCFMUSP, pela disponibilidade e recepção amiga. 
À equipe da Divisão de Laboratório do Instituto Central, pela organização e seriedade na coleta e análise das amostras.

Ao Lucas Petri Damiani, pela colaboração valiosa na análise estatística do projeto.

Ao Queni Winters, pela eficiência e prontidão para revisão do texto.

A todos os docentes do PROESA, pela seriedade e colaboração intensa na minha formação.

À Secretaria de Pós-graduação da Escola de Enfermagem da USP, pela eficiência $e$ disponibilidade em serviços administrativos.

A todos os funcionários da Escola de Enfermagem da USP, pela gentileza $e$ acolhimento.

Às amigas e companheiras Lilia de Souza Nogueira, Mariana Alvina, Cristiane de Alencar Domingues, Rita de Cássia Almeida Vieira, Rafaela Andolhe, Erika de Souza Guedes e Luciana Reberte, pela alegria, apoio e força nessa jornada.

A toda a equipe e amigos do Conjunto Hospitalar do Mandaqui, especialmente a enfermeira Kazue Watanabe, pela compreensão e apoio.

E aos familiares $\boldsymbol{e}$ amigos que me influenciaram positivamente em todas etapas deste projeto. 
Estranha é nossa situação aqui na Terra. Cada um de nós chega para uma breve visita, sem saber por quê, parece que às vezes por um propósito divino. Do ponto de vista da vida cotidiana, porém, existe uma coisa que sabemos de fato: que estamos aqui pelo bem dos outros." 
Settervall, CHC. Intervenções para adesão terapêutica medicamentosa de pacientes com epilepsia [tese] São Paulo: Escola de Enfermagem da Universidade de São Paulo, 2014.

\section{RESUMO}

Objetivo: O presente estudo objetivou comparar o efeito da intervenção de instrução complementar isolada e associada a recursos auxiliares, na adesão terapêutica medicamentosa de pacientes com epilepsia, além de verificar a correlação entre as medidas de adesão utilizadas - dosagem sérica de drogas antiepilépticas (DAEs), frequência de crises e autorrelato. Método: Realizou-se uma pesquisa clínica, experimental, incluindo 91 indivíduos com diagnóstico de epilepsia em acompanhamento ambulatorial que apresentavam alteração na adesão ao tratamento medicamentoso (Universal Trial Number- U1111-1142-3660). A alocação foi realizada de forma randomizada em Grupo Intervenção 1 (instrução complementar), Intervenção 2 (instrução complementar e lembrete da tomada da medicação por alarme de celular) e Intervenção 3 (instrução complementar e caixa organizadora de medicação). As mensurações da adesão foram realizadas imediatamente antes e quatro semanas após a implantação das intervenções. Resultados: A distribuição dos participantes quanto ao gênero foi similar. A idade média foi de 37,8 anos $(\mathrm{dp}=12,1)$. A escolaridade foi, em média, de 9,8 anos ( $\mathrm{dp}=$ $3,3)$. Cerca de metade dos pacientes era da raça negra, não tinha vínculo conjugal e não estava inserida no mercado de trabalho. A duração do tratamento com DAEs foi em média de 20,7 anos ( $\mathrm{dp}=12,9)$, o Índice de Complexidade do Tratamento Medicamentoso em Epilepsia (ICTME) médio foi 18,8 pontos $(\mathrm{dp}=9,8)$, predominou a politerapia $(68,3 \%)$ e as crises do tipo focal sintomática $(75,6 \%)$. Na avaliação inicial, 59,4\% dos pacientes tinham percepção de que suas crises não estavam adequadamente controladas e os participantes da amostra informaram apresentar em média 4,9 crises no mês anterior $(\mathrm{dp}=13,0)$. Indicação de baixa e média adesão pelo teste de Morisky foi um critério para inclusão na amostra e $84,6 \%$ dos participantes apresentou média adesão antes das intervenções. Na dosagem sérica inicial das DAEs, somente $42 \%$ dos participantes tiveram nível inferior ao terapêutico. Não houve correlação entre os resultados das medidas de adesão utilizadas, também não houve associação estatisticamente significativa das categorias do Morisky com a presença de crises e dosagem sérica inferior ao nível terapêutico. Além de tudo, a presença de crise foi independente da dosagem sérica abaixo da desejável. Segundo o teste de Morisky, os três grupos apresentaram melhora na adesão, significativa $(\mathrm{p}<0,001)$ e similar $(\mathrm{p}=0,870)$, após as intervenções. A frequência de crises e a dosagem sérica indicaram que somente o grupo de intervenção 2 apresentou aumento na adesão na avaliação final; entretanto, quando o efeito clínico desejado com as intervenções foi analisado, não se observou diferença estatisticamente significativa entre os três grupos. Conclusão: A instrução complementar, sobre a doença e regime terapêutico prescrito, aplicada isoladamente apresentou efeito similar ao seu uso associado com o lembrete de tomada de medicamentos por alarme de celular e caixa organizadora de medicamentos. Não obstante, os valores das medidas de adesão não convergiram e, enquanto o escore do teste de Morisky indicou o aumento da adesão dos três grupos após as intervenções, a dosagem sérica e a frequência de crises apontaram essa melhora somente no grupo em que o alarme de celular foi utilizado.

Palavras-Chave: Adesão à medicação, Assistência ambulatorial, Epilepsia, Estudo de intervenção. 
Settervall, CHC. Interventions to enhance medication adherence of patients with epilepsy [thesis] São Paulo: Escola de Enfermagem da Universidade de São Paulo, 2014.

\begin{abstract}
Goal: This study's purpouse is compare the effect of the intervention of additional instruction alone and its association to ancillary resources to the medication adherence of patients with epilepsy, as well as investigate the correlation between the adherence measures used - serum levels of antiepileptic drugs (AEDs), frequency of crisis and self-report. Method: We performed a clinical, experimental research, including 91 individuals with a diagnosis of epilepsy in outpatient following with altered adherence to drug treatment (Universal Trial NumberU1111-1142-3660). The allocation was done randomly in Intervention Group 1 (supplementary statement), Intervention 2 (supplementary investigation and medication reminder alarm of mobile phone) and Intervention 3 (supplementary instruction and medication organizer box). Measurements were taken immediately before and four weeks after the implantation of the interventions. Results: The distribution of participants according to gender was similar. The average age was 37,8 years $(\mathrm{SD}=12,1)$. Schooling was on average 9,8 years $(\mathrm{SD}=3,3)$. About half of patients were black, had no marital bond and were not inserted in the labor market. The treatment with AEDs lasted on average 20,7 years $(\mathrm{SD}=12,9)$, the Epilepsy Medication and Treatment Complexity Index (EMTCI) average was 18,8 points $(\mathrm{SD}=9,8)$, polytherapy $(68,3 \%)$ and symptomatic focal seizures $(75,6 \%)$ were predominant. At baseline, 59,4\% of patients thought that their seizures were not adequately controlled and the sample reported an average of 4,9 seizures the previous month $(\mathrm{SD}=13,0)$. Indication of low and intermediate adherence by Morisky test was a criterion for inclusion in the sample and 84,6\% of participants showed an average adherence before interventions. Considering the initial serum levels of AEDs, only $42 \%$ of participants had less than the therapeutic level. There was no correlation between the results of the adherence measures used, and there was no statistically significant association of the categories of Morisky on the presence of seizures and serum level less than the therapeutic level. Above all, the frequency of crisis was independent of the serum level below the desired dosage. According to the Morisky test, the three groups showed improvement in adherence, significant $(\mathrm{p}<0,001)$ and similar $(\mathrm{p}=0,870)$ after the intervention. The frequency of seizures and the serum level indicated that only the intervention group 2 showed increase in adherence at the final evaluation; however, when the desired clinical effect with the interventions was analyzed, no statistically significant difference among the three groups was seen. Conclusion: The additional instruction on the illness and prescribed treatment regimen applied alone had similar effect to its use associated with medication reminder alarm by mobile phone and medication organizer box. Nevertheless, the values of the adherence measurements have not converged, and while the score of the Morisky test indicated increased adherence of the three groups after intervention, the serum level and the frequency of seizures showed improvement only in the group where the alarm cell was used.
\end{abstract}

Keywords: Medication Adherence; Ambulatory Care; Epilepsy; Intervention Study. 


\section{LISTA DE ILUSTRAÇÕES}

Figura 1 Porta-comprimidos com 28 espaços G-Life ${ }^{\circledR}$

Figura 2 Fluxograma da Composição dos Grupos de Pesquisa. São Paulo, 2013-2014.

Gráfico 1- Porcentagem dos pacientes, segundo medicamento prescrito. São Paulo, 2013-2014.

Gráfico 2- Distribuição dos pacientes $(n=91)$, segundo categoria de adesão pelo teste de Morisky (n=91). São Paulo, 2013-2014.

Gráfico 3- Porcentagem de pacientes que deram respostas afirmativas às questões do teste de Morisky. São Paulo, 2013-2014.

Gráfico 4- Gráficos de dispersão 2 a 2 e coeficiente de correlação de Spearman entre as variáveis escore do teste de Morisky, frequência de crises nos últimos 30 dias e dosagem sérica padronizada. São Paulo. 2013-2014. .....63

Gráfico 5- Porcentagem de pacientes que participaram das duas fases do estudo e deram respostas afirmativas às questões do teste de Morisky segundo tempo. São Paulo, 2013-2014. 


\section{LISTA DE TABELAS}

Tabela 1 Distribuição dos pacientes $(n=91)$, segundo sexo, idade, vinculo conjugal e raça.

São Paulo, 2013-2014.

Tabela 2 Distribuição dos pacientes $(\mathrm{n}=91)$, segundo escolaridade e situação ocupacional.

São Paulo, 2013-2014.

Tabela 3 Distribuição dos pacientes $(\mathrm{n}=91)$, segundo renda per capita familiar (R\$). São Paulo, 2013-2014.

Tabela 4 Distribuição dos pacientes ( $n=91$ ), segundo tipo de crise, tempo de diagnóstico de epilepsia e de tratamento com DAEs. São Paulo, 2013-2014.

Tabela 5 Distribuição dos pacientes com diagnóstico de crise focal sintomática $(n=69)$, segundo evidência de lesão, localização de lesão e presença de esclerose mesial temporal. São Paulo, 2013-2014.

Tabela 6 Distribuição dos pacientes com epilepsia (n=91), segundo ICTME total e número de DAEs em uso. São Paulo, 2013-2014.

Tabela 7- Distribuição dos pacientes ( $\mathrm{n}=91)$, segundo aquisição das DAEs no HCFMUSP e procedimento quando falta medicamento. São Paulo, 2013-2014.

Tabela 8 Distribuição dos pacientes $(n=91)$, segundo a percepção quanto ao controle de crises e apoio de familiares e amigos. São Paulo, 2013-2014.

Tabela 9- Distribuição dos pacientes $(n=91)$ segundo frequência de crises nos últimos 30 dias. São Paulo, 2013-2014.

Tabela 10 Distribuição dos pacientes de acordo com DAEs dosadas e estatísticas descritivas dos resultados das dosagens séricas realizadas $\left(\mathrm{n}=89^{¥}\right)$. São Paulo, 2013-2014.

Tabela 11 Estatísticas descritivas e inferenciais para frequência de crises nos últimos 30 dias e dosagem sérica padronizada segundo categorias de adesão do teste de Morisky. São Paulo, 2013-2014.

Tabela 12 Distribuição dos pacientes $\left(n=90^{¥}\right)$ segundo categoria do teste de Morisky e presença de crises nos últimos 30 dias. São Paulo, 2013-2014.

Tabela 13 Distribuição dos pacientes $\left(n=89^{¥}\right)$ segundo categoria do teste de Morisky e presença de baixo nível sérico das DAEs para controle de crise. São Paulo, 2013-2014.

Tabela 14 Distribuição dos pacientes $\left(n=88^{\ddagger}\right)$ segundo presença de crises nos últimos 30 dias e baixo nível sérico das DAEs para controle de crises. São Paulo, 2013-2014

Tabela 15 Comparação dos grupos de intervenção segundo variáveis numéricas tendo em vista os participantes até fase final do estudo (n=62). São Paulo 2013-2014.

Tabela 16 Comparação dos grupos de intervenção segundo variáveis categóricas tendo em vista os participantes até fase final do estudo (n=62). São Paulo, 2013-2014

Tabela 17 Distribuição conjunta dos pacientes que participaram das duas fases do estudo $(n=62)$, segundo escores no teste de Morisky e tempo. São Paulo 2013-2014.

Tabela 18 Distribuição conjunta dos pacientes que participaram das duas fases do estudo ( $n=62)$, segundo classificação no teste de Morisky e tempo. São Paulo, 2013-2014. 
Tabela 19 Distribuição conjunta dos pacientes que participaram das duas fases do estudo ( $n=62$ ), segundo frequência de crises nos últimos 30 dias e tempo. São Paulo, 2013-2014.

Tabela 20 Distribuição dos pacientes que participaram das duas fases do estudo $\left(n=57^{¥}\right)$ segundo a presença de dosagem sérica abaixo do nível terapêutico e tempo (inicial e final). São Paulo, 2013-2014.

Tabela 21 Resultado do teste de Morisky dos pacientes que participaram das duas fases do estudo ( $n=62)$ por grupo de intervenção e tempo. São Paulo, 2013-2014.

Tabela 22 Estatísticas descritivas e inferenciais para diferença do escore de Morisky entre tempos (final - inicial) segundo grupo de intervenção. São Paulo, 2013-2014.

Tabela 23 Comparação do efeito dos três grupos de intervenção segundo classificação do teste de Morisky, considerando pacientes que participaram das duas fases do estudo $(n=62)$. São Paulo, 2013-2014.

Tabela 24 Estatísticas descritivas para frequência de crises por grupo e tempos considerando pacientes que participaram das duas fases do estudo $(n=62)$. São Paulo, 20132014

Tabela 25 Estatísticas descritivas e inferenciais para diferença da frequência de crises entre tempos (final - inicial) segundo grupo de intervenção. São Paulo, 2013-2014.

Tabela 26 Comparação do efeito dos três grupos de intervenção segundo frequência de crises, considerando pacientes que participaram das duas fases do estudo $(n=62)$. São Paulo, 2013-2014.

Tabela 27 Estatísticas descritivas e inferenciais para diferença da dosagem sérica padronizada entre tempos (final - inicial) segundo grupo de intervenção. São Paulo, 20132014

Tabela 28 Evolução clínica da dosagem sérica das DAEs, considerando pacientes que participaram das duas fases do estudo $(\mathrm{n}=57)$. São Paulo, 2013-2014.

Tabela 29 Comparação do efeito dos três grupos de intervenção segundo dosagem sérica, considerando pacientes que participaram das duas fases do estudo $(n=57)$. São Paulo, 20132014. 


\section{LISTA DE SIGLAS}

DAE - Droga Antiepiléptica

EEUSP - Escola de Enfermagem da Universidade de São Paulo

HCFMUSP- Hospital das Clínicas da Faculdade de Medicina da Universidade de São Paulo

HIV- Vírus da Imunodeficiência Humana

ICTME- Índice de Complexidade do Tratamento Medicamentoso em Epilepsia

ILAE- International League Against Epilepsy

MEMS- Medication Event Monitoring System

OMS- Organização Mundial da Saúde

SEE- Sepulveda Epilepsy Education

SMS- Short Message Service

SUS- Sistema Único de Saúde

UTN- Universal Trial Number 


\section{SUMÁRIO}

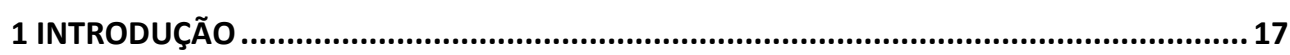

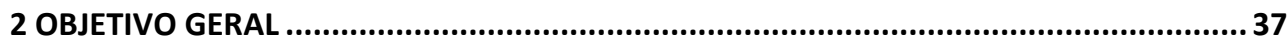

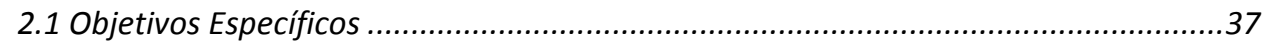

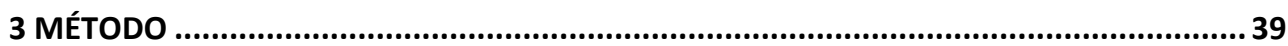

3.1 Local do Estudo

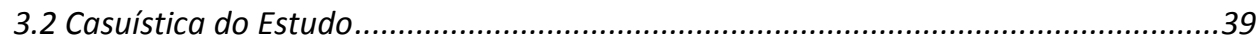

3.3 Grupos de Intervenção ......................................................................................40

3.3.1 Grupo Intervenção 1 - Instrução Complementar Isolada.....................................40

3.3.2 Grupo Intervenção 2 - Instrução Complementar Associada com Lembrete de Tomada dos Medicamentos por Alarme de Celular......................................................41

3.3.3 Grupo Intervenção 3 - Instrução Complementar Associada com Caixa

Organizadora de Medicamentos ...........................................................................41

3.4 Amostragem e Alocação dos Pacientes.................................................................42

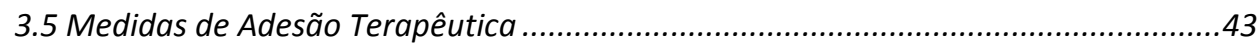

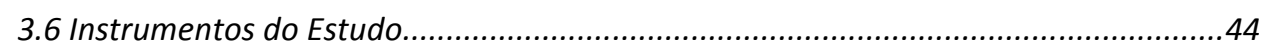

3.6.1 Instrumento para Seleção dos Participantes da Pesquisa (Apêndice D) ..............44

3.6.2 Termo de Consentimento Livre e Esclarecido (Apêndice A) ..................................44

3.6.3 Formulário para Entrevista (Apêndice E) ...........................................................4

3.6.4 Índice de Complexidade do Tratamento Medicamentoso em Epilepsia (ICTME)

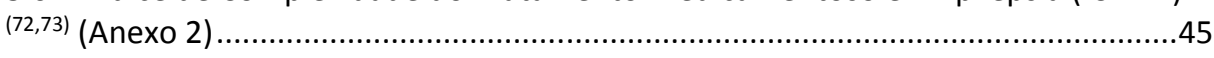

3.6.5 Diário de Medicação (Apêndice B) ................................................................45

3.6.6 Instrumento para Acompanhamento (Apêndice F) ..........................................45

3.7 Operacionalização da Coleta de Dados..................................................................45

3.7.1 Fase 1 ou Tempo Inicial $($ Tempo $=0)$...............................................................4

3.7.2 Fase 2 ou Tempo Final (Tempo $=4$ semanas) ……..............................................49

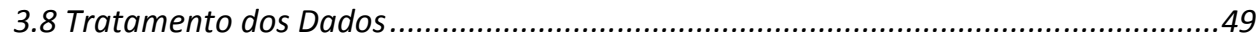

3.8.1 Tratamento dos Resultados das Medidas de Adesão ..........................................5

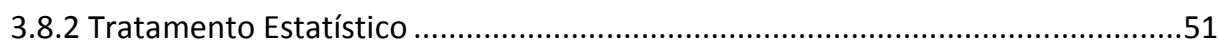

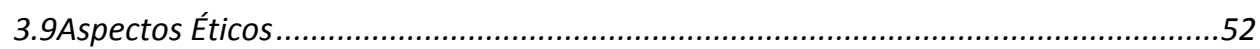

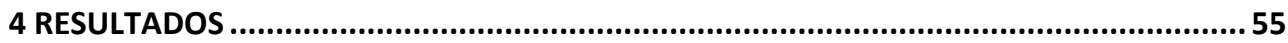

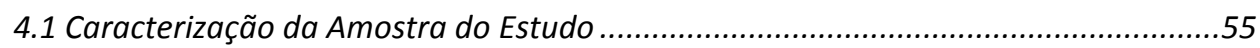

4.2 Medidas de Adesão ao Tratamento Medicamentoso ..............................................60

4.3 Comparação das Características Demográficas, Clínicas e Relacionadas ao Tratamento dos Grupos de Intervenção...................................................................66

4.4 Efeito das Intervenções na Amostra ...................................................................68

4.4.1 Efeito Avaliado pela Mudança no Escore e Categoria do Teste de Morisky .......68

4.4.2 Efeito avaliado pela mudança na frequência de crises nos últimos 30 dias .......70

4.4.3 Efeito avaliado pela mudança na dosagem sérica das DAEs .............................71

4.5 Comparação do Efeito das Intervenções ..........................................................71 
4.5.1- Comparação do Efeito das Intervenções tendo como Medida de Adesão o Teste de Morisky.....

4.5.2- Comparação do Efeito das Intervenções tendo como Medida de Adesão a

Frequência de Crises nos Últimos 30 Dias...................................................................73

4.5.3 Comparação do Efeito das Intervenções tendo como Medida de adesão a

Dosagem Sérica das DAEs ................................................................................... 75

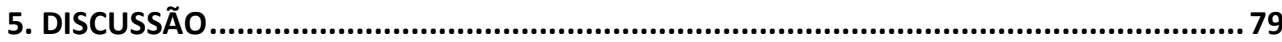

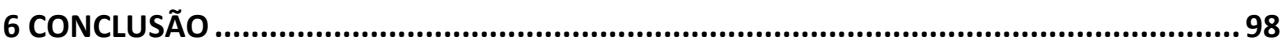

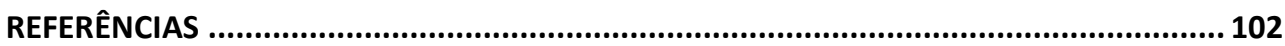

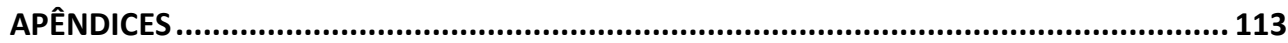

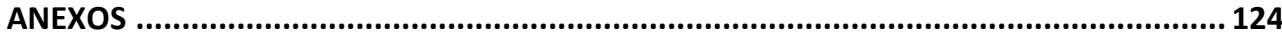




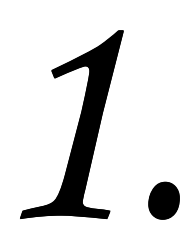

Introdução 


\section{INTRODUÇÃO}

Estima-se atualmente que 50 milhões de pessoas convivem com a epilepsia em todo o mundo. Destas, 40 milhões vivem em países em desenvolvimento e 5 milhões pertencem a algum país da América Latina e Caribe $^{(1-3)}$.

Nos países desenvolvidos, a epilepsia está na quarta posição na classificação das doenças neurológicas mais frequentes, com incidência anual de 24 a 53 casos para cada 100.000 habitantes $^{(4)}$. Nos países em desenvolvimento, essa taxa se eleva para 122 a 190/100.000, provavelmente em virtude de causas parasitárias como neurocisticercose, infecções intracranianas virais ou bacterianas, lesões fetais durante o trabalho de parto, traumatismo craniencefálico e doenças encefalovasculares ${ }^{(3,5)}$.

A epilepsia pode ser caracterizada como uma condição clínica crônica na qual o indivíduo está predisposto a desenvolver crises epilépticas recorrentes devido a alterações presentes no sistema nervoso central ${ }^{(4)}$. A crise epiléptica é uma ocorrência transitória de sinais e/ou sintomas resultante de atividade neuronal anormal, excessiva e sincronizada; no entanto, ela traz consequências neurobiológicas, psicológicas e sociais aos indivíduos que a apresentam ${ }^{(6,7)}$

Em dezembro de 2013, a Liga Internacional contra Epilepsia (ILAE, International League Against Epilepsy) definiu a epilepsia como "doença", já que o termo "distúrbio", anteriormente recomendado, é pouco compreendido pela população e, em geral, minimiza sua gravidade ${ }^{(7)}$.

Embora seja considerada uma doença crônica, a epilepsia pode não ser uma doença presente por toda a vida. Ela é considerada solucionada se o indivíduo passar 10 anos sem crises epiléticas após, pelo menos, cinco anos sem uso de drogas anti-epilépticas (DAEs) ou se o paciente passar da faixa etária das síndromes epilépticas relacionadas à idade, cujas crises apresentam remissão espontânea ${ }^{(7)}$. 
Mesmo assim, o tratamento farmacológico para epilepsia pode acompanhar muitos anos da vida dos pacientes. Muitas vezes, é necessário o uso de diversas DAEs para controle das crises ${ }^{\left({ }^{(8)}\right.}$.

Os medicamentos utilizados para o tratamento da epilepsia incluem barbitúricos, benzodiazepínicos, hidantoínas e succinimidas que, em geral, aumentam o limiar convulsivo e regulam a atividade elétrica dos neurônios, inibindo os processos excitatórios ou aumentando processos inibitórios ${ }^{(9)}$. Tem sido recomendado que, ao escolher a DAE mais adequada para o tratamento do indivíduo com epilepsia, leve-se em consideração o perfil do paciente, a eficácia da droga contra a atividade convulsiva ou síndrome epiléptica, a sua tolerabilidade, a praticidade e a segurança do fármaco, a farmacocinética com outros medicamentos em uso, as comorbidades presentes e o custo final do tratamento ${ }^{(10)}$.

Não obstante, muitas vezes, os regimes terapêuticos indicados atendem conceitos teóricos e empíricos estabelecidos pelos especialistas como ótimos para o cuidado à saúde do indivíduo, porém ignoram questões relacionadas ao próprio paciente, como as características pessoais, as experiências e a cultura, além de ignorar as inconveniências, os estereótipos, o custo e os efeitos adversos do tratamento ${ }^{(11)}$.

Consequentemente, muitos pacientes apresentam dificuldade de seguir o esquema terapêutico. A adesão ao tratamento medicamentoso, assim, torna-se um problema frequente do indivíduo com epilepsia, em decorrência das dificuldades do paciente de se ajustar às exigências do tratamento por um período prolongado ${ }^{(11)}$.

A não adesão ao tratamento é um problema que se relaciona com muitas peculiaridades pessoais e da doença, além daquelas relacionadas ao tratamento. As características afetivas e emocionais do doente em relação à epilepsia, incluindo negação do diagnóstico, autoestima diminuída, descrédito em relação à equipe de saúde e tratamento, além da vergonha das crises, são fatores negativos para adesão, difíceis de serem superados pelos profissionais da saúde ${ }^{(12)}$. 
A epilepsia apresenta sintomas pontuais e esporádicos. As crises epilépticas, diferentemente de um sintoma contínuo como a dor, não apresentam melhora imediata com o tratamento medicamentoso. Além disso, o paciente pode não fazer uso de DAE e não apresentar consequências indesejáveis, concluindo erroneamente que a adesão à terapia medicamentosa não é importante, pois o resultado da não adesão na epilepsia pode não se apresentar imediatamente após a esse comportamento (12)

Fantasias relacionadas ao diagnóstico e aos medicamentos, as repercussões das drogas e da epilepsia sobre as atividades diárias, a percepção desfavorável em relação ao custo-benefício do tratamento, os impedimentos religiosos, familiares, no trabalho ou na escola para tomar a medicação, além da dificuldade financeira para aquisição do medicamento, são condições sociais que conduzem os pacientes à não adesão ao tratamento. Por outro lado, o suporte social, o apoio de familiares e amigos, atitudes positivas em relação à epilepsia e o medo de novas crises são importantes fatores relacionados à tomada correta dos medicamentos ${ }^{(12-14)}$.

A adesão terapêutica pode ser definida como a extensão em que o comportamento do indivíduo, em relação a tomar medicamentos, seguir dieta, realizar mudanças de hábitos de vida, corresponde às recomendações acordadas com um profissional da saúde $\mathrm{e}^{(15-18)}$.

A definição de adesão terapêutica é abrangente e inclui diferentes tipos de regimes terapêuticos. Por exemplo, em indivíduos com diabetes mellitus tipo 2, a adesão terapêutica envolve a realização de uma dieta específica, o aumento da frequência de exercícios físicos, a cessação do hábito de fumar, o uso de drogas hipoglicemiantes e o controle de riscos por meio de cuidados à saúde realizados pelo próprio paciente ${ }^{(11)}$.

Nesta investigação, a questão central foi a adesão ao tratamento medicamentoso e as intervenções direcionadas para melhorar esse comportamento, dado que o uso contínuo das DAEs permanece como o principal tratamento para epilepsia. Estes fármacos são o tratamento de 
escolha para maioria das pessoas com epilepsia e são capazes de abolir ou reduzir a frequência de crises em aproximadamente $70 \%$ dos doentes ${ }^{(19)}$.

A adesão ao tratamento medicamentoso consiste na utilização das drogas prescritas observando-se horários, doses, tempo de tratamento e os cuidados na administração dos medicamentos, como ingerir em jejum, tomar no momento das refeições, amassar o comprimido, entre outros. Desse comportamento depende o sucesso da terapia proposta, a cura de uma enfermidade, o controle de uma doença crônica e a prevenção do desenvolvimento de uma patologia ${ }^{(17)}$.

Estimativas apontam um índice de 30 a $50 \%$ de não adesão ao tratamento medicamentoso entre os indivíduos com epilepsia ${ }^{(8,19,20)}$. Considerando as doenças crônicas em geral, estima-se que apenas a metade dos pacientes que utiliza medicamentos de uso contínuo alcança os efeitos terapêuticos desejados em consequência da falta de adesão( ${ }^{(18)}$.

Assim, muitas vezes, para alcançar os efeitos terapêuticos desejados, a dose das drogas é aumentada ou elas são substituídas por demonstrarem ineficiência, sendo este resultado do uso inadequado pela falta de adesão ao tratamento $^{(11)}$.

$\mathrm{Na}$ epilepsia, as metas do regime terapêutico medicamentoso são evitar e reduzir a gravidade da atividade epiléptica, balanceando as possíveis consequências, inconveniências e efeitos adversos da DAE selecionada ${ }^{(21)}$.

Em pacientes com epilepsia, a baixa adesão ao tratamento medicamentoso dificulta a avaliação do efeito terapêutico da DAE no controle de crises $^{(11)}$. A não adesão ao tratamento é provavelmente a causa mais importante da epilepsia não controlada ${ }^{(22,23)}$. Estudo realizado com um grupo de pacientes adultos com epilepsia em acompanhamento ambulatorial, em São Paulo, mostrou relação significativa entre média/baixa adesão ao tratamento medicamentoso e a presença de crises $^{(19,20)}$.

Análise retrospectiva de pacientes com diagnóstico de epilepsia assistidos por vários planos de saúde nos Estados Unidos mostrou, por meio de dados de consulta médica e atendimento em serviço de emergência, que a 
não adesão, identificada pelo registro de aquisição de DAEs, aumentou em $21 \%$ a frequência de crises epilépticas ${ }^{(24)}$.

Revisão de literatura apontou que indivíduos com epilepsia estão envolvidos em maior número de acidentes, apresentando maior número de lesões traumáticas, quando comparados à população em geral. Esse maior risco é provavelmente mais prevalente em pacientes com epilepsia sintomática e crises frequentes ${ }^{(23)}$. O tipo de crise, a frequência e a gravidade das crises epilépticas são fatores peditores de lesões traumáticas nas análises multivariadas de pacientes com epilepsia ${ }^{(12)}$.

As crises epilépticas são responsáveis por $25 \%$ dos acidentes que causam lesões em pacientes com esse diagnóstico ${ }^{(23,25)}$. A maioria desses acidentes ocorre em ambiente doméstico, na casa do paciente ${ }^{(25)}$. Além do risco de acidentes, existe a preocupação de que as crises epilépticas possam trazer consequências fatais.

O óbito em indivíduos acometidos por epilepsia pode ser decorrente de inúmeras causas, relacionadas ou não à doença epiléptica. No entanto, a ausência de tratamento na epilepsia é relacionada a uma maior morbimortalidade ${ }^{(22)}$.

Em casos de diagnóstico recente de epilepsia, a doença subjacente (p. ex., tumor cerebral, meningite) é a principal causa de morte. Em epilepsias crônicas, porém, as principais causas são as relacionadas à própria doença, que podem causar morte durante uma crise epiléptica, morte súbita e inexplicável, estado de mal epiléptico, pneumonia aspirativa, trauma e

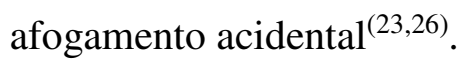

Em estudo retrospectivo de coorte com dados relativos a um período de 10 anos e inclusão de 33.658 pacientes, observou-se a presença de $26 \%$ de não adesão ao tratamento medicamentoso e chance de morrer três vezes maior nesses indivíduos em comparação aos que aderiram ao tratamento. Além do mais, evidenciou-se que períodos de não adesão nos pacientes são associados ao aumento de passagens por serviços de emergência, internações, acidentes automobilísticos e fraturas, quando comparados a períodos de adesão terapêutica ${ }^{(27)}$. 
O comportamento de não adesão é comum e dinâmico, e não pode ser visto como um fenômeno binário, pois pessoas não são sempre "aderentes" ou "não aderentes". Revisão realizada no ano de 2012 demonstrou que não temos um método padronizado para medida de adesão e que é difícil diferenciar aqueles que aderem ao tratamento daqueles que não apresentam esse comportamento, pois as medidas de adesão não têm capacidade de medir o valor exato e a natureza do comportamento de não adesão é dinâmica e variável ${ }^{(28)}$.

A avaliação da adesão terapêutica tem sido realizada em estudos por meio de medidas objetivas diretas, como a contagem de pílulas, dosagem da concentração das drogas em urina, saliva e sangue, uso do Medication Event Monitoring System (MEMS) e também por meio de medidas subjetivas ou indiretas, assim como autorrelato e avaliação de marcadores clínicos ${ }^{(11,29-31)}$.

Tanto as medidas objetivas diretas quanto as subjetivas ou indiretas apresentam limitações que devem ser ponderadas quando se avalia a adesão ao tratamento medicamentoso. A contagem de pílulas pode superestimar a real adesão, pois os pacientes facilmente podem desprezar as doses em vez de ingeri-las ${ }^{(29)}$. Além disso, com frequência, os pacientes esquecem de levar os medicamentos às consultas para contagem. A alternativa de obter informações junto à base de dados de centrais farmacêuticas informatizadas oferece o conhecimento sobre a aquisição das drogas, o que não garante que a ingestão do medicamento tenha ocorrido ${ }^{(29,31)}$.

No estudo da adesão ao tratamento medicamentoso, a dosagem do nível sérico da droga ou a concentração urinária tem sido considerada em alguns estudos como "padrão ouro" ${ }^{(32-35)}$. Não se pode ignorar, porém, que elas não oferecem informações sobre a tomada do medicamento nos intervalos entre as dosagens de concentração das drogas. Segundo BenMenachem et al. (2010) ${ }^{(36)}$, essas dosagens são os métodos mais precisos para mensurar a adesão, mas também são invasivas e pouco práticas para avaliação de grandes grupos de pacientes.

O MEMS é um recurso sofisticado criado especificamente para estimar a adesão do paciente ao tratamento medicamentoso. Trata-se de um 
frasco de medicamento com um chip que registra data e horário de sua abertura. A despeito das óbvias vantagens desse sistema para estimar a adesão, ele ainda não é um método perfeito, pois seu uso pressupõe que a abertura do frasco significa ingestão da droga ${ }^{(37)}$. Trata-se também de um método caro, ainda não disponível em nosso país e que se torna mais oneroso e complexo à medida que o paciente necessita de várias medicações $^{(31)}$.

Entre os métodos utilizados de autorrelato, o registro diário dos medicamentos ingeridos também tem utilidade limitada na avaliação da adesão, pois a maioria dos pacientes não segue as instruções dadas e faz o registro pouco antes da consulta médica. Os questionários que analisam a adesão por autorrelato, assim como o teste de Morisky, são instrumentos comumente utilizados para a avaliação da adesão. Eles são relativamente baratos, convenientes e facilmente aplicáveis, tanto na clínica como nas investigações científicas $^{(12,31,36)}$; no entanto, eles falham na quantificação, pois oferecem uma avaliação subjetiva, e a adesão pode ser superestimada $^{(29,31)}$.

A medida por autorrelato torna-se mais eficiente na prática clínica quando permite diferenciar os comportamentos de adesão intencionais dos não intencionais, posto que os fatores a eles associados são diferentes, assim como as abordagens para intervenção ${ }^{(31)}$.

O teste de Morisky ${ }^{(38)}$ é um questionário que identifica, por meio da resposta a quatro questões, o nível de adesão ao tratamento medicamentoso prescrito e permite avaliar se a não adesão decorre de um comportamento intencional ou não. Esse teste já foi utilizado em vários estudos ${ }^{(12,30,39-41)} \mathrm{e}$ também traduzido e aplicado no Brasil ${ }^{(19,20,42-45)}$.

A avaliação de marcadores clínicos é uma medida indireta da adesão medicamentosa de grande valia para estabelecer a eficiência do tratamento. Os marcadores clínicos são identificados no paciente diabético e hipertenso pelos níveis glicêmicos ${ }^{(46)}$ e pressóricos ${ }^{(42)}$, respectivamente, e, no paciente epiléptico, pelo controle das crises convulsivas ${ }^{(29,47)}$. Esses marcadores 
clínicos estão sujeitos à resposta da doença ao medicamento, portanto não devem ser usados de forma isolada como medida de adesão ao tratamento.

Nas investigações em pacientes com epilepsia, a adesão ao tratamento com DAEs tem sido mensurada de forma objetiva e subjetiva $^{(12,29,32-34,41,48-53)}$. No entanto, a medida pelo MEMS e a dosagem sérica têm se destacado entre as demais medidas por permitir resultados considerados válidos e confiáveis ${ }^{(29,36,37,47,48,53,54)}$.

Investigadores brasileiros que estudaram a adesão ao tratamento de epilepsia em um grupo de 38 pacientes por meio de dosagens séricas semanais das DAEs observaram que a diferenciação dos pacientes resistentes a DAEs daqueles que fazem uso irregular da medicação pode ser feita por esse tipo de medida ${ }^{(55)}$.

$\mathrm{Na}$ Alemanha, estudo realizado com 52 pacientes do Centro de Epilepsia de Bethel evidenciou em seus resultados associação entre baixo nível sérico da droga no período pós-ictal e baixa adesão terapêutica ${ }^{(56)}$. Handoko et $a l .{ }^{(47)}$ também demonstraram, em estudo realizado no sul da Holanda, clara associação entre a baixa concentração sérica das DAEs e a ocorrência de crise.

Investigação em indivíduos com epilepsia em acompanhamento ambulatorial que comparou níveis sanguíneos das DAEs, ingestão autorreferida dessas drogas e controle das crises epilépticas concluiu que a avaliação isolada do nível sérico plasmático não é suficiente para o reconhecimento da ingestão inadequada das drogas e que marcadores clínicos e adesão autorreferida também devem ser considerados para esse tipo de avaliação ${ }^{(32)}$.

Nos indivíduos com epilepsia, o marcador clínico frequência das crises é utilizado em muitos estudos para avaliar a adesão terapêutica medicamentosa, assim como os questionários de autorrelato do paciente $^{(24,47,49,57)}$. Pesquisadores têm apontado ${ }^{(16,30,58)}$ que a medida de adesão por meio desses questionários fornece mais informações nos resultados, visto que permite identificar as causas da não adesão ao tratamento. 
Sabe-se que nenhuma das medidas, direta ou indireta, é completamente satisfatória para a medida da adesão ${ }^{(11,59)}$. Na ausência de um único método acurado para medir a adesão terapêutica, múltiplas formas de medida são concomitantemente utilizadas nas investigações científicas. Recomenda-se incluir, sempre que possível, uma medida objetiva entre as mensurações realizadas ${ }^{(11,30,59)}$.

Revisão dos métodos de mensuração de adesão observados em publicações relata dificuldade em hierarquizar as medidas ou afirmar a existência de um "padrão ouro". As formas de mensuração apresentam limitações no seu uso. Recomenda-se que se priorize o uso daquelas que alcançam os objetivos propostos e, para melhorar a estimativa da adesão, as medidas não devem ser aplicadas de forma isolada, mas associadas a outras que apresentem qualidades distintas das suas, buscando a complementaridade do poder de mensuração ${ }^{(30)}$.

Ainda são poucas as pesquisas que evidenciam a efetividade de estratégias para auxiliar os pacientes no processo de melhora da adesão ao tratamento; nos últimos anos, porém, elas apresentaram tendência de crescimento $^{(12,33-35,48-52,57,60)}$.

Revisão de literatura que analisou pesquisas que utilizaram intervenções isoladas ou combinadas para melhorar a adesão terapêutica de pacientes com diversas condições clínicas identificou vários tipos de intervenções, as quais foram categorizadas em: Instrução complementar ao paciente, Aconselhamento terapêutico complementar, Aprimoramento da conveniência ao tratamento, Administração supervisionada da medicação, Terapias psicológicas, Reforço ou premiação condicionados a adesão e resposta ao tratamento e Envolvimento do paciente no tratamento ${ }^{(11)}$.

As intervenções categorizadas como Instrução complementar ao paciente incluem oferecimento de informações verbais ou escritas para o aprendizado programado do paciente sobre a doença e o regime terapêutico $\operatorname{adotado}^{(11)}$.

O oferecimento de informação sobre o regime terapêutico, ou aconselhamento terapêutico do paciente, é uma estratégia aplicada na prática 
clínica com pacientes que têm um novo regime medicamentoso a seguir. Essa prática se inicia durante a consulta médica e é complementada no atendimento do enfermeiro, que oferece orientações sobre doses, horários e efeitos dos medicamentos. O aprimoramento dessa intervenção pode ser obtido com o uso do diário de medicação, preenchido pelo paciente com auxílio do enfermeiro, que organiza os fármacos da prescrição médica em uma tabela de forma a facilitar a compreensão do paciente e de lembrar-lhe de tomar os medicamentos nos horários indicados ${ }^{(11)}$.

As intervenções classificadas como Aconselhamento terapêutico complementar incluem a monitorização e o aconselhamento terapêutico por meio de computador ou telefone e intervenções familiares. Estas últimas envolvem o aconselhamento de familiares do paciente, buscando a colaboração para o aumento da adesão ao tratamento ${ }^{(11)}$.

As intervenções com o objetivo de Aprimorar a conveniência ao tratamento provêm de programas de saúde específicos, com estrutura física, recursos humanos especializados na condição clínica e protocolos direcionados a facilitar o tratamento de pacientes. Nesse tipo de intervenção, também é possível simplificar a dosagem do medicamento de forma a facilitar a adesão do paciente ${ }^{(11)}$.

A Administração supervisionada da medicação consiste na observação direta da ingestão da droga pelo paciente por um profissional de saúde, em horário e local predeterminados para manutenção do regime terapêutico ${ }^{(11)}$.

As Terapias psicológicas podem incluir técnicas do tipo cognitiva, comportamental ou multissistêmica e buscam estratégias específicas e especializadas para o aumento da $\operatorname{adesão}^{(11)}$.

Reforço ou premiação condicionados a adesão e resposta ao tratamento refere-se àquelas intervenções que podem ser exemplificadas por aumento da frequência de consultas ou descontos no pagamento de equipamentos para monitorização da doença, dependendo da resposta clínica do paciente ao tratamento ${ }^{(11)}$. 
Envolvimento do paciente no tratamento é a categoria que inclui intervenções voltadas ao autocuidado com recursos auxiliares que ajudam o paciente na adoção de hábitos diários específicos, como registro da pressão sanguínea ou das crises epilépticas e uso adequado dos medicamentos. Embalagens que facilitam o paciente a lembrar-se das medicações ou lembretes de esquemas terapêuticos ou consultas são os recursos auxiliares aplicados nesse tipo de intervenção ${ }^{(11)}$.

Dispositivos portáteis, como aparelhos celulares, podem armazenar dados e informações, e servem como recurso para assistência à adesão do paciente $^{(51,61-65)}$. Profissionais envolvidos na assistência primária que fazem uso desses dispositivos na clínica acreditam que eles não só aumentam a eficiência do tratamento, mas também reduzem erros no uso de medicamentos e custos com o tratamento ${ }^{(61)}$.

Apesar de certas restrições quanto a custo, disponibilidade, ausência de padrões universais e segurança, as tecnologias de informação móveis e sem fio se propagam mundialmente e, da mesma forma, no mercado brasileiro, onde o número de telefones celulares ultrapassou o número de telefones fixos há alguns anos ${ }^{(65)}$.

O uso de aparelhos celulares pela população em geral trouxe uma nova forma de abordagem do paciente pelos profissionais da saúde, com contatos por dispositivos móveis que incluem o envio de lembretes relacionados à medicação, à promoção da saúde e à monitorização de doenças crônicas ${ }^{(61)}$.

Poucas investigações têm analisado os dispositivos eletrônicos portáteis como auxiliares na intervenção à adesão. Sua aplicação para lembretes programados de consulta e uso de medicamentos, porém, tem mostrado resultados positivos em estudos pilotos com idosos, pacientes cardíacos e diabéticos ${ }^{(62-65)}$. Faz-se necessário avaliar a confiabilidade desses recursos em casuísticas maiores e com outras especificidades ${ }^{(61)}$.

Em estudo piloto recente que avaliou o uso de dispositivo eletrônico portátil por 12 semanas em 27 pacientes com relato de dificuldade de fazer uso das medicações prescritas, observou-se adesão ao tratamento 
medicamentoso em 89,64\% dos pacientes. Esse estudo, no entanto, não avaliou a adesão antes do início da intervenção, o que dificulta a interpretação do resultado ${ }^{(61)}$.

Experimento com 64 pacientes portadores do vírus da imunodeficiência humana (HIV) utilizou, no grupo de intervenção, um dispositivo programado que avisava com um alarme o horário da tomada dos medicamentos e oferecia instruções sobre o seu uso. Resultados mostraram que a adesão avaliada pelo MEMS foi maior entre aqueles que fizeram uso do dispositivo em relação ao grupo controle $(77 \%$ versus $52 \%)^{(63)}$.

Sterns (2005), em um estudo piloto, testou um dispositivo eletrônico que funcionava como lembrete de horários de medicação e consultas médicas acoplado a uma caixa de medicação para armazenamento de drágeas e comprimidos. Resultados positivos foram observados com o uso desse dispositivo denominado Personal Digital Assistent ${ }^{(62)}$.

A caixa organizadora de medicamentos é um recurso auxiliar presente na prática clínica em doenças crônicas de tratamento medicamentoso contínuo. Ela envolve o paciente em seu tratamento, evita esquecimentos e erros de medicações e tem baixo custo ${ }^{(66)}$.

Revisão sistemática e metanálise de estudos randomizados sobre o efeito de caixas e embalagens organizadoras, utilizadas para aperfeiçoar a adesão de pacientes em tratamentos crônicos, identificaram, em 6 de 10 publicações, melhora na adesão dos pacientes que receberam esse tipo de intervenção aplicada isoladamente ou associada a outras ${ }^{(66)}$.

Estudo de coorte realizado em pacientes portadores do HIV avaliou o uso das caixas organizadoras de medicação em pacientes de um programa de saúde. Seus resultados mostraram que a caixa organizadora aumentou entre 4,1 e 4,5\% a adesão do paciente, medida pela contagem de pílulas, e reduziu significativamente a carga viral dessa amostra ${ }^{(67)}$.

Apesar de seu uso comum na prática clínica e da simplicidade de aplicação, os investigadores que exploraram o uso da caixa organizadora de 
medicação e avaliaram seu efeito na adesão de pacientes ainda não alcançaram evidências seguras quanto ao benefício de seu uso. Portanto, estudos que avaliem essa intervenção constituem uma área de pesquisa a ser explorada ${ }^{(66)}$.

A diversidade, a falta de descrição, a complexidade e a imprecisão dos efeitos das intervenções observadas em estudos que avaliam a adesão dificultam a identificação das formas mais eficazes de aumento da adesão do paciente ao tratamento. Intervenções novas são aplicadas em estudos sem descrições que possibilitem sua reprodução e as diferenças nas condições clínicas dos grupos de pacientes fragilizam a avaliação e a comparação do efeito das intervenções sobre a adesão ${ }^{(16,30,66)}$.

Para tratamentos de curto prazo, diversas intervenções ocasionam aumento da adesão terapêutica. Destacam-se, porém, o aconselhamento do paciente durante a consulta e informar e orientar o paciente de que todos os medicamentos prescritos devem ser consumidos no período estabelecido. Em 4 de 10 estudos que envolveram pacientes em tratamento de curto prazo, evidenciou-se melhora da adesão associada a melhora do quadro clínico por meio desse tipo de intervenção ${ }^{(16)}$.

Considerando estudos direcionados à adesão de pacientes em tratamento de longo prazo, todas as intervenções consideradas efetivas são bastante complexas, incluindo a combinação de diversos tipos das intervenções descritas anteriormente ${ }^{(16)}$.

Demonstraram efetividade intervenções que consomem muitos esforços e recursos, como a simplificação da ingestão dos medicamentos pela alteração da apresentação da droga (de pílula para xarope, por exemplo) ou diminuição da quantidade de comprimidos e/ou frequência de doses, além das estratégias complexas e combinadas que promovem maior interação com o paciente pelo uso de recursos auxiliares. Ainda se questiona, porém, o custo-benefício de tais medidas ${ }^{(16,41)}$.

Focalizando as pesquisas sobre intervenções direcionadas para adesão terapêutica de pacientes com epilepsia, uma revisão sistemática sobre o tema, no ano de 2011, mostrou limitações importantes referentes à 
quantidade e qualidade dos estudos existentes. Apenas seis investigações atenderam aos critérios estabelecidos pela Cochrane; uma delas tinha como população-alvo os pais de crianças com epilepsia, e as demais foram direcionadas para adultos com essa doença. As pesquisas foram publicadas de 1982 a 2009 e evidenciaram alguns aspectos que devem ser considerados nas atuais investigações ${ }^{(68)}$.

O primeiro estudo foi realizado em 1982, com uma amostra de conveniência de 55 pacientes com epilepsia de uma clínica do Canadá. Os participantes foram divididos em três diferentes grupos de intervenção e receberam informações sobre o uso das DAEs: o primeiro grupo recebeu pessoalmente instruções escritas; o segundo recebeu pessoalmente informações verbais; o terceiro foi somente contatado por telefone para instrução das DAEs. Foram realizadas duas entrevistas ou contatos telefônicos com o intervalo de quatro semanas.

Resultados demonstraram que os grupos que receberam pessoalmente instruções escritas ou verbais apresentaram melhor retenção que aquele que foi acompanhado e orientado por contato telefônico. O aumento do conhecimento dos pacientes, porém, não foi relacionado com o aumento dos níveis séricos das DAEs ${ }^{(33)}$.

Este estudo sugere que o oferecimento de informação complementar ao paciente de forma pessoal, apesar de aumentar o conhecimento referente à epilepsia e ao uso de DAEs, não resulta necessariamente no aumento da adesão ${ }^{(33)}$. Portanto, a Instrução complementar ao paciente escrita ou verbal foi frágil, ainda que essencial para o conhecimento do tratamento, quando utilizada isoladamente em pacientes com epilepsia.

Em 1984, foi publicado estudo realizado na Austrália com uma amostra de 53 indivíduos com epilepsia que foram alocados aleatoriamente em um grupo controle e intervenção. A intervenção proposta foi uma combinação de estratégias com o objetivo de aumentar a adesão. Foram utilizadas Instruções complementares ao paciente, uma caixa para guardar e organizar os medicamentos, e também foram enviados pelo correio 
lembretes de datas de consultas médicas e de dias de retirada do medicamento na farmácia ${ }^{(34)}$.

Os resultados mostraram que houve maior nível plasmático das DAEs no grupo de intervenção em relação ao grupo controle, com diferença estatisticamente significante. O registro da aquisição de medicamentos na farmácia apontou que o grupo intervenção apresentou maior adesão. Além disso, observou-se maior controle das crises entre os participantes que receberam a intervenção, ainda que o retorno às consultas médicas não apresentasse diferença entre os dois grupos ${ }^{(34)}$.

Nesse último estudo citado $^{(34)}$, a Informação complementar ao paciente, intervenção evidenciada como frágil no primeiro estudo para melhora da adesão, foi associada a intervenções relacionadas ao Envolvimento do paciente no tratamento por meio de recursos auxiliares, tendo-se observado melhores resultados.

Hegelson et al. (1990), nos EUA, em uma amostra de 120 pacientes com epilepsia, alocados randomicamente em grupo controle e intervenção, aplicaram neste último grupo o programa Sepulveda Epilepsy Education (SEE). Esse programa consiste em uma terapia psicoeducacional voltada ao paciente e à família, oferecida por uma equipe multiprofissional em dois dias. Trata-se de uma associação de intervenções de aconselhamento complementar e terapia psicológica ${ }^{(35)}$.

No grupo intervenção, observou-se, quatro meses após o programa, a diminuição da depressão, do medo de lesão encefálica e da morte. Houve também diminuição de erros no manejo das DAEs, redução da desinformação e do preconceito da epilepsia, além de aumento da concentração plasmática de DAEs, com diferença estatisticamente significativa do grupo controle. Não obstante, não houve diferença na redução do número de crises comparando-se os grupos intervenção e controle $^{(35)}$.

Os resultados sugerem que o uso associado de aconselhamento complementar e terapia psicológica, oferecido pelo programa SEE, é benéfico em relação à desinformação, ao medo, à depressão, ao manejo de 
DAEs e sua concentração plasmática, embora não tenha sido observada diferença no efeito desejado com regime medicamentoso empregado ${ }^{(35)}$.

Estudo randomizado com 69 pacientes com epilepsia, realizado no Reino Unido, 19 anos depois de Hegelson et al. (1990), propôs como estratégia no grupo intervenção um exercício de memorização das tomadas de medicações ${ }^{(48)}$.

A intervenção proposta mostrou impacto positivo na adesão ao tratamento. Após um mês, os pacientes pertencentes ao grupo intervenção haviam tomado $18,1 \%$ mais doses prescritas que o controle; o número de doses ingeridas corretamente foi $35,9 \%$ maior no grupo intervenção, assim como foi mais frequente a ingestão das medicações nos horários corretos $(42,5 \%)^{(48)}$.

Dilório et al. (2009), no mesmo ano, realizaram um estudo com 22 pacientes de três clínicas neurológicas, alocados randomicamente nos grupos intervenção e controle. Os pacientes do grupo intervenção, afora a abordagem pessoal, tiveram acompanhamento com um aplicativo de computador com áudio por 12 semanas, manejado pelo paciente de forma independente. Além da instrução do manejo individual do aplicativo, foram realizados dois contatos telefônicos por enfermeiras previamente treinadas que seguiram um roteiro de entrevista e orientação ${ }^{(49)}$.

Nesse estudo ${ }^{(49)}$, não foi observada melhora na adesão ao tratamento nem no grupo intervenção nem no controle. Somente alguns pacientes de cada grupo apresentaram melhora da adesão, não havendo diferença estatisticamente significativa entre os grupos.

Após revisão da Cochrane realizada em 2011 ${ }^{(68)}$, novos estudos de intervenção para melhorar a adesão em pacientes com epilepsia foram realizados, testando novas intervenções isoladas ou associadas, com ou sem uso de tecnologias. Nessas últimas publicações, há descrições mais detalhadas das intervenções realizadas e aperfeiçoamentos nos métodos, demonstrando preocupação em superar as limitações apontadas em estudos anteriores. 
No Irã, Aliasghapour (2013) aplicou um programa educacional para gestão pessoal do tratamento da epilepsia. Esse programa consistia em aulas para pequenos grupos com informações complementares sobre a doença e o tratamento da epilepsia, incluindo aconselhamento do paciente sobre o uso de DAEs e manejo da doença ${ }^{(52)}$.

Diferença significativa nas respostas dos questionários de gestão pessoal do tratamento foi identificada quando se comparou os períodos pré e pós-intervenção $(\mathrm{p}<0,001)$, o que indicou que os participantes que completaram o programa educacional melhoraram o manejo do tratamento da epilepsia após um mês. Além do mais, os escores dos questionários no final do estudo foram diferentes quando comparados os grupos intervenção e controle $(\mathrm{p}<0,001)^{(52)}$

Lua e Neni (2013), interessados na adesão de pacientes com epilepsia na Malásia, testaram o efeito de um sistema de educação por meio de telefones celulares que incluía o recebimento de mensagens eletrônicas do tipo Short Message Service (SMS) ${ }^{(51)}$.

Esse foi um estudo controlado e randomizado, com o seguimento de 136 pacientes com epilepsia por um período de três meses. O grupo intervenção recebeu, por meio de mensagens enviadas pelo SMS, Informações complementares sobre a doença e medicamentos, bem como lembretes de tomada de medicamentos e consultas médicas ${ }^{(51)}$.

O grupo intervenção apresentou aumento significativo da adesão segundo resultado do teste de Morisky inicial e final. No grupo controle, não houve diferença estatisticamente significativa entre essas duas aplicações do teste ${ }^{(51)}$.

Em pesquisa com 183 indivíduos com epilepsia, em uma comunidade rural da China, foi avaliada a aplicação de um conjunto de intervenções composto de quatro componentes: instrução educacional intensiva; acesso livre a consultas com profissionais de saúde; cartão para o registro de crises e ocorrências pelo paciente; e instrução impressa para tomada dos medicamentos a cada aquisição de DAEs no serviço de farmácia ${ }^{(59)}$. 
Nesse estudo, os participantes alocados de forma randomizada nos grupos de intervenção e controle tiveram seguimento por 12 meses. No entanto, antes de intervir, os pesquisadores realizaram estudo observacional por seis meses e, após, seguiram os pacientes por mais seis meses, quando fizeram sua reavaliação. Os resultados mostraram maior queda na frequência de crises $(\mathrm{p}<0,001)$ e maior frequência de pacientes com relato de alta adesão no grupo submetido à intervenção $(\mathrm{p}<0,05)^{(59)}$.

Ibinda et al. (2014) recentemente realizaram, no Quênia, um estudo controlado e randomizado com amostra de 581 pacientes com epilepsia. Os autores descrevem em sua publicação a aplicação de uma intervenção educacional às pessoas com epilepsia e seus cuidadores. $\mathrm{O}$ seguimento foi de um ano e a avaliação da adesão foi realizada por meio da avaliação da frequência de crises, dosagem sérica das DAEs, e aplicação do teste de Morisky ${ }^{(50)}$.

No grupo intervenção, foi maior a frequiência de indivíduos que apresentaram DAEs detectáveis na avaliação final ( $\mathrm{p}<0,001)$, assim como no grupo controle $(\mathrm{p}<0,001)$. Quando os níveis terapêuticos foram considerados na análise dos resultados, também houve diferença estatisticamente significante entre as fases inicial e final do estudo nos dois grupos ( $\mathrm{p}=0,04$ para o grupo intervenção e $\mathrm{p}=0,001$ para o grupo controle). No teste de Morisky, os grupos intervenção e controle tiveram indicação de melhora na adesão quando comparados os períodos inicial e final do estudo $\left(\mathrm{p}<0,001\right.$ para ambos os grupos) ${ }^{(50)}$.

A diversidade de associações de intervenções testadas em indivíduos epilépticos e de métodos utilizados na medida da adesão terapêutica dificulta a comparação de resultados observados nas diferentes investigações. Além do mais, esses estudos de intervenção, assim como os relacionados a indivíduos com outros tipos de doenças crônicas, não identificaram as mais eficazes intervenções na adesão terapêutica. Não obstante, mostraram que parte das intervenções testadas resultou em melhor adesão perante grupos controles, dentre as quais se observam os lembretes e 
exercícios de memorização direcionados a evitar os esquecimentos ${ }^{(34,48,51)}$ e a caixa organizadora associada a outras intervenções ${ }^{(34)}$.

A instrução complementar à prescrição médica, voltada ao suporte, informação e educação perante o diagnóstico e tratamento, foi uma intervenção que permeou a maior parte dos estudos, uma vez que é considerada pelos profissionais de saúde instrumento essencial à promoção da adesão de pacientes ao tratamento e ao uso de medicamentos.

Considerando-se os resultados das pesquisas de intervenção, a difícil tarefa de mensurar a adesão ao tratamento e a acessibilidade em nosso meio das caixas organizadoras e lembretes da tomada de medicamentos por alarme de celular, optou-se por realizar o presente estudo, que tem como objetivo comparar intervenções de adesão que incluem esses recursos com a finalidade de auxiliar os profissionais da saúde em sua difícil atribuição de promover a adesão terapêutica dos pacientes e mensurar os resultados de suas intervenções. 


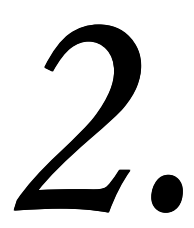

Objetivo Geral 


\section{OBJETIVO GERAL}

- Avaliar o efeito da aplicação de instrução complementar isolada e associada com recursos auxiliares (lembrete de tomada do medicamento por alarme de celular e caixa organizadora dos medicamentos) na adesão terapêutica medicamentosa de pacientes com epilepsia em acompanhamento ambulatorial.

\subsection{OBJETIVOS ESPECÍFICOS}

- Descrever as características demográficas, clínicas e relacionadas ao tratamento dos pacientes epilépticos incluídos na amostra.

- Verificar a associação entre os resultados das medidas da adesão utilizadas: teste de Morisky, frequência de crises nos últimos 30 dias e dosagens séricas das DAEs.

- Descrever o efeito de três intervenções para melhorar a adesão terapêutica (Intervenção 1 - Instrução Complementar Isolada; Intervenção 2 - Instrução Complementar Associada com Lembrete de Tomada dos Medicamentos por Alarme de Celular; Intervenção 3 - Instrução Complementar Associada a Caixa Organizadora de Medicamentos) de pacientes que apresentaram autorrelato de média ou baixa adesão.

- Comparar o efeito dessas três intervenções. 


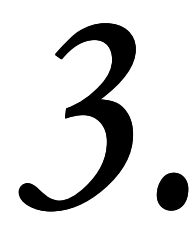

Método 


\section{MÉTODO}

Pesquisa clínica com delineamento experimental que buscou avaliar o efeito de três intervenções para melhorar a adesão à terapia medicamentosa em pacientes com epilepsia em acompanhamento ambulatorial.

A investigação foi registrada como Ensaio Clínico Brasileiro, com identificador RBR-943kwq e número universal de ensaio (Universal Trial Number/UTN) U1111-1142-3660 ${ }^{(69)}$.

\subsection{LOCAL DO ESTUDO}

O estudo foi realizado no ambulatório de epilepsia de adultos da divisão de clínica neurológica do Hospital das Clínicas da Faculdade de Medicina da Universidade de São Paulo (HCFMUSP), referência no tratamento da epilepsia, localizado na região centro-oeste do município de São Paulo. Esse ambulatório tem funcionamento semanal, com consultas médicas previamente agendadas.

O local do estudo atualmente tem 3.000 pacientes cadastrados com epilepsia, residentes em São Paulo e outras localidades do Brasil. O serviço possui 1.500 atendimentos ativos, ocorrendo 60 a 80 atendimentos/semana. Os pacientes cadastrados nesse ambulatório foram, em geral, encaminhados de outros serviços em virtude da complexidade de sua doença.

\subsection{CASUÍSTICA DO ESTUDO}

A casuística do estudo constituiu-se de pacientes com diagnóstico de epilepsia há mais de um ano, em acompanhamento ambulatorial, idade maior ou igual a 18 anos, com escolaridade mínima de quatro anos, independentes na vida diária, sem deficiência mental e psíquica prévia, com 
baixa ou média adesão ao tratamento medicamentoso segundo teste de Morisky $^{(38)}$.

Foram excluídos da amostra pacientes com prescrição médica de aumento ou retirada de doses de DAEs diária ou semanalmente, aqueles que já faziam uso dos recursos testados neste estudo para melhorar adesão e portadores de outras doenças crônicas em tratamento medicamentoso contínuo. Foram excluídos também pacientes que não faziam uso de carbamazepina, fenitoína, fenobarbital ou valproato de sódio, DAEs que têm sua dosagem plasmática realizada no laboratório de análises clínicas do HCFMUSP.

Para tomar parte desta investigação, os pacientes deveriam possuir aparelho celular, ter disponibilidade e concordar em participar do estudo, ao assinar o Termo de Consentimento Livre e Esclarecido (Apêndice A).

\subsection{GRUPOS DE INTERVENÇÃO}

\subsubsection{Grupo Intervenção 1 - Instrução Complementar Isolada}

Composto de pacientes que receberam orientação individual sobre o uso das DAEs e também elaboraram, com a pesquisadora, o diário de medicação apresentado no Apêndice B.

A elaboração do diário de medicação junto do paciente consistiu na atividade de reescrever a prescrição das DAEs recebida pelo paciente em consulta médica. $\mathrm{O}$ esquema terapêutico foi escrito com a colaboração do paciente em forma de tabela, a fim de melhorar a compreensão da prescrição médica. Na ocasião, solicitou-se ao paciente a descrição de como ele fazia o uso das DAEs e como adequaria o regime terapêutico às suas atividades diárias, de forma que não se esquecesse de tomar o medicamento nos horários indicados. Essas informações foram a base para estabelecer o esquema diário de tomada de medicamentos dos pacientes. 
O diário de medicação foi elaborado conforme as Instruções para Elaboração do Diário de Medicação junto do paciente, apresentadas no Apêndice C.

\subsubsection{Grupo Intervenção 2 - Instrução Complementar Associada com Lembrete de Tomada dos Medicamentos por Alarme de Celular}

Este grupo foi composto de pacientes que, além de receberem a instrução complementar para adesão terapêutica, tiveram orientação específica sobre o uso do aparelho celular. Neste grupo, o alarme do celular foi um recurso adicional para melhorar a adesão. A pesquisadora orientou e auxiliou o paciente a programar o alarme do celular em horários de tomadas das medicações, conforme o esquema terapêutico estabelecido no diário de medicação.

\subsubsection{Grupo Intervenção 3 - Instrução Complementar Associada com Caixa Organizadora de Medicamentos}

Pacientes incluídos neste grupo receberam, além da instrução complementar, uma caixa organizadora de fármacos com 28 espaços (portacomprimidos com 28 espaços G-Life ${ }^{\circledR}$ ) e orientação quanto ao seu uso.

Figura 1 Porta-comprimidos com 28 espaços G-Life ${ }^{\circledR}$
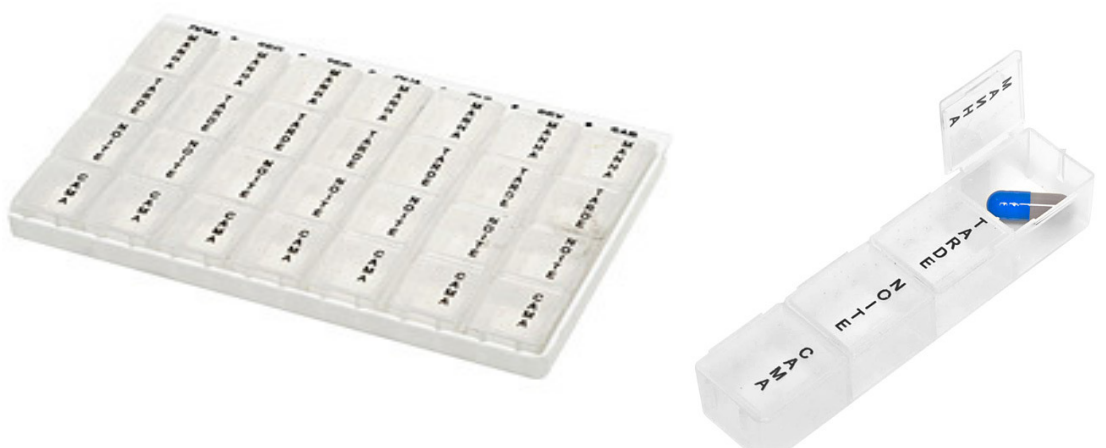

[Disponível em: http://www.g-life.com.br/. Acesso em 20 de maio de 2012.] 


\subsection{AMOSTRAGEM E ALOCAÇÃO DOS PACIENTES}

A amostragem foi não aleatória e todos os pacientes que atenderam aos critérios de elegibilidade e compareceram ao ambulatório de epilepsia após o início da coleta de dados foram incluídos na casuística, até que um ano de coleta de dados fosse completado. A inclusão de novos casos na amostra ocorreu de janeiro de 2013 a fevereiro de 2014.

Para inclusão na amostra, os pacientes do ambulatório de epilepsia do departamento de neurologia da HCFMUSP foram abordados pela equipe de pesquisa na sala de espera dos consultórios, após pré-seleção realizada pelo confronto dos dados de prontuário e critérios de elegibilidade desta investigação.

Nessa abordagem, os pacientes foram questionados em relação às informações relacionadas à seleção da casuística do estudo que não constavam em prontuário ou não estavam claramente descritas e também foram avaliados pelo teste de Morisky (Apêndice D).

Indivíduos que apresentaram resultado do teste de Morisky indicando baixa ou média adesão foram convidados a participar do estudo, desde que atendessem aos critérios estabelecidos para inclusão na casuística.

A alocação dos pacientes nos grupos de intervenção foi realizada de forma randomizada, por meio do software Research Randomizer (Version $4.0)^{(70)}$. Foram criados conjuntos de sequências com a distribuição da intervenção 1, intervenção 2 e intervenção 3 de forma aleatória. Assim, o investigador alocou os pacientes nos grupos Intervenção 1, Intervenção 2 ou Intervenção 3 seguindo a sequência randomizada estabelecida pelo software.

Houve sigilo de alocação nos grupos, visto que os elementos da equipe de pesquisa, responsáveis pela seleção inicial dos pacientes, não tinham contato com a lista que registrava a sequência de alocação dos pacientes, a qual só era conhecida pela pesquisadora que realizava a intervenção. 


\subsection{MEDIDAS DE ADESÃO TERAPÊUTICA}

Foram utilizados na pesquisa, concomitantemente, três métodos para avaliar a adesão terapêutica: a dosagem sérica das DAEs, considerada medida objetiva direta; a frequência de doses nos últimos 30 dias, como marcador clínico; e o teste de Morisky ${ }^{(38)}$, que avaliou a adesão ao tratamento por meio de autorrelato.

- Nível de dosagens séricas das DAEs: medida da concentração plasmática das DAEs expressa por valor numérico e resultado do exame laboratorial realizado nos períodos inicial e final da pesquisa. Conforme os métodos laboratoriais utilizados, os níveis terapêuticos das drogas dosadas foram: ácido valproico de 40 a $100 \mathrm{ug} / \mathrm{mL}$, carbamazepina de 8 a 12 ng/mL, fenitoína de 10 a $20 \mu \mathrm{g} / \mathrm{mL}$ e fenobarbital de 10 a $40 \mu \mathrm{g} / \mathrm{mL}^{(71)}$.

- Frequência de crises nos últimos 30 dias: medida indireta da adesão, visto que não aderir à prescrição médica das DAEs reduz os benefícios que podem ser adquiridos com esses medicamentos e pode ser um fator importante do não controle das crises. O resultado da medida está expresso nesta investigação pelo número de crises que o paciente referiu ter apresentado no mês que antecedeu a entrevista com a equipe da pesquisa.

- Teste de Morisky ${ }^{(38)}$ : instrumento que foi aplicado em forma de entrevista para avaliação da adesão terapêutica. É constituído por quatro questões que, se respondidas de forma afirmativa, indicam um comportamento de não adesão ao tratamento. $\mathrm{Na}$ presente investigação, as respostas foram avaliadas de forma a expressar o resultado do teste como variável, ordinal e categórica. A ordinal foi traduzida em escores de zero a quatro. A categórica classificou os pacientes com alta adesão (se responderam negativamente as quatro questões e receberam escore quatro), adesão média (quando a resposta afirmativa foi observada em uma ou duas questões, recebendo escores dois e três) e adesão baixa (se mais de duas 
respostas afirmativas foram apresentadas pelos pacientes, com escores zero ou um).

\subsection{INSTRUMENTOS DO ESTUDO}

\subsubsection{Instrumento para Seleção dos Participantes da Pesquisa (Apêndice D)}

Instrumento utilizado para seleção da casuística desta pesquisa. $\mathrm{O}$ impresso continha dados de identificação, o teste de Morisky ${ }^{(38)}$ e cheklist para conferir se o paciente atendia aos critérios de participação na pesquisa.

Para aplicação do teste de Morisky, foram utilizadas as instruções apresentadas no Anexo 1.

\subsubsection{Termo de Consentimento Livre e Esclarecido (Apêndice A)}

Instrumento utilizado para manifestação do paciente sobre sua anuência para participar do estudo (Apêndice A). Inclui informações sobre objetivos do estudo e investigador responsável, oferece confidencialidade na participação da pesquisa, além de atestar a ausência de ônus ou prejuízo no tratamento ambulatorial se houver desistência na participação da investigação. Foi apresentado ao paciente após a conferência se ele atendia aos critérios de elegibilidade do estudo e foi assinado pelo paciente, após seu consentimento na participação.

\subsubsection{Formulário para Entrevista (Apêndice E)}

Adaptação do impresso utilizado por Ferrari ${ }^{(20)}$, para caracterização de pacientes com epilepsia em acompanhamento ambulatorial, inclui ao final local para registro dos resultados dos exames laboratoriais de dosagem plasmática das DAEs coletados no primeiro encontro com o paciente. 


\subsection{4 Índice de Complexidade do Tratamento Medicamentoso em Epilepsia (ICTME) ${ }^{(72,73)}$ (Anexo 2)}

Versão adaptada e validada culturalmente ${ }^{(72)}$ do Epilepsy Medication and Treatment Complexity Index ${ }^{(73)}$. As instruções utilizadas para aplicação do instrumento estão descritas no Anexo 1.

\subsubsection{Diário de Medicação (Apêndice B)}

Este instrumento, aplicado durante a Instrução Complementar, foi utilizado como apoio para reescrever a prescrição das DAEs recebida pelo paciente em consulta médica. Ele separa e ordena as medicações que compõem o regime terapêutico, conforme a quantidade de comprimidos e o período indicado para tomada do medicamento. Foi utilizado com os três grupos de intervenção e entregue aos pacientes depois de preenchido pelo participante e pesquisador.

\subsubsection{Instrumento para Acompanhamento (Apêndice F)}

Impresso elaborado para uso no segundo encontro com o paciente, quando a avaliação do efeito das intervenções foi realizada. Inclui local para registro de informações relativas à adesão terapêutica descrita por meio do autorrelato $^{(38)}$, frequência de crises e dosagens séricas.

\subsection{OPERACIONALIZAÇÃO DA COLETA DE DADOS}

Antecedendo o horário de atendimento ambulatorial, foi realizada a pré-seleção dos participantes pelo confronto das informações dos prontuários dos pacientes agendados para consultas na data e critérios de elegibilidade. Desta análise resultou uma relação de pacientes prováveis participantes da pesquisa que passariam em consulta no dia. 
No horário de atendimento ambulatorial, os pré-selecionados eram localizados na sala de espera das consultas pela equipe de pesquisa e convidados a participar da entrevista inicial.

Em sala reservada para coleta de dados da pesquisa foi aplicado o Instrumento para Seleção dos Participantes da Pesquisa (Apêndice D), começando pelo teste de Morisky. Nos casos em que os resultados do teste indicaram baixa ou média adesão, deu-se continuidade à entrevista visando completar o checklist do instrumento, que permitiu identificar pacientes que atenderam aos demais critérios de participação do estudo.

Pacientes com autorrelato de média ou baixa adesão, segundo teste de Morisky, que atenderam aos critérios de participação no estudo foram convidados a participar da pesquisa, e a eles foi apresentado o Termo de Consentimento Livre e Esclarecido (Apêndice A). Nessa apresentação, o membro da equipe de investigação esclareceu ao paciente o objetivo, os procedimentos e métodos do estudo e consultou sobre seu interesse e disponibilidade em participar da pesquisa.

Nos casos de anuência do paciente, este foi incluído em um dos grupos de pesquisa, conforme estabelecido pela técnica de randomização (item 3.4).

Pacientes que apresentaram média ou baixa adesão, mas não atendiam aos critérios de elegibilidade ou não desejavam participar da pesquisa, foram orientados individualmente sobre o uso das DAEs e receberam a instrução complementar. Esses pacientes, no entanto, não tiveram o seguimento programado como os demais participantes da pesquisa.

O Fluxograma da Composição dos Grupos de Pesquisa está apresentado na Figura 2. 
Figura 2 Fluxograma da Composição dos Grupos de Pesquisa. São Paulo, 2013-2014.

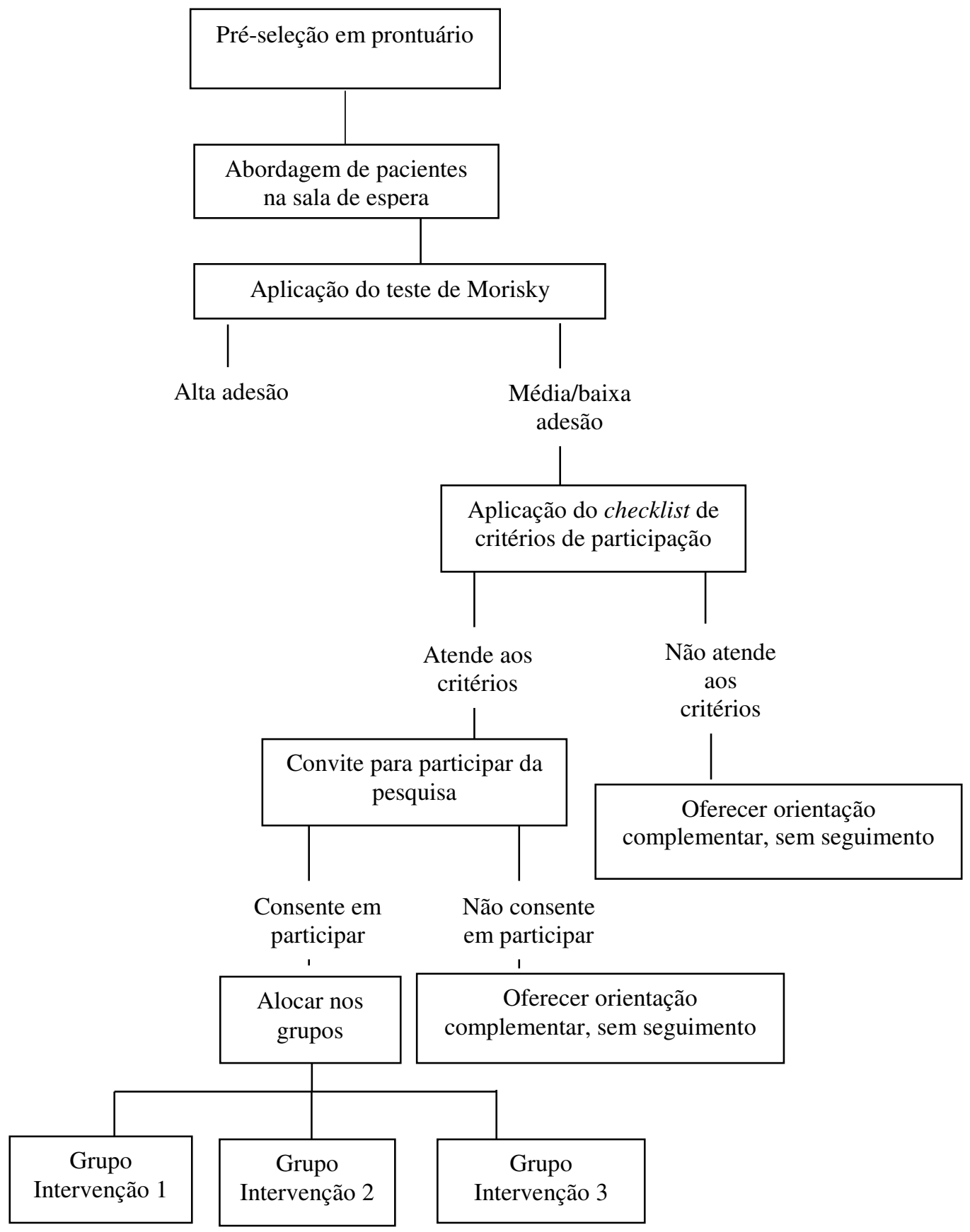

Os pacientes selecionados para participar da pesquisa e alocados nos três grupos de estudo foram, então, submetidos aos procedimentos a seguir, realizados em duas fases que compuseram a coleta de dados desta investigação. 


\subsubsection{Fase 1 ou Tempo Inicial $($ Tempo $=0)$}

Após o consentimento do paciente em participar do estudo, deu-se início à coleta de informações e o participante da pesquisa recebeu a Instrução Complementar isolada ou associada com a orientação do uso dos recursos auxiliares propostos.

Os pacientes foram entrevistados com o Formulário para Entrevista apresentado no Apêndice E. Nessa ocasião, também se realizou a avaliação da complexidade medicamentosa do tratamento dos selecionados para a pesquisa (Anexo 2).

Após o preenchimento desses instrumentos pela equipe de pesquisa, o investigador principal alocava o paciente no grupo de intervenção indicado pela lista randomizada e realizava a instrução complementar do paciente, que incluiu o preenchimento do diário de medicação, conforme as instruções apresentadas no Apêndice C.

As entrevistas com o investigador principal para o grupo de intervenção 1 foram finalizadas após esses procedimentos; o grupo de intervenção 2 ainda era orientado pelo pesquisador em relação à programação do aparelho celular para alertar em horários de tomada de medicação, e o grupo de intervenção 3 recebia a caixa organizadora semanal de medicações (porta-comprimidos com 28 espaços GTech $^{\circledR}$ ), juntamente com a orientação de seu uso.

Concluídas as orientações dessa etapa da pesquisa, os pacientes retornaram aos membros da equipe de pesquisa, que realizaram a entrevista inicial e coletaram amostras de sangue para dosagem sérica das DAEs. Após a coleta do exame laboratorial, uma segunda entrevista foi agendada com o pesquisador, quatro semanas depois desse primeiro encontro.

Todas as amostras de exames laboratoriais foram identificadas e encaminhadas ao serviço de laboratório imediatamente após o término da coleta de dados com o paciente. 


\subsubsection{Fase 2 ou Tempo Final $($ Tempo $=4$ semanas)}

O reencontro com o paciente agendado na primeira fase foi confirmado por meio de contato telefônico realizado pela equipe de pesquisa, na semana anterior à data do retorno. Após três tentativas de contato sem sucesso ou recusa de retorno, considerou-se encerrada a participação do paciente na pesquisa.

No segundo encontro, em todos os grupos, realizou-se a avaliação da adesão pelo teste de Morisky e coleta de sangue para dosagem sérica. O acesso do paciente às DAEs e a frequência de crises nos últimos 30 dias também foram verificados.

Todos os pacientes foram entrevistados em salas reservadas para coleta de dados e as informações obtidas foram registradas no Instrumento para Acompanhamento (Apêndice F).

Nessa fase, foram retomadas pela pesquisadora as orientações relativas ao diário de medicação (Apêndice B), programação do alarme do celular no grupo de intervenção 2 e uso da caixa organizadora de medicação no grupo de intervenção 3 (porta-comprimidos com 28 espaços GLife ${ }^{\circledR}$ ). Nesse encontro, dúvidas em relação ao esquema terapêutico, recursos auxiliares utilizados e pertinentes ao estudo também foram respondidas.

\subsection{TRATAMENTO DOS DADOS}

Todas as informações coletadas foram armazenadas em banco de dados computadorizado construído com uso do software Windows Excel. Os dados das tabelas e gráficos foram organizados com auxílio desse programa de computador. Para as provas estatísticas, realizadas pelo especialista na área, foi utilizado o software estatístico R 3.0.2 ${ }^{\circledR}(74)$. 


\subsubsection{Tratamento dos Resultados das Medidas de Adesão}

Os resultados das medidas de adesão utilizadas foram submetidos a diferentes tratamentos durante as análises realizadas, os quais estão sintetizados a seguir.

- Dosagem sérica padronizada

Para que os valores da concentração plasmática fossem comparados independentemente da DAE utilizada, foi realizada uma padronização dos resultados: de cada valor de dosagem sérica observado foi subtraído o valor mínimo terapêutico estabelecido para a droga $(40 \mathrm{ug} / \mathrm{mL}$ para ácido valproico; $8 \mathrm{ng} / \mathrm{mL}$ para carbamazepina; $10 \mathrm{ug} / \mathrm{mL}$ para fenitoína e fenobarbital ${ }^{(71)}$ e então dividido o valor encontrado pela estimativa do desvio padrão total de cada droga, para que todas as diferenças ficassem na mesma escala.

- Resultado das dosagens séricas segundo o nível terapêutico As concentrações plasmáticas das DAEs foram analisadas tendo em vista o nível mínimo terapêutico da droga dosada e categorizadas de forma dicotômica segundo a presença ou não de dosagem sérica inferior ao nível terapêutico

- Efeito segundo dosagem sérica das DAEs

Os valores das dosagens séricas das DAEs também foram examinados considerando o efeito desejado com a aplicação das intervenções. Participantes que atingiram o nível mínimo terapêutico das drogas após intervenções ou mantiveram esse nível, quando já alcançado no tempo inicial, tiveram indicação de efeito presente segundo a dosagem sérica, ao passo que aqueles com concentração plasmática abaixo do mínimo terapêutico no tempo final foram categorizados como ausência de efeito.

- Efeito segundo teste de Morisky

Para descrever a presença ou não de efeito das intervenções, considerando os resultados do teste de Morisky, foi analisada a evolução de cada paciente nas categorias do teste entre o tempo inicial e final do estudo. O efeito da intervenção foi considerado 
presente quando houve evolução de média para alta, de baixa para média ou alta adesão. Por outro lado, a manutenção da categoria alcançada no tempo inicial indicou ausência de efeito da intervenção.

- Efeito segundo frequência de crises nos últimos 30 dias

Em relação à frequência de crises, o efeito das intervenções foi considerado presente nos casos em que o paciente apresentou redução de pelo menos $30 \%$ das crises ou ausência de crises na fase final da pesquisa.

\subsubsection{Tratamento Estatístico}

Estatísticas descritivas foram realizadas para todas as variáveis, visando à caracterização geral da amostra do estudo e descrição da adesão ao tratamento.

Para verificar associação entre as medidas de adesão ao tratamento medicamentoso foi utilizado o teste de correlação de Spearman. Para comparação dos grupos com baixa e média adesão no teste de Morisky em relação à frequência de crises nos últimos 30 dias e dosagem sérica padronizada, foi aplicado o teste de Mann-Whitney para amostras independentes. Na comparação dos mesmos grupos quanto à presença de crises e dosagem sérica inferior a níveis terapêuticos, foi aplicado o teste Qui-quadrado.

Visando testar a similaridade dos três grupos de intervenção em relação às variáveis demográficas, clínicas e relacionadas ao tratamento foi aplicado o teste $\mathrm{F}$ de ANOVA para um fator nas comparações de médias das variáveis contínuas e o teste Qui-quadrado na análise de variáveis categóricas.

As comparações dos resultados pré e pós-intervenções dos escores de Morisky, da frequência de crises nos últimos 30 dias e da dosagem sérica padronizada foram realizadas com o teste de Mann-Whitney pareado, visto tratar-se de comparação de duas amostras dependentes. Nessa análise, as 
comparações foram realizadas considerando a diferença dos valores finais menos iniciais observada no resultado das medidas de adesão. A opção por um teste não paramétrico está relacionada ao caráter ordinal do resultado de Morisky e à distribuição bastante assimétrica das frequências de crises na amostra, conforme se pode observar no Apêndice G.

A comparação dos grupos de intervenções relacionada à presença do efeito desejado após intervenções foi realizada por meio do teste Quiquadrado. Esse teste ainda foi utilizado para comparar os grupos de intervenção quanto à distribuição nas categorias do Morisky, no tempo inicial e final, e também na análise da evolução da dosagem sérica durante o estudo. O teste de Kruskal-Wallis foi utilizado para verificar a diferença nos grupos de intervenção quando os resultados do teste de Mann-Whitney pareado alcançou o nível de significância nos três grupos.

\subsection{ASPECTOS ÉTICOS}

O estudo recebeu parecer favorável do Comitê de Ética em Pesquisa da Escola de Enfermagem da Universidade de São Paulo (EEUSP), pelo parecer 170.405 (Anexo 3), e pela Comissão de Ética para Análise de Projetos de Pesquisa do HCFMUSP, pelo parecer 172.864 (Anexo 4).

Em todas as fases deste estudo, os entrevistados foram previamente informados e esclarecidos sobre o objetivo da investigação e que não haveria prejuízo em relação à assistência que recebem no ambulatório, devido à recusa de participação. No primeiro encontro, foi entregue a todos os pacientes o Termo de Consentimento Livre e Esclarecido (Apêndice A) após sua anuência expressa de forma verbal e escrita. 


$$
\begin{array}{r}
4 . \\
\text { Resultados }
\end{array}
$$




\section{RESULTADOS}

\subsection{CARACTERIZAÇÃO DA AMOSTRA DO ESTUDO}

A casuística do estudo foi composta de 91 pacientes com diagnóstico de epilepsia que foram atendidos no ambulatório de neurologia do HCFMUSP de fevereiro de 2013 a janeiro de 2014.

Tabela 1 Distribuição dos pacientes ( $\mathrm{n}=91)$, segundo sexo, idade, vinculo conjugal e raça. São Paulo, 2013-2014.

\begin{tabular}{|c|c|c|c|}
\hline \multicolumn{2}{|l|}{ Idade em anos } & $\mathbf{N}^{\mathbf{o}}$ & $\%$ \\
\hline \multirow{8}{*}{ Idade em anos } & $\geq 18<30$ & 28 & 30,8 \\
\hline & $\geq 30<42$ & 26 & 28,5 \\
\hline & $\geq 42<60$ & 35 & 38,5 \\
\hline & 60 anos & 2 & 2,2 \\
\hline & Média & 37,8 & \\
\hline & Desvio padrão & 12,1 & \\
\hline & Mediana & & \\
\hline & Mín-Máx & $18-60$ & \\
\hline \multirow[t]{3}{*}{ Sexo } & & $\mathbf{N}^{\mathbf{o}}$ & $\%$ \\
\hline & Feminino & 46 & 50,5 \\
\hline & Masculino & 45 & 49,5 \\
\hline \multirow[t]{4}{*}{ Vínculo conjugal } & & $\mathbf{N}^{\mathbf{o}}$ & $\%$ \\
\hline & Casado & 45 & 49,5 \\
\hline & Solteiro & 26 & 28,5 \\
\hline & Viúvo/Separado & 20 & 22,0 \\
\hline \multirow[t]{4}{*}{ Raça } & & $\mathbf{N}^{\mathbf{o}}$ & $\%$ \\
\hline & Branca & 46 & 50,5 \\
\hline & Negra & 44 & 48,4 \\
\hline & Amarela & 1 & 1,1 \\
\hline
\end{tabular}

A distribuição da amostra quanto ao gênero mostrou que 50,5\% dos pacientes eram do sexo feminino. A idade média dos participantes foi de 37,8 anos, com desvio padrão de 12,1 anos. Indivíduos maiores de 60 anos não atenderam aos critérios de inclusão do estudo. 
Metade da amostra do estudo informou ter vínculo conjugal (49,5\%), enquanto $28,5 \%$ e $22 \%$ eram, respectivamente, solteiros e viúvos ou separados. Em relação à raça, observou-se uma distribuição similar de indivíduos da raça branca $(50,5 \%)$ e negra $(48,4 \%)$.

Tabela 2 Distribuição dos pacientes ( $n=91)$, segundo escolaridade e situação ocupacional. São Paulo, 2013-2014.

\begin{tabular}{|c|c|c|}
\hline Escolaridade & $\mathbf{N}^{\mathbf{o}}$ & $\%$ \\
\hline Ensino fundamental incompleto & 20 & 22,0 \\
\hline Ensino fundamental completo & 9 & 9,9 \\
\hline Ensino médio incompleto & 7 & 7,7 \\
\hline Ensino médio completo & 39 & 42,8 \\
\hline Ensino superior incompleto & 7 & 7,7 \\
\hline Ensino superior completo & 9 & 9,9 \\
\hline Média & 9,8 anos & \\
\hline Desvio padrão & 3,3 anos & \\
\hline Mediana & 11 anos & \\
\hline Mín-Máx & 4-17anos & \\
\hline Situação ocupacional & $\mathrm{N}^{\mathrm{o}}$ & $\%$ \\
\hline Empregado & 27 & 29,6 \\
\hline Autônomo & 15 & 16,5 \\
\hline Afastado com auxílio-doença & 9 & 9,8 \\
\hline Aposentado & 20 & 22,2 \\
\hline Estudante & 1 & 1,1 \\
\hline Do lar & 4 & 4,3 \\
\hline Desempregado & 15 & 16,5 \\
\hline
\end{tabular}

Em média, os participantes apresentaram 9,8 anos de escolaridade. A maioria dos pacientes completou o ensino médio $(42,8 \%)$ ou cursou ensino superior (7,7\% incompleto e 9,9\% completo). Em contrapartida, $22 \%$ da amostra não finalizou o ensino fundamental.

Em relação à situação ocupacional, observou-se que os aposentados representaram 22,2\% dos participantes, mesmo não havendo idosos na amostra. Somente $46,1 \%$ dos participantes estavam inseridos no mercado de trabalho, como empregados ou autônomos no período da avaliação.

Tabela 3 Distribuição dos pacientes ( $n=91)$, segundo renda per capita familiar (R\$). São Paulo, 2013-2014.

\begin{tabular}{lcc}
\hline Renda per capita & $\mathbf{N}^{\mathbf{0}}$ & \% \\
$\leq 250,00$ & 8 & 8,8 \\
$\geq 251,00 \leq 500,00$ & 24 & 26,3 \\
$\geq 501,00 \leq 750,00$ & 16 & 17,6 \\
$\geq 751,00 \leq 1000,00$ & 11 & 12,1
\end{tabular}




\begin{tabular}{lcc}
$\geq 1001,00 \leq 1500,00$ & 5 & 5,5 \\
$>1500,00$ & 7 & 7,7 \\
Não sabem informar & 18 & 19,8 \\
Recusaram informação & 2 & 2,2 \\
\hline
\end{tabular}

Entre os pacientes entrevistados, $71(78 \%)$ informaram a renda per capita familiar. Entre eles, a maior parte $(26,3 \%)$ tinha renda entre $\mathrm{R} \$$ 250,00 e $\mathrm{R} \$ 500,00$ e somente cerca de um quarto dos participantes informou valor superior a $\mathrm{R} \$ 750,00$, salário mínimo no estado de São Paulo em $2013^{(75)}$.

Tabela 4 Distribuição dos pacientes ( $\mathrm{n}=91$ ), segundo tipo de crise, tempo de diagnóstico de epilepsia e de tratamento com DAEs. São Paulo, 2013-2014.

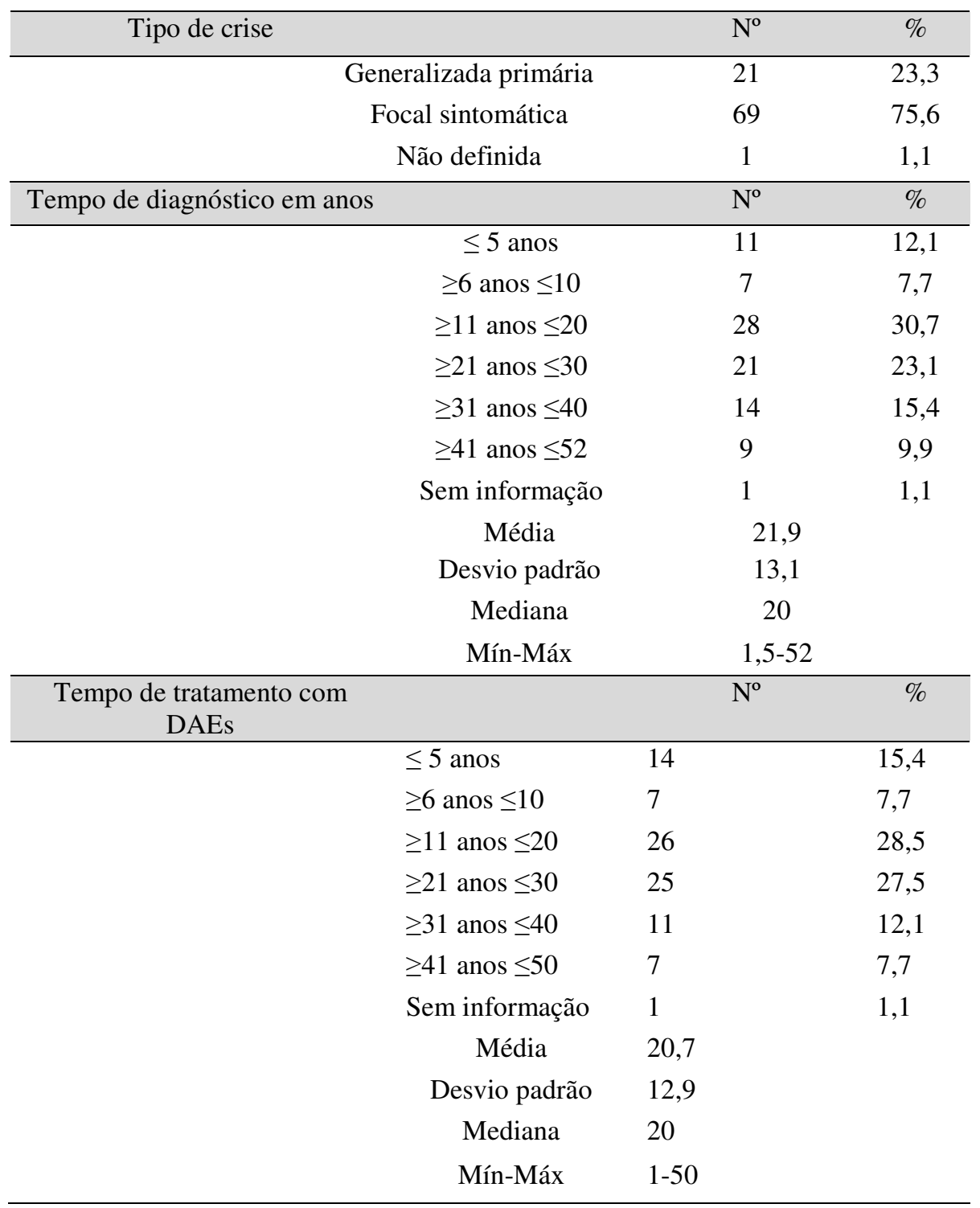


Observou-se que a maioria dos pacientes entrevistados tinha conhecimento de seu diagnóstico há mais de dez anos e fazia tratamento com DAEs por um tempo similar. A média de tempo pelo qual os indivíduos conheciam o diagnóstico de sua doença foi 21,9 anos e a duração do tratamento com DAEs atingiu, em média, 20,7 anos.

O tipo de crise mais frequente foi a focal sintomática, observada em 69 indivíduos (75,6\% dos participantes da amostra). A Tabela 5 apresenta dados relativos à evidência de lesão, localização e presença de esclerose mesial temporal nestes pacientes.

Tabela 5 Distribuição dos pacientes com diagnóstico de crise focal sintomática (n=69), segundo evidência de lesão, localização de lesão e presença de esclerose mesial temporal. São Paulo, 2013-2014.

\begin{tabular}{cccc}
\hline Evidência de lesão/localização & $\mathrm{N}^{\mathbf{o}}$ & $\%$ \\
\hline & Não & 25 & 36,2 \\
& Sim/localização temporal & 29 & 42,0 \\
& Sim/localização extratemporal & 10 & 14,5 \\
& Sim/localização temporal e extratemporal & 5 & 7,3 \\
\hline Presença de esclerose mesial temporal & $\mathrm{N}^{\text {o }}$ & $\%$ \\
\hline Sim & 27 & 39,1 \\
Não & 42 & 60,9 \\
\hline
\end{tabular}

A maioria dos pacientes que apresentava diagnósticos de epilepsia focal sintomática tinha lesão evidenciada e 49,3\% apresentava lesão localizada em lobo temporal isolada (42\%) ou combinada com lesão extratemporal (7,3\%). A esclerose mesial temporal foi evidenciada em 27 pacientes, $39,1 \%$ dos indivíduos com crise focal sintomática.

Tabela 6 Distribuição dos pacientes com epilepsia (n=91), segundo ICTME total e número de DAEs em uso. São Paulo, 2013-2014.

\begin{tabular}{|c|c|c|}
\hline ICTME Total & $\mathrm{N}^{\mathbf{0}}$ & $\%$ \\
\hline$\geq 5 \leq 14$ & 41 & 45,0 \\
\hline$\geq 15 \leq 29$ & 34 & 37,4 \\
\hline$\geq 30 \leq 48$ & 16 & 17,6 \\
\hline Média & 18,8 & \\
\hline Desvio padrão & 9,8 & \\
\hline Mediana & 16 & \\
\hline Mín-Máx & $5-48$ & \\
\hline Número de DAEs & $\mathbf{N}^{\circ}$ & $\%$ \\
\hline 1 & 29 & 31,8 \\
\hline 2 & 30 & 33,0 \\
\hline 3 & 30 & 33,0 \\
\hline 4 & 2 & 2,2 \\
\hline
\end{tabular}


A complexidade terapêutica segundo ICTME foi, em média, 18,8 pontos. O valor mínimo encontrado foi de cinco pontos e o máximo, 48. Houve predomínio de pacientes com até 14 pontos pelo ICTME; entretanto, indivíduos com 15 a 29 pontos também foram frequentes.

Gráfico 1- Porcentagem dos pacientes, segundo medicamento prescrito. São Paulo, 20132014.

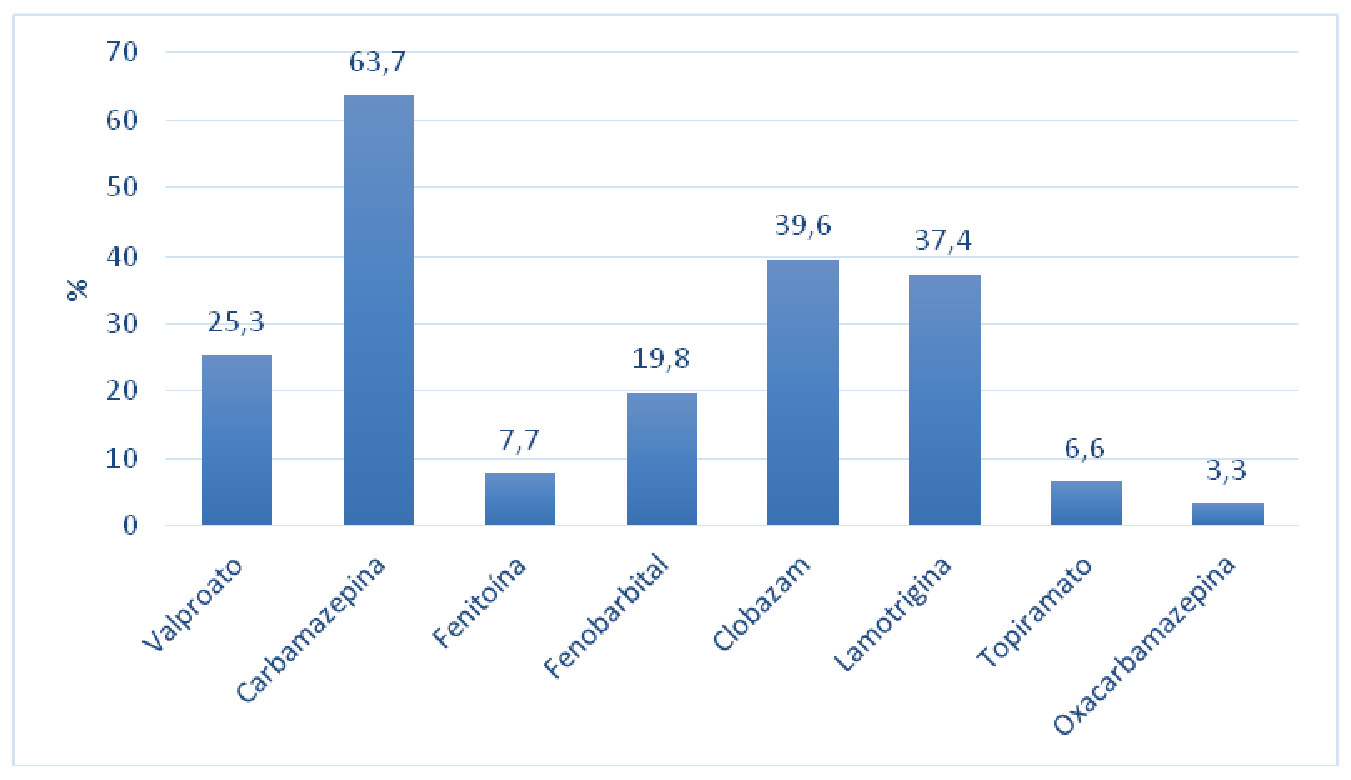

Conforme a Tabela 6, os pacientes entrevistados faziam uso de até quatro DAEs e $66 \%$ deles tomavam dois ou três medicamentos. No Gráfico 1, observa-se que as DAEs mais prescritas foram a carbamazepina $(63,7 \%)$, o clobazam $(39,6 \%)$ e a lamotrigina $(37,4 \%)$. Nesta investigação, foram realizadas dosagens séricas de valproato, carbamazepina, fenitoína e fenobarbital e pelo menos uma dessas DAEs estava prescrita para os participantes deste estudo.

Tabela 7- Distribuição dos pacientes ( $n=91$ ), segundo aquisição das DAEs no HCFMUSP e procedimento quando falta medicamento. São Paulo, 2013-2014.

\begin{tabular}{clc}
\hline Aquisição das DAEs no HCFMUSP & No & \% \\
\hline Consegue todas & 69 & 75,8 \\
Consegue parte & 21 & 23,1 \\
Não consegue & 1 & 1,1 \\
\hline Procedimento quando falta medicamento & $\mathbf{N o}$ & \% \\
\hline Compra & 56 & 61,5 \\
Fica sem tomar & 9 & 9,9 \\
Busca em outros locais & 26 & 28,6 \\
\hline
\end{tabular}


A grande maioria dos pacientes do grupo entrevistado adquiria todos seus medicamentos por meio da farmácia do hospital local do estudo (75,8\%). Quando havia falta das DAEs prescritas, cerca de $10 \%$ ficavam sem tomar. Em geral, os pacientes realizavam a compra dos fármacos em falta $(61,5 \%)$ ou buscavam em outro serviço público $(28,6 \%)$, por exemplo, unidade básica de saúde, ambulatório de especialidades, entre outros.

Tabela 8 Distribuição dos pacientes $(n=91)$, segundo a percepção quanto ao controle de crises e apoio de familiares e amigos. São Paulo, 2013-2014.

\begin{tabular}{llcc}
\hline Percepção do controle de crises & No & \% \\
\hline & Controlada & 36 & 39,5 \\
& Nem sempre & 28 & 30,8 \\
& Controlada & 26 & 28,6 \\
& Não controlada & 1 & 1,1 \\
\hline Não informado & $\mathbf{N o}$ & $\mathbf{\%}$ \\
\hline Apoio de familiares & & 62 & 68,1 \\
& Sempre & 7 & 7,7 \\
& Quase sempre & 4 & 4,4 \\
& Raramente & 17 & 18,7 \\
& Não tem apoio & 1 & 1,1 \\
\hline
\end{tabular}

Em relação à percepção do controle de crises, resultados mostrados na Tabela 8 indicam que 39,5\% dos pacientes consideravam suas crises controladas, porém 59,4\% da amostra afirmava que suas crises eram "nem sempre controladas" ou "não controladas". Na mesma tabela, observa-se que a maioria dos pacientes relatava ter apoio de familiares ou amigos no tratamento da epilepsia.

\subsection{MEDIDAS DE ADESÃO AO TRATAMENTO MEDICAMENTOSO}

Nesta seção, estão organizados os dados iniciais referentes à adesão ao tratamento medicamentoso dos pacientes tendo em vista as três formas de medida utilizadas: teste de Morisky em categoria e escore, frequência de crises nos últimos 30 dias e dosagem sérica das DAEs. Os resultados referentes a essas medidas estão descritos a seguir e também comparados. 
Gráfico 2- Distribuição dos pacientes $(\mathrm{n}=91)$, segundo categoria de adesão pelo teste de Morisky (n=91). São Paulo, 2013-2014.

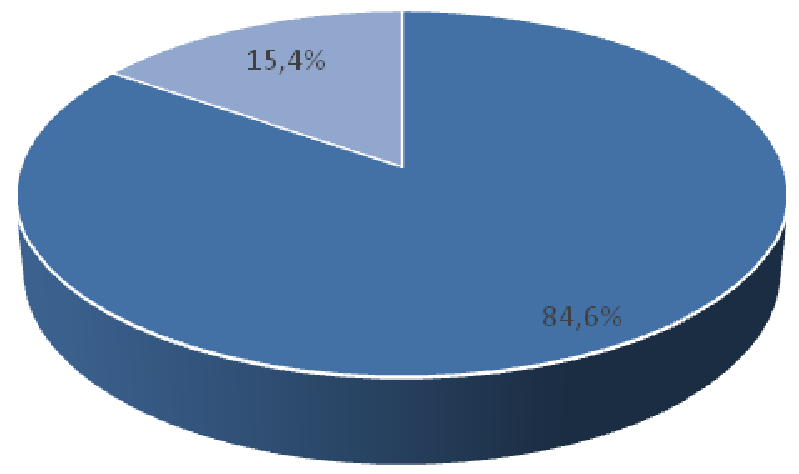

- Média Adesão

- Baixa Adesão

Os 91 pacientes incluídos nesta investigação apresentaram, na avaliação inicial, autorrelato de baixa ou média adesão segundo o teste de Morisky. Nesta fase, o comportamento da grande maioria dos participantes $(84,6 \%)$ foi categorizado como de média adesão.

Gráfico 3- Porcentagem de pacientes que deram respostas afirmativas às questões do teste de Morisky. São Paulo, 2013-2014.

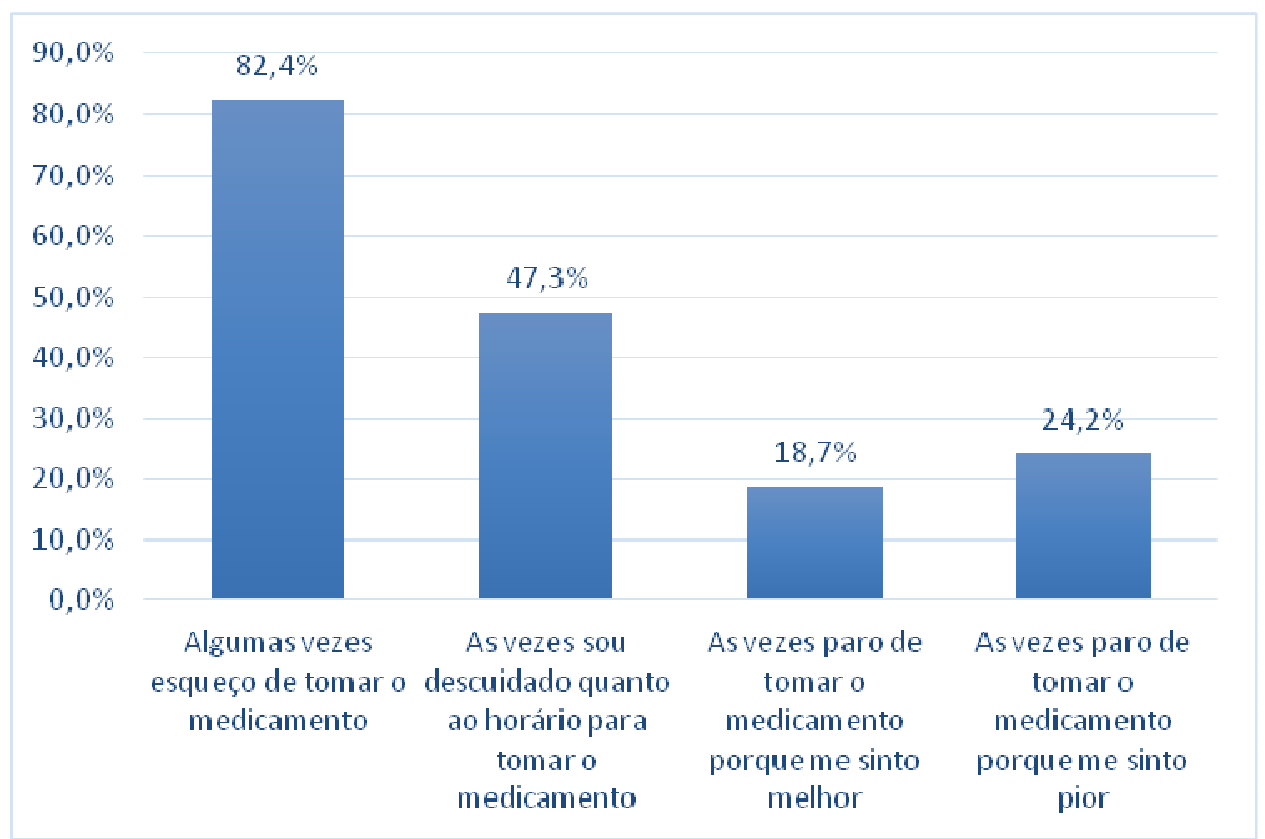


A resposta afirmativa à primeira questão "Algumas vezes esqueço de tomar o medicamento" foi a mais frequente, dada por $82,4 \%$ dos participantes, seguida pela questão "às vezes sou descuidado quanto ao horário para tomar o medicamento" (47,3\%). O comportamento intencional de parar de tomar o medicamento foi referido por $18,7 \%$ e $24,2 \%$ dos participantes, motivados pela melhora e piora da sintomatologia, respectivamente.

Tabela 9- Distribuição dos pacientes $(n=91)$ segundo frequência de crises nos últimos 30 dias. São Paulo, 2013-2014.

\begin{tabular}{|c|c|c|}
\hline Frequência de crises (30 dias) & $\mathbf{N}^{\mathbf{0}}$ & $\%$ \\
\hline $\begin{array}{ll}\text { Sem crise } \\
\end{array}$ & 26 & 28,6 \\
\hline$\geq 1 \leq 2$ & 31 & 34,0 \\
\hline$\geq 3 \leq 4$ & 15 & 16,5 \\
\hline$\geq 5 \leq 10$ & 9 & 9,9 \\
\hline$>10$ & 9 & 9,9 \\
\hline Sem informação & 1 & 1,1 \\
\hline Média & 4,9 & \\
\hline Desvio padrão & 13,0 & \\
\hline Mediana & 1 & \\
\hline Mín-Máx & $0-100$ & \\
\hline
\end{tabular}

Em relação à frequência de crises, verificou-se que, em média, os pacientes apresentaram 4,9 crises nos últimos 30 dias antes da primeira avaliação. A maioria $(62,6 \%)$ apresentou até duas crises no período e, entre eles, $28,6 \%$ relataram não apresentar nenhuma crise nesse período. A distribuição dos pacientes segundo frequência de crises foi bastante variada, com muitos outliers e variação de zero a 100 crises mensais (Apêndice G).

Tabela 10 Distribuição dos pacientes de acordo com DAEs dosadas e estatísticas descritivas dos resultados das dosagens séricas realizadas $\left(n=89^{\ddagger}\right)$. São Paulo, 2013-2014.

\begin{tabular}{|c|c|c|c|c|c|c|c|}
\hline \multirow[b]{2}{*}{ DAEs } & \multirow[b]{2}{*}{$\mathbf{N}^{\mathbf{o}}$} & \multirow[b]{2}{*}{$\%$} & & \multicolumn{4}{|c|}{ Resultados } \\
\hline & & & Média & Mediana & Mín & Máx & $\begin{array}{l}\text { Desvio } \\
\text { padrão }\end{array}$ \\
\hline $\begin{array}{l}\text { Ácido valproico } \\
(40-100 \mathrm{ug} / \mathrm{mL})^{*}\end{array}$ & 19 & 21,3 & 58,0 & 67,0 & 2,4 & 111 & 35,9 \\
\hline $\begin{array}{l}\text { Carbamazepina } \\
(8-12 \mathrm{ng} / \mathrm{mL})^{*}\end{array}$ & 54 & 60,7 & 7,3 & 7,2 & 0,11 & 12,8 & 3,4 \\
\hline $\begin{array}{l}\text { Fenitoína } \\
(10-20 \mu \mathrm{g} / \mathrm{mL})^{*}\end{array}$ & 7 & 7,9 & 14,2 & 13,5 & 6,7 & 25,8 & 14,2 \\
\hline $\begin{array}{l}\text { Fenobarbital } \\
(10-40 \mu \mathrm{g} / \mathrm{mL})^{*}\end{array}$ & 9 & 10,1 & 19,4 & 21,5 & 1,1 & 33,2 & 9,2 \\
\hline
\end{tabular}


A DAE dosada com maior frequência foi a carbamazepina $(60,7 \%)$, seguida pelo ácido valproico $(21,3 \%)$. Em dois pacientes, houve perda de informação por erro na dosagem sérica. Pelo valor da mediana, nota-se que pelo menos metade dos participantes medicados com ácido valproico, fenitoína e fenorbabital já tinha alcançado o valor de referência para controle das crises na avaliação inicial e o nível sérico da carbamazepina foi em maior frequência abaixo do terapêutico. Nessa fase, ainda foram observados casos em que a dosagem sérica indicava valores superiores aos indicados como terapêuticos, conforme é possível divisar pelos valores máximos apresentados.

Gráfico 4- Gráficos de dispersão 2 a 2 e coeficiente de correlação de Spearman entre as variáveis escore do teste de Morisky, frequência de crises nos últimos 30 dias e dosagem sérica padronizada. São Paulo. 2013-2014.
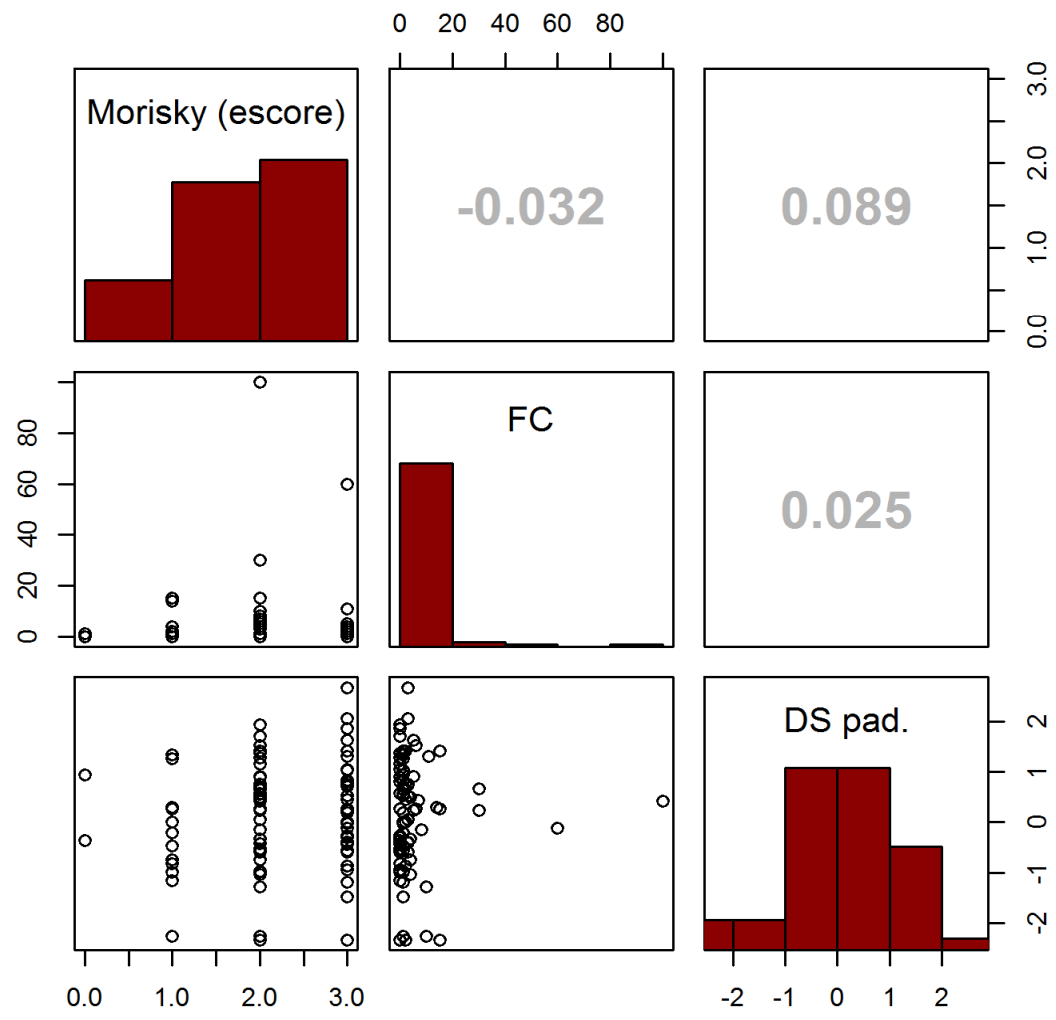

O resultado do coeficiente de correlação de Spearman foi muito baixo entre as medidas de adesão utilizadas: - 0,032 , entre escore do teste de Morisky e frequência de crises mensais; 0,089, entre esse escore e dosagem sérica padronizada e 0,025 entre frequência de crises nos últimos 30 dias e 
essa dosagem. Consequentemente, não houve correlação estatisticamente significativa, segundo o teste de Mann-Whitney, entre as medidas da avaliação de adesão inicial realizada na amostra do estudo.

Tabela 11 Estatísticas descritivas e inferenciais para frequência de crises nos últimos 30 dias e dosagem sérica padronizada segundo categorias de adesão do teste de Morisky. São Paulo, 2013-2014.

\begin{tabular}{|c|c|c|c|c|c|c|c|c|c|}
\hline Medida & $\begin{array}{c}\text { Categoria } \\
\text { Morisky }\end{array}$ & $\mathbf{N}^{\mathbf{o}}$ & $\%$ & Mín & Máx & Média & $\begin{array}{l}\text { Desvio } \\
\text { padrão }\end{array}$ & Mediana & $\mathbf{p}^{*}$ \\
\hline \multirow{3}{*}{$\begin{array}{l}\text { Frequência } \\
\text { de crises }\end{array}$} & Todas & 90 $^{¥}$ & 100 & $\mathbf{0}$ & 100 & 4,9 & 13,0 & 1,0 & \multirow{3}{*}{0,523} \\
\hline & Baixa & 14 & 15,6 & 0 & 15 & 2,9 & 5,0 & 1,0 & \\
\hline & Média & 76 & 84,4 & 0 & 100 & 5,2 & 13,9 & 1,0 & \\
\hline \multirow{3}{*}{$\begin{array}{l}\text { Dosagem } \\
\text { sérica } \\
\text { padronizada }\end{array}$} & Todas & $89^{¥ ¥}$ & 100 & $-2,3$ & 2,7 & 0,1 & 1,1 & 0,3 & \multirow{3}{*}{0,164} \\
\hline & Baixa & 14 & 15,7 & $-2,2$ & 1,3 & $-0,2$ & 1,0 & $-0,3$ & \\
\hline & Média & 75 & 84,3 & $-2,3$ & 2,7 & 0,2 & 1,1 & 0,3 & \\
\hline
\end{tabular}

A estatística descritiva da frequência de crises nos últimos 30 dias mostrou média de 2,9, entre indivíduos com baixa adesão, valor menor que aqueles com média adesão $(5,2)$. Entretanto, segundo desvio padrão, foi mais elevada a variabilidade entre os categorizados com média adesão pelo Morisky, o que contribuiu para seu maior valor médio. A dosagem sérica padronizada média foi inferior naqueles com indicação de baixa adesão pelo teste de Morisky $(-0,2)$ quando comparada ao valor dos demais $(0,2)$. Não obstante, não houve diferença estatisticamente significativa entre os grupos com média e baixa adesão, tanto em relação à frequência de crises mensais como quanto à dosagem sérica padronizada.

Tabela 12 Distribuição dos pacientes $\left(n=90^{\ddagger}\right)$ segundo categoria do teste de Morisky e presença de crises nos últimos 30 dias. São Paulo, 2013-2014.

\begin{tabular}{|c|c|c|c|c|c|}
\hline \multirow{3}{*}{ Categoria Morisky } & \multicolumn{4}{|c|}{ Presença de crises } & \multirow{3}{*}{$\mathbf{p}^{*}$} \\
\hline & \multicolumn{2}{|c|}{ SIM } & \multicolumn{2}{|c|}{ NÃO } & \\
\hline & $\mathbf{N}^{\mathbf{o}}$ & $\%$ & $\mathbf{N}^{\mathbf{o}}$ & $\%$ & \\
\hline Baixa $(n=14)$ & 10 & 15,6 & 4 & 15,4 & \\
\hline & & & & & 1,00 \\
\hline Média $(\mathrm{n}=76)$ & 54 & 84,4 & 22 & 84,6 & \\
\hline TOTAL $(n=90)$ & 64 & 100,0 & 26 & 100,0 & \\
\hline
\end{tabular}


Pela Tabela 12 observa-se que pacientes que tiveram crises nos últimos 30 dias que antecederam a avaliação inicial apresentaram autorrelato de baixa adesão $(15,6 \%)$ de forma similar aos que não apresentaram crises no período $(15,4 \%)$. Esta observação foi confirmada pelo teste Qui-quadrado utilizado para comparação dos resultados das medidas. Ainda é importante destacar nos dados desta tabela que 26 dos 90 casos $(28,9 \%)$ não apresentaram crises nos últimos 30 dias que antecederam a primeira avaliação.

Tabela 13 Distribuição dos pacientes $\left(n=89^{¥}\right)$ segundo categoria do teste de Morisky e presença de baixo nível sérico das DAEs para controle de crise. São Paulo, 2013-2014.

\begin{tabular}{|c|c|c|c|c|c|}
\hline \multirow{3}{*}{ Categoria Morisky } & \multicolumn{4}{|c|}{ Dosagem Sérica < nível terapêutico } & \multirow{3}{*}{$\mathbf{p}^{*}$} \\
\hline & \multicolumn{2}{|c|}{ SIM } & \multicolumn{2}{|c|}{ NÃ̃O } & \\
\hline & $\mathbf{N}^{\circ}$ & $\%$ & $\mathbf{N}^{\mathbf{o}}$ & $\%$ & \\
\hline Baixa $(n=14)$ & 9 & 23,7 & 5 & 9,8 & \\
\hline Média $(\mathrm{n}=75)$ & 29 & 76,3 & 46 & 90,2 & 0,137 \\
\hline TOTAL (n=89) & 38 & 100,0 & 51 & 100,0 & \\
\hline
\end{tabular}

Os pacientes que, na avaliação inicial, apresentavam baixo nível sérico das DAEs para controle das crises informaram com maior frequência $(23,7 \%)$ baixa adesão ao tratamento medicamentoso do que os que alcançaram nível terapêutico $(9,8 \%)$, porém essa diferença não alcançou o nível de significância estatístico estabelecido.

Tabela 14 Distribuição dos pacientes $\left(n=88^{\ddagger}\right)$ segundo presença de crises nos últimos 30 dias e baixo nível sérico das DAEs para controle de crises. São Paulo, 2013-2014

\begin{tabular}{|c|c|c|c|c|c|}
\hline \multirow{3}{*}{ Presença de crises } & \multicolumn{4}{|c|}{ Dosagem Sérica < nível terapêutico } & \multirow{3}{*}{$\mathbf{p}^{*}$} \\
\hline & \multicolumn{2}{|c|}{ SIM } & \multicolumn{2}{|c|}{ NÃO } & \\
\hline & $\mathbf{N}^{0}$ & $\%$ & $\mathbf{N}^{\mathbf{o}}$ & $\%$ & \\
\hline $\operatorname{SIM}(n=62)$ & 23 & 62,2 & 39 & 76,5 & \\
\hline & & & & & 0,224 \\
\hline NÃO (n=26) & 14 & 37,8 & 12 & 23,5 & \\
\hline TOTAL $\left(\mathbf{n}=\mathbf{8 8}^{\ddagger}\right)$ & 37 & $\mathbf{1 0 0 , 0}$ & 51 & 100,0 & \\
\hline
\end{tabular}


$\mathrm{Na}$ avaliação inicial não houve diferença estatisticamente significativa dos grupos com e sem DS inferior ao nível terapêutico em relação à presença de crises nos últimos 30 dias. Vale destaque na tabela 14 que somente 37 dos participantes, 42\%, tiveram na avaliação inicial DS inferior ao nível terapêutico.

\subsection{COMPARAÇÃO DAS CARACTERÍSTICAS DEMOGRÁFICAS, CLÍNICAS E RELACIONADAS AO TRATAMENTO DOS GRUPOS DE INTERVENÇÃO}

A amostra inicial do estudo foi composta de 91 pacientes do ambulatório de neurologia com diagnóstico de epilepsia. Destes, 28 (30,8\%) foram alocados no grupo de intervenção 1 e receberam somente instrução complementar; $31(34,1 \%)$ foram incluídos no grupo de intervenção 2 e utilizaram o alarme de celular como lembrete, além de receber essa instrução; e o grupo de intervenção 3 foi composto de 32 (35,1\%) participantes que receberam instrução complementar associada à caixa organizadora de medicamentos.

Para avaliação dos efeitos dessas intervenções, 62 pacientes retornaram, em média, 36,5 dias após aplicação das intervenções e avaliação inicial. As perdas foram de 10, 11 e 8 pacientes, nos grupos de intervenção 1,2 e 3, respectivamente. Por conseguinte, na avaliação final, o grupo de intervenção 1 incluiu 18 pacientes (29\%), o segundo grupo teve 20 participantes $(32,3 \%)$ e o terceiro, $24(38,7 \%)$.

Tabela 15 Comparação dos grupos de intervenção segundo variáveis numéricas tendo em vista os participantes até fase final do estudo (n=62). São Paulo 2013-2014.

\begin{tabular}{|c|c|c|c|c|c|c|c|c|c|}
\hline \multirow[t]{2}{*}{ Variáveis } & \multicolumn{2}{|c|}{$\begin{array}{c}\text { Intervenção } 1 \\
(n=18)\end{array}$} & \multicolumn{2}{|c|}{$\begin{array}{c}\text { Intervenção } 2 \\
(\mathbf{n = 2 0})\end{array}$} & \multicolumn{2}{|c|}{$\begin{array}{c}\text { Intervenção } 3 \\
(\mathbf{n}=\mathbf{2 4})\end{array}$} & \multicolumn{2}{|c|}{ Total $(n=62)$} & \multirow[t]{2}{*}{$\mathbf{p}^{*}$} \\
\hline & Média & $D P$ & Média & $D P$ & Média & $D P$ & Média & $D p$ & \\
\hline Idade (anos) & 42,2 & 10,0 & 38,1 & 10,4 & 38,3 & 14,6 & 39,4 & 12,1 & 0,495 \\
\hline Escolaridade (anos) & 8,8 & 4,1 & 10,2 & 2,8 & 10,5 & 2,8 & 9,9 & 3,3 & 0,245 \\
\hline Renda per capita $(\mathrm{R} \$)$ & 751,7 & 668,3 & 748,4 & 597,6 & 1026,8 & 1089,3 & 842,2 & 806,7 & 0,522 \\
\hline Tempo de diagnóstico (anos) & 27,7 & 10,3 & 22,9 & 13,5 & 21,0 & 14,0 & 23,5 & 13,0 & 0,24 \\
\hline $\begin{array}{l}\text { Tempo de tratamento com } \\
\text { DAEs (anos) }\end{array}$ & 26,2 & 10,8 & 21,4 & 14,3 & 19,7 & 12,7 & 22,1 & 12,8 & 0,255 \\
\hline ICTME total & 20,7 & 11,8 & 16,9 & 10,0 & 20,0 & 9,7 & 19,2 & 10,4 & 0,475 \\
\hline
\end{tabular}


A comparação dos três grupos de intervenção pelo teste $\mathrm{F}$ de ANOVA indicou similaridade em relação à idade, escolaridade, renda per capita, tempo de diagnóstico e tratamento com DAEs. A complexidade do tratamento medicamentoso, pelo ICTME, também foi semelhante entre os três grupos.

Tabela 16 Comparação dos grupos de intervenção segundo variáveis categóricas tendo em vista os participantes até fase final do estudo (n=62). São Paulo, 2013-2014.

\begin{tabular}{|c|c|c|c|c|c|c|c|c|c|c|}
\hline \multirow[t]{2}{*}{ Variáveis } & \multirow[t]{2}{*}{ Fator } & \multicolumn{2}{|c|}{$\begin{array}{c}\text { Intervenção } 1 \\
(\mathrm{n}=18)\end{array}$} & \multicolumn{2}{|c|}{$\begin{array}{c}\text { Intervenção } 2 \\
(\mathbf{n = 2 0})\end{array}$} & \multicolumn{2}{|c|}{$\begin{array}{c}\text { Intervenção } 3 \\
(\mathbf{n}=\mathbf{2 4})\end{array}$} & \multicolumn{2}{|c|}{ Total $(n=62)$} & \multirow[t]{2}{*}{ Valor $\mathbf{p}^{*}$} \\
\hline & & $\mathrm{N}^{\circ}$ & $\%$ & $\mathrm{~N}^{\circ}$ & $\%$ & $\mathrm{~N}^{\circ}$ & $\%$ & $\mathrm{~N}^{\circ}$ & $\%$ & \\
\hline \multirow[t]{2}{*}{ Sexo } & Masculino & 9 & 50 & 12 & 60 & 15 & 62,5 & 36 & 58,1 & \multirow[t]{2}{*}{0,703} \\
\hline & Solteiro & 5 & 27,8 & 7 & 35,0 & 5 & 20,8 & 17 & 27,4 & \\
\hline \multirow[t]{3}{*}{ Vínculo conjugal } & Casado & 8 & 44,4 & 8 & 40,0 & 12 & 50,0 & 28 & 45,2 & \multirow[t]{2}{*}{0,892} \\
\hline & Viúvo/separado & 5 & 27,8 & 5 & 25,0 & 7 & 29,2 & 17 & 27,4 & \\
\hline & Amarela & - & - & - & - & 1 & 4,1 & 1 & 1,6 & \multirow{3}{*}{0,210} \\
\hline \multirow[t]{3}{*}{ Raça } & Branca & 8 & 44,4 & 11 & 55,0 & 13 & 54,2 & 32 & 51,6 & \\
\hline & Negra & 10 & 55,6 & 9 & 45,0 & 10 & 41,7 & 29 & 46,8 & \\
\hline & Não & 5 & 27,7 & 3 & 15,0 & 4 & 16,6 & 12 & 19,3 & \multirow{4}{*}{0,672} \\
\hline \multirow{3}{*}{ Apoio de familiares } & Raramente & 1 & 5,6 & - & - & 1 & 4,2 & 2 & 3,2 & \\
\hline & $\begin{array}{l}\text { Quase } \\
\text { sempre }\end{array}$ & 1 & 5,6 & 3 & 15,0 & 1 & 4,2 & 5 & 8,1 & \\
\hline & Sempre & 11 & 61,1 & 14 & 70,0 & 18 & 75,0 & 43 & 69,4 & \\
\hline \multirow{3}{*}{$\begin{array}{c}\text { Aquisição das DAEs } \\
\text { no HCFMUSP }\end{array}$} & $\begin{array}{c}\text { Não } \\
\text { consegue }\end{array}$ & - & - & - & - & - & - & - & - & \multirow{3}{*}{0,869} \\
\hline & Em parte & 5 & 27,8 & 5 & 25,0 & 5 & 20,8 & 15 & 24,2 & \\
\hline & $\begin{array}{l}\text { Consegue } \\
\text { todas }\end{array}$ & 13 & 72,2 & 15 & 75,0 & 19 & 79,2 & 47 & 75,8 & \\
\hline \multirow{3}{*}{$\begin{array}{l}\text { Procedimento quando } \\
\text { falta medicamento }\end{array}$} & Compra & 12 & 66,6 & 15 & 75,0 & 12 & 50 & 39 & 62,9 & \multirow{3}{*}{0,350} \\
\hline & Não toma & 1 & 5,6 & - & - & 3 & 12,5 & 4 & 6,5 & \\
\hline & $\begin{array}{r}\text { Busca em } \\
\text { outros locais }\end{array}$ & 5 & 27,8 & 5 & 25,0 & 9 & 37,5 & 19 & 30,6 & \\
\hline Tipo de crise & $\begin{array}{l}\text { Generalizada } \\
\text { primária }\end{array}$ & 3 & 16,7 & 2 & 10,0 & 8 & 34,8 & 13 & 21,3 & 0,120 \\
\hline \multirow[t]{2}{*}{ Evidência de lesão } & Sim & 12 & 80,0 & 12 & 66,7 & 11 & 73,3 & 35 & 72,9 & \multirow[t]{2}{*}{0,691} \\
\hline & $\begin{array}{r}\text { Extra } \\
\text { temporal }\end{array}$ & 3 & 25 & - & - & 3 & 33,3 & 6 & 19,4 & \\
\hline \multirow[t]{2}{*}{ Localização da lesão } & Temporal & 7 & 58,3 & 8 & 80 & 6 & 66,7 & 21 & 67,7 & \multirow[t]{2}{*}{0,277} \\
\hline & $\begin{array}{r}\text { Temporal e } \\
\text { Extratemporal }\end{array}$ & 2 & 16,7 & 2 & 20 & - & - & 4 & 12,9 & \\
\hline $\begin{array}{l}\text { Presença de esclerose } \\
\text { mesial temporal }\end{array}$ & Sim & 7 & 38,9 & 7 & 35 & 6 & 26,1 & 20 & 32,8 & 0,665 \\
\hline
\end{tabular}

*Teste Qui-quadrado

Não houve diferença estatisticamente significante entre os três grupos em relação a sexo, vínculo conjugal, raça, apoio de familiares, aquisição de drogas no HCFMUSP e procedimento quando falta 
medicamento. As características da doença - tipo de crise, evidência e local da lesão, além de presença de esclerose mesial temporal - também foram similares nos três grupos.

Além dessas comparações dos grupos, foi realizada a análise das perdas de pacientes entre a avaliação inicial e final. A similaridade dos 29 pacientes que não completaram sua participação no estudo foi testada em relação aos 62 que finalizaram o seguimento quanto às variáveis apresentadas nas tabelas 15 e 16 e, também, quanto ao escore de Morisky, frequência de crises mensais e dosagem sérica padronizada.

Os resultados dos testes estatísticos evidenciaram que, exceto em relação a idade, os indivíduos que completaram o seguimento foram similares aos demais $(\mathrm{p}>0,05)$. Participantes da avaliação final apresentaram idade média de 39,5 anos (desvio-padrão de 12,2) enquanto aqueles que não tomaram parte desta avaliação média de idade de 34,7 anos (desvio-padrão de 11,8$)$, sendo valor de $\mathrm{p}$ do teste, 0,09 .

\subsection{EFEITO DAS INTERVENÇÕES NA AMOSTRA}

$\mathrm{O}$ efeito das intervenções na amostra foi analisado considerando a evolução na adesão de cada paciente e no grupo em geral. Nas análises a seguir é apresentado o efeito observado nos 62 pacientes que participaram das avaliações inicial e final, segundo as medidas de adesão aplicadas. O tipo de intervenção não foi foco nesta fase da investigação.

\subsubsection{Efeito Avaliado pela Mudança no Escore e Categoria do Teste de Morisky}

Tabela 17 Distribuição conjunta dos pacientes que participaram das duas fases do estudo ( $n=62$ ), segundo escores no teste de Morisky e tempo. São Paulo 2013-2014.

\begin{tabular}{ccccccc}
\hline $\begin{array}{c}\text { Escore inicial no } \\
\text { teste de } \\
\text { Morisky }\end{array}$ & $\mathbf{0}$ & $\mathbf{1}$ & $\mathbf{2}$ & $\mathbf{3}$ & $\mathbf{4}$ \\
\cline { 2 - 6 } & $\mathbf{0}$ & - & - & - & - & 1 \\
$\mathbf{1}$ & - & - & 4 & 3 & 2 \\
$\mathbf{2}$ & - & - & $\mathbf{3}$ & 11 & 10 \\
$\mathbf{3}$ & - & - & 1 & $\mathbf{5}$ & 22 \\
$\mathbf{4}$ & & - & - & - & - \\
\hline
\end{tabular}


Ao final do estudo, nenhum paciente referiu baixa adesão ao tratamento medicamentoso, segundo teste de Morisky (pontuação zero ou um). Oito participantes mantiveram seu autorrelato nas duas avaliações realizadas (realce em azul) e somente em um caso observou-se diminuição de escore, de três para dois pontos (realce em vermelho). Em vista disso, maior pontuação na avaliação final foi observada em 53 indivíduos, 85,5\% dos quais completaram sua participação no estudo.

Tabela 18 Distribuição conjunta dos pacientes que participaram das duas fases do estudo (n=62), segundo classificação no teste de Morisky e tempo. São Paulo, 2013-2014.

\begin{tabular}{ccccc}
\hline \multirow{2}{*}{$\begin{array}{c}\text { Categoria Morisky } \\
\text { fase inicial }\end{array}$} & \multicolumn{3}{c}{ Categoria Morisky fase final } & TOTAL \\
\cline { 2 - 5 } & $\begin{array}{c}\text { Baixa } \\
\mathbf{n}(\boldsymbol{\%})\end{array}$ & $\begin{array}{c}\text { Média } \\
\mathbf{n}(\boldsymbol{\%})\end{array}$ & $\begin{array}{c}\text { Alta } \\
\mathbf{n}(\boldsymbol{\%})\end{array}$ & \begin{tabular}{c} 
n(\%) \\
\hline Baixa
\end{tabular} \\
Média & - & $7(11,3 \%)$ & $3(4,8 \%)$ & $10(16,1 \%)$ \\
\hline Total & - & $20(32,3 \%)$ & $32(51,6 \%)$ & $52(83,9 \%)$ \\
\hline
\end{tabular}

$\mathrm{Na}$ fase final do estudo, a maioria, 35 pacientes, apresentou relato de alta adesão e 7 evoluíram de baixa para média adesão, totalizando 42 $(67,7 \%)$ participantes que alcançaram melhor categoria no teste de Morisky após as intervenções.

Gráfico 5- Porcentagem de pacientes que participaram das duas fases do estudo e deram respostas afirmativas às questões do teste de Morisky segundo tempo. São Paulo, 20132014.

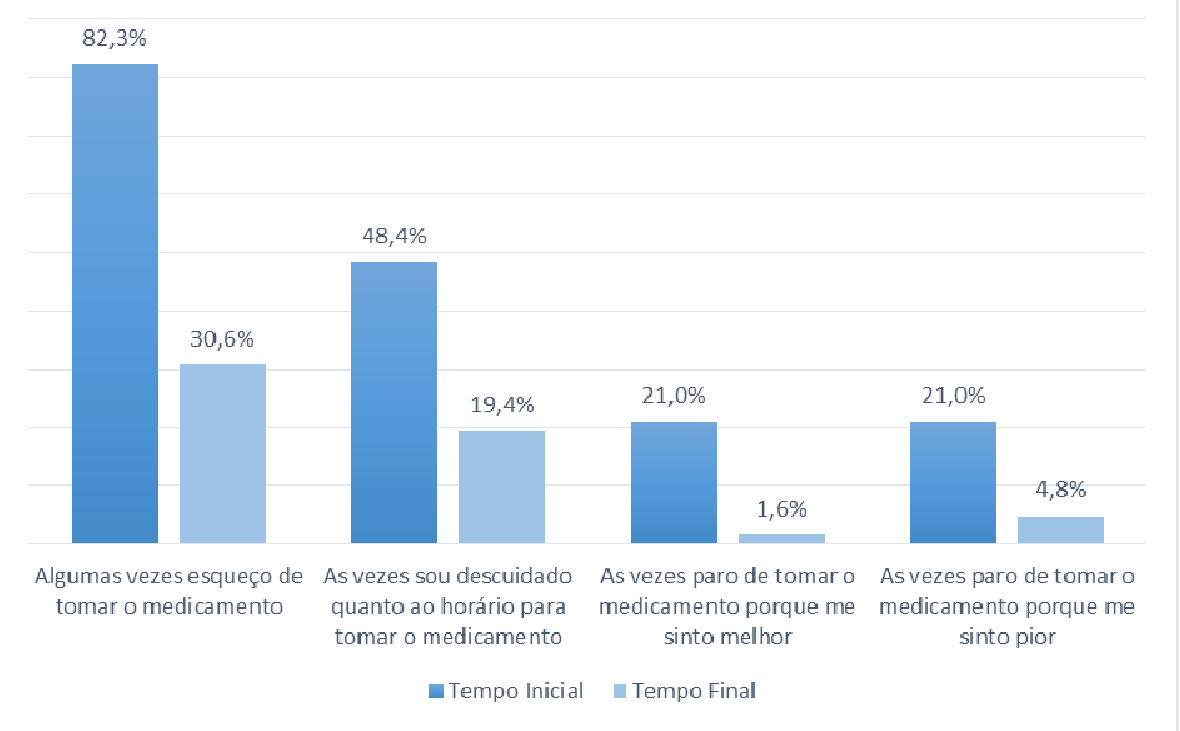


As respostas afirmativas às questões do teste de Morisky reduziram expressivamente na avaliação final. A porcentagem de participantes que referiu esquecer-se de tomar medicamentos diminuiu mais de 50\% e indivíduos que informaram parar de tomar as DAEs intencionalmente nas questões 3 e 4 passaram de $21 \%$ para menos de 2 e $5 \%$, respectivamente.

\subsubsection{Efeito avaliado pela mudança na frequência de crises nos últimos 30 dias}

Tabela 19 Distribuição conjunta dos pacientes que participaram das duas fases do estudo $(\mathrm{n}=62)$, segundo frequência de crises nos últimos 30 dias e tempo. São Paulo, 2013-2014.

\begin{tabular}{rrrrrrrrrrr}
\hline $\begin{array}{c}\text { Frequência de } \\
\text { crises no tempo } \\
\text { inicial }\end{array}$ & \multicolumn{6}{c}{ Frequência de crises no tempo final } \\
\cline { 2 - 10 } & $\mathbf{0}$ & 13 & 4 & 1 & 1 & - & - & - & - & - \\
& $\mathbf{1}$ & 9 & 2 & 2 & 1 & - & - & - & - & - \\
& $\mathbf{2}$ & 3 & - & 1 & - & - & - & - & - & - \\
& $\mathbf{3}$ & 1 & 4 & - & 1 & 1 & 1 & - & - & - \\
& $\mathbf{4}$ & - & - & 1 & 1 & - & - & - & 1 & - \\
$\mathbf{5}$ & 2 & - & - & 1 & - & - & - & - & - \\
& $\mathbf{6}$ & - & 2 & - & - & - & - & - & - & - \\
$\mathbf{7}$ & - & 1 & - & - & - & - & - & - & - \\
$\mathbf{8}$ & - & 1 & - & - & - & - & - & - & - \\
$\mathbf{1 0}$ & - & - & 1 & - & - & - & - & - & - \\
$\mathbf{1 1}$ & - & - & - & 1 & - & - & - & - & - \\
$\mathbf{1 5}$ & - & - & - & 1 & - & - & 1 & - & 1 \\
$\mathbf{6 0}$ & - & 1 & - & - & - & - & - & - & - \\
$\mathbf{1 0 0}$ & - & - & - & - & - & - & - & - & 1 \\
\hline
\end{tabular}

A frequência de crises mensais aumentou, na avaliação final, para 13 (21\%) pacientes (realce em vermelho); em 32 casos (51,6\%), o número de crises diminuiu após intervenção e $17(27,4 \%)$ participantes tiveram no tempo final a mesma frequência de crises (realce em azul). É importante destacar que, entre os indivíduos que mantiveram a frequência de crises, 13 (21\%) apresentavam ausência de crises já na primeira avaliação. No tempo inicial do estudo, a ausência de crises foi observada em 19 pacientes e, no final, em 28. No entanto, 6 dos pacientes que não apresentaram crises nos 30 dias que antecederam a inclusão na pesquisa tiveram até 3 crises no mês 
subsequente. $\mathrm{O}$ número médio de crises na avaliação inicial dos pacientes foi de 5,3 e, na final, 2, com desvio padrão de 14,7 e 4,1, respectivamente.

\subsubsection{Efeito avaliado pela mudança na dosagem sérica das DAEs}

Tabela 20 Distribuição dos pacientes que participaram das duas fases do estudo ( $\mathrm{n}=57^{¥}$ ) segundo a presença de dosagem sérica abaixo do nível terapêutico e tempo (inicial e final). São Paulo, 2013-2014.

\begin{tabular}{|c|c|c|c|}
\hline \multirow{2}{*}{$\begin{array}{c}\text { Tempo inicial } \\
\text { dosagem sérica }<\text { nível } \\
\text { terapêutico }\end{array}$} & \multicolumn{2}{|c|}{$\begin{array}{c}\text { Tempo final } \\
\text { dosagem sérica }<\text { nível terapêutico }\end{array}$} & \multirow[b]{2}{*}{$\begin{array}{l}\text { TOTAL } \\
\mathbf{N}^{\circ}(\%)\end{array}$} \\
\hline & $\begin{array}{c}\text { Sim } \\
\mathbf{N}^{\circ}(\%)\end{array}$ & $\begin{array}{c}\text { Não } \\
\mathbf{N}^{\circ}(\%)\end{array}$ & \\
\hline Sim & $13(22,8 \%)$ & $9(15,8 \%)$ & $22(38,6 \%)$ \\
\hline Não & $2(3,5 \%)$ & $33(57,9 \%)$ & $35(61,4 \%)$ \\
\hline TOTAL & $15(26,3)$ & $42(73,7 \%)$ & $57(100,0 \%)$ \\
\hline
\end{tabular}

No tempo final do estudo, $15(26,3 \%)$ dos pacientes avaliados apresentavam dosagem sérica abaixo do nível terapêutico; porém, ainda que a totalidade dos participantes tivesse autorrelato de baixa ou média adesão ao tratamento medicamentoso, somente $22(38,6 \%)$ apresentaram dosagem sérica das DAEs abaixo do desejável na primeira dosagem. Após intervenção, 9 deles alcançaram nível terapêutico na dosagem sérica das DAEs; no entanto, 2 participantes tiveram queda no nível desses medicamentos, passando a apresentar dosagem sérica abaixo do recomendado ao seu tratamento. Vale, entretanto, mencionar que, em 62,9\% dos casos, houve aumento dos valores da dosagem sérica entre a primeira e a segunda avaliação.

\subsection{COMPARAÇÃO DO EFEITO DAS INTERVENÇÕES}

Nesta fase da investigação, todas as análises foram realizadas considerando os três grupos distintos de intervenção e buscando diferenças entre eles. Os dados organizados em tabelas são relacionados aos 62 pacientes que participaram das avaliações inicial e final. Da mesma forma 
que na seção anterior, as análises foram realizadas tendo em vista os três tipos de medidas de adesão utilizadas e a evolução do comportamento de cada paciente e do grupo em relação a aderir à prescrição médica de medicamentos.

\subsection{1- Comparação do Efeito das Intervenções tendo como Medida de Adesão o Teste de Morisky}

Tabela 21 Resultado do teste de Morisky dos pacientes que participaram das duas fases do estudo ( $n=62)$ por grupo de intervenção e tempo. São Paulo, 2013-2014.

\begin{tabular}{|c|c|c|c|c|c|c|c|c|}
\hline \multirow{2}{*}{ Tempo } & \multirow{2}{*}{$\begin{array}{c}\text { Categoria } \\
\text { Morisky }\end{array}$} & \multicolumn{2}{|c|}{ Grupo 1} & \multicolumn{2}{|c|}{ Grupo 2} & \multicolumn{2}{|c|}{ Grupo 3} & \multirow[b]{2}{*}{$\mathbf{p}^{*}$} \\
\hline & & $\mathbf{N}^{0}$ & $\%$ & $\mathbf{N}^{\circ}$ & $\%$ & $\mathbf{N}^{\circ}$ & $\%$ & \\
\hline \multirow{3}{*}{ 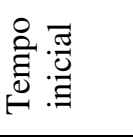 } & Baixa & 3 & 16,7 & 5 & 25,0 & 2 & 8,3 & \multirow{3}{*}{0,325} \\
\hline & Média & 15 & 83,3 & 15 & 75,0 & 22 & 91,7 & \\
\hline & Total & 18 & 100,0 & 20 & 100,0 & 24 & 100,0 & \\
\hline \multirow{4}{*}{ 善㞼 } & Baixa & - & - & - & - & - & - & \multirow{4}{*}{0,052} \\
\hline & Média & 7 & 38,9 & 13 & 65,0 & 7 & 29,2 & \\
\hline & Alta & 11 & 61,1 & 7 & 35,0 & 17 & 70,8 & \\
\hline & Total & 18 & 100,0 & 20 & 100,0 & 24 & 100,0 & \\
\hline
\end{tabular}

Na avaliação inicial, os três grupos de intervenção não apresentaram diferença estatisticamente significativa quanto à distribuição nas categorias do teste de Morisky ( $\mathrm{p}=0,325)$. Após as intervenções, esse resultado foi mantido, embora o p tenha se aproximado do limiar de significância $(0,052)$ para refutar que os grupos diferem entre si.

Tabela 22 Estatísticas descritivas e inferenciais para diferença do escore de Morisky entre tempos (final - inicial) segundo grupo de intervenção. São Paulo, 2013-2014.

\begin{tabular}{|c|c|c|c|c|c|c|c|c|c|}
\hline \multirow[t]{2}{*}{ Intervenção } & \multirow[t]{2}{*}{$\mathbf{N}^{\mathbf{o}}$} & \multirow[t]{2}{*}{ Mín } & \multirow[t]{2}{*}{ Máx } & \multirow[t]{2}{*}{ Média } & \multirow[t]{2}{*}{$\begin{array}{l}\text { Desvio } \\
\text { padrão }\end{array}$} & \multirow[t]{2}{*}{ Mediana } & $\begin{array}{l}\text { IC } \\
\text { média } \\
(95 \%)\end{array}$ & para & \multirow[t]{2}{*}{$\mathbf{p}^{*}$} \\
\hline & & & & & & & Inf & Sup & \\
\hline 1 & 18 & -1 & 3 & 1,2 & 0,9 & 1,0 & 0,7 & 1,6 & $<0,001$ \\
\hline 2 & 20 & 0 & 4 & 1,2 & 0,9 & 1,0 & 0,7 & 1,6 & $<0,001$ \\
\hline 3 & 24 & 0 & 3 & 1,2 & 0,7 & 1,0 & 0,9 & 1,5 & $<0,001$ \\
\hline
\end{tabular}

Melhora da adesão foi evidenciada em todos os grupos que retornaram na segunda fase da pesquisa. Em média, na avaliação final, os grupos tiveram aumento de 1,2 ponto no teste de Morisky. Diferença 
estaticamente significativa foi observada nos três grupos quando analisado o valor da mediana da subtração dos escores dos tempos final e inicial de cada paciente $(\mathrm{p}=<0,001)$. Contudo, o teste de Kruskal-Wallis resultou em $\mathrm{p}=$ 0,870 quando os três grupos foram comparados entre si e, portanto, foi similar a melhora na adesão dos grupos de intervenção.

Tabela 23 Comparação do efeito dos três grupos de intervenção segundo classificação do teste de Morisky, considerando pacientes que participaram das duas fases do estudo ( $\mathrm{n}=62$ ). São Paulo, 2013-2014.

\begin{tabular}{|c|c|c|c|c|}
\hline $\begin{array}{c}\text { Efeito pelo teste de } \\
\text { Morisky }\end{array}$ & $\begin{array}{l}\text { Grupo } 1 \\
\mathbf{N}^{\circ}(\%)\end{array}$ & $\begin{array}{l}\text { Grupo } 2 \\
\mathbf{N}^{\circ}(\%)\end{array}$ & $\begin{array}{l}\text { Grupo } 3 \\
\mathbf{N}^{\circ}(\%)\end{array}$ & $\mathbf{p}^{*}$ \\
\hline Ausente & $5(27,7 \%)$ & $9(45 \%)$ & $6(25 \%)$ & \multirow{2}{*}{0,327} \\
\hline Presente & $13(72,3 \%)$ & $11(55 \%)$ & $18(75 \%)$ & \\
\hline Total & $18(100 \%)$ & $20(100 \%)$ & $24(100 \%)$ & \\
\hline
\end{tabular}

Para analisar novamente o efeito das intervenções e testar a diferença entre os grupos, cada caso foi categorizado em relação à presença e ausência de resultado da intervenção. Como se pode observar na Tabela 23, a maioria dos participantes dos grupos teve indicação de efeito da intervenção (entre $55 \%$ e $75 \%$ dos participantes) e logo evoluiu para uma melhor categoria de adesão no teste de Morisky. Mais uma vez, a comparação por meio de teste estatístico indicou efeito similar entre grupos $(\mathrm{p}=0,327)$.

\subsection{2- Comparação do Efeito das Intervenções tendo como Medida de Adesão a Frequência de Crises nos Últimos 30 Dias}

A média de frequência de crises mensais na fase inicial foi maior em todos os grupos. Assimetria na distribuição da frequência de crises foi observada entre os três grupos de pacientes que participaram nas duas fases desta investigação, na fase inicial e final, como pode ser visto na Tabela 24. Esses resultados indicaram o uso de testes não paramétricos nas comparações realizadas a seguir. 
Tabela 24 Estatísticas descritivas para frequência de crises por grupo e tempos considerando pacientes que participaram das duas fases do estudo $(n=62)$. São Paulo, 20132014.

\begin{tabular}{|c|c|c|c|c|c|c|c|}
\hline & Grupo & $\mathbf{N}^{\mathbf{o}}$ & Média & $\begin{array}{l}\text { Desvio } \\
\text { padrão }\end{array}$ & Mediana & Mín & Máx \\
\hline \multirow{3}{*}{ 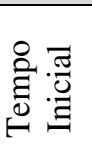 } & 1 & 18 & 2,9 & 4,1 & 1,0 & 0 & 15 \\
\hline & 2 & 20 & 3,4 & 4,1 & 2,0 & 0 & 15 \\
\hline & 3 & 24 & 8,6 & 23,0 & 1,5 & 0 & 100 \\
\hline \multirow{3}{*}{ 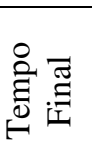 } & 1 & 18 & 2,2 & 4,7 & 1,0 & 0 & 20 \\
\hline & 2 & 20 & 1,0 & 1,1 & 1,0 & 0 & 3 \\
\hline & 3 & 24 & 2,7 & 5,0 & 1,0 & 0 & 20 \\
\hline
\end{tabular}

Tabela 25 Estatísticas descritivas e inferenciais para diferença da frequência de crises entre tempos (final - inicial) segundo grupo de intervenção. São Paulo, 2013-2014.

\begin{tabular}{cccccccccc}
\hline Intervenção & N & Mín & Máx & Média & $\begin{array}{c}\text { Desvio } \\
\text { padrão }\end{array}$ & Mediana & $\begin{array}{c}\text { IC para } \\
\text { média }(95 \%)\end{array}$ & $\mathbf{p}^{*}$ \\
\hline 1 & 18 & -8 & 5 & $-0,7$ & 2,8 & 0,0 & $-2,0$ & 0,7 & 0,361 \\
2 & 20 & -12 & 3 & $-2,5$ & 3,6 & $-1,0$ & $-4,1$ & $-0,8$ & $\mathbf{0 , 0 0 7}$ \\
3 & 24 & -80 & 9 & $-5,9$ & 20,0 & 0,0 & $-14,3$ & 2,6 & 0,195 \\
\hline
\end{tabular}

*Teste de Mann-Whitney pareado

Conforme teste de Mann-Whitney para medidas repetidas, houve diminuição significativa na frequência de crises somente no grupo 2 quando se considera o número de crises mensais após a intervenção. A mediana indica diminuição de pelo menos uma crise na maioria desse grupo e o intervalo de confiança da média, no nível de 95\%, apontou diminuição de crises após intervenção (entre -0,8 e -4,1). Nos demais grupos, o intervalo de confiança (95\%) estimado variou entre valores positivos, 0,7 e 2,6 e negativos, $-2,0$ e $-14,3$.

Tabela 26 Comparação do efeito dos três grupos de intervenção segundo frequência de crises, considerando pacientes que participaram das duas fases do estudo $(n=62)$. São Paulo, 2013-2014.

\begin{tabular}{lcccc}
\hline $\begin{array}{l}\text { Efeito pela frequência } \\
\text { de crises }\end{array}$ & Grupo 1 & Grupo 2 & Grupo 3 & p $^{*}$ \\
\hline Ausente & $6(33,3 \%)$ & $3(15,0 \%)$ & $9(37,5 \%)$ & 0,233 \\
Presente & $12(66,7 \%)$ & $17(85,0 \%)$ & $15(62,5 \%)$ & \\
\hline Total & $\mathbf{1 8 ( 1 0 0 \% )}$ & $\mathbf{2 0 ( 1 0 0 \% )}$ & $\mathbf{2 4}(\mathbf{1 0 0 \% )}$ \\
\hline & & & \multirow{2}{*}{$*$ Teste Qui- quadrado }
\end{tabular}


A Tabela 26 mostra a distribuição dos pacientes tendo em vista 0 efeito desejado com as intervenções: diminuição das crises pelo menos $30 \%$ ou ausência de crises na fase final da pesquisa. Dentro deste critério, a presença de efeito foi observada na maioria dos três grupos, entre 62,5\% e $85 \%$. O grupo 2 foi o que apresentou maior percentual de casos com presença de efeito; no entanto, a diferença não alcançou o nível de significância estabelecido nesta investigação $(p=0,233)$.

\subsubsection{Comparação do Efeito das Intervenções tendo como Medida de adesão a Dosagem Sérica das DAEs}

Tabela 27 Estatísticas descritivas e inferenciais para diferença da dosagem sérica padronizada entre tempos (final - inicial) segundo grupo de intervenção. São Paulo, 20132014.

\begin{tabular}{cccccccccccc}
\hline Intervenção & $\mathbf{N}$ & Mínimo & Máximo & Média & $\begin{array}{c}\text { Desvio } \\
\text { padrão }\end{array}$ & Mediana & \multicolumn{4}{c}{$\begin{array}{c}\text { IC para } \\
\text { média } \\
\mathbf{( 9 5 \% )}\end{array}$} & p* \\
\hline 1 & 17 & $-0,55$ & 1,23 & 0,30 & 0,56 & 0,12 & 0,01 & 0,59 & 0,076 \\
2 & 20 & $-0,59$ & 2,34 & 0,40 & 0,77 & 0,30 & 0,04 & 0,76 & $\mathbf{0 , 0 4 6}$ \\
3 & 20 & $-0,95$ & 2,49 & 0,30 & 0,83 & 0,13 & $-0,09$ & 0,69 & 0,164 \\
\hline
\end{tabular}

*Teste de Mann-Whitney pareado

A diferença da medida padronizada da dosagem sérica entre tempo final e inicial apresentou valores médios semelhantes nos grupos de intervenção 1 e 3, p=0,076 e 0,164, respectivamente. Somente o grupo 2 alcançou o nível de significância estabelecido e, portanto, evidenciou aumento da dosagem sérica das DAEs após a intervenção $(\mathrm{p}=0,046)$.

Tabela 28 Evolução clínica da dosagem sérica das DAEs, considerando pacientes que participaram das duas fases do estudo (n=57). São Paulo, 2013-2014.

\begin{tabular}{|c|c|c|c|c|c|c|c|}
\hline \multirow{2}{*}{ Evolução da dosagem sérica } & \multicolumn{2}{|c|}{ Grupo 1} & \multicolumn{2}{|c|}{ Grupo2 } & \multicolumn{2}{|c|}{ Grupo 3} & \multirow{2}{*}{$\mathbf{p}^{*}$} \\
\hline & $\mathbf{N}$ & $\%$ & $\mathbf{N}$ & $\%$ & $\mathbf{N}$ & $\%$ & \\
\hline $\begin{array}{l}\text { Manutenção da dosagem } \\
\text { sérica em níveis terapêuticos }\end{array}$ & 12 & 70,6 & 9 & 45,0 & 12 & 60,0 & \\
\hline $\begin{array}{l}\text { Manutenção da dosagem } \\
\text { sérica < níveis terapêuticos }\end{array}$ & 2 & 11,8 & 5 & 25,0 & 6 & 30,0 & \\
\hline $\begin{array}{l}\text { Aumento da dosagem sérica } \\
\text { para níveis terapêuticos }\end{array}$ & 3 & 17,6 & 4 & 20,0 & 2 & 10,0 & 0,334 \\
\hline $\begin{array}{l}\text { Redução da dosagem sérica } \\
\text { para níveis < terapêuticos }\end{array}$ & - & - & 2 & 10,0 & - & - & \\
\hline Total & 17 & 100,0 & 20 & 100,0 & 20 & 100,0 & \\
\hline
\end{tabular}


Em contrapartida, ao analisar a evolução clínica dos participantes quanto à dosagem sérica das DAEs, observou-se que não houve diferença estatisticamente significante entre os grupos. Foram maioria nos três grupos aqueles que mantiveram a dosagem sérica em níveis terapêuticos, visto que 35 indivíduos $(64,4 \%)$ já haviam alcançado os níveis mínimos terapêuticos das drogas na avaliação inicial. Entretanto, o grupo 2 foi o único que apresentou redução da dosagem sérica para níveis abaixo do terapêutico. Além disso, teve o maior percentual de participantes com mudança de condição em relação à dosagem sérica mínima desejada: $20 \%$ alcançaram este patamar e $10 \%$ tiveram redução para níveis inferiores ao terapêutico.

Tendo em vista que o efeito desejado das intervenções foi a manutenção da dosagem sérica em níveis terapêuticos, além do alcance desses níveis, na Tabela 28 foram comparados os grupos considerando-se a presença ou não desse resultado.

Tabela 29 Comparação do efeito dos três grupos de intervenção segundo dosagem sérica, considerando pacientes que participaram das duas fases do estudo $(n=57)$. São Paulo, 20132014.

\begin{tabular}{lcccc}
\hline $\begin{array}{l}\text { Efeito pela dosagem } \\
\text { sérica das DAEs }\end{array}$ & Grupo 1 & Grupo 2 & Grupo 3 & p* \\
\hline Ausente & $2(11,8 \%)$ & $7(35,0 \%)$ & $6(30,0 \%)$ & \multirow{2}{*}{$\begin{array}{c}\text { * } \\
\text { Presente }\end{array}$} \\
\hline Total & $15(88,2 \%)$ & $13(65,0 \%)$ & $14(70,0 \%)$ & 0,249 \\
\hline & $\mathbf{1 7 ( 1 0 0 \% )}$ & $\mathbf{2 0}(\mathbf{1 0 0 \% )}$ & $\mathbf{2 0}(\mathbf{1 0 0 \% )}$ & \\
\hline
\end{tabular}

Novamente a comparação dos grupos mostrou que não houve diferença estatisticamente significante entre eles em relação ao efeito das intervenções. 


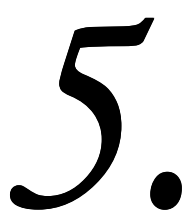

Discussão 


\section{DISCUSSÃO}

Os pacientes com epilepsia em acompanhamento ambulatorial incluídos na amostra do presente estudo tiveram perfil similar à população de indivíduos com essa doença, porém apresentaram conjuntamente características específicas de pacientes refratários ao tratamento e relacionadas aos critérios de elegibilidade da amostra.

Os participantes eram jovens ou adultos e somente dois tinham 60 anos. A maior incidência da epilepsia está na faixa etária abaixo de 1 ano (100/100.000), com redução acentuada à medida que há aumento da idade, mantendo-se baixa até a faixa etária dos 60 anos, quando se observa um drástico aumento de casos, alcançando 175/100.000. ${ }^{(4,76)}$

O aparecimento da doença na idade adulta é relatado como baixo em países desenvolvidos ${ }^{(77)}$; porém, a prevalência aumenta com o passar dos anos. Participantes desta investigação tinham, em média, 21,9 anos de diagnóstico, sendo a grande maioria $(79,1 \%)$ maior de dez anos. Os critérios de elegibilidade adotados no presente estudo também devem ser considerados na análise dos resultados obtidos, pois excluíram indivíduos menores de 18 anos e limitaram a participação de idosos, devido à exclusão de portadores de outras doenças crônicas em terapia medicamentosa. Sabese que, nessa faixa etária, $70 \%$ das pessoas apresentam pelo menos uma condição clínica crônica em tratamento ${ }^{(78)}$.

A incidência da epilepsia é maior entre homens que entre mulheres em todo o mundo ${ }^{(76,77)}$, em consequência à maior incidência entre homens dos fatores de risco para o desenvolvimento da epilepsia, como trauma craniencefálico, doença vascular encefálica e infecções do sistema nervoso central. No presente estudo, porém, houve similaridade na distribuição dos gêneros.

Poucos estudos foram realizados sobre a incidência da epilepsia entre diferentes raças. Banjeree, Fillipe e Alen $(2009)^{(76)}$, em sua revisão, 
encontraram apenas um estudo, realizado no ano de 1999, em que não foram evidenciadas diferenças na incidência da epilepsia entre brancos, hispânicos, afro-americanos e asiáticos ${ }^{(76,79)}$. Estudos de prevalência entre diferentes raças têm sido realizados em classes sociais menos favorecidas da população, confundido a análise racial dos casos de epilepsia ${ }^{(77)}$.

No presente estudo, observou-se uma grande parcela da amostra com baixo poder aquisitivo, isto é, renda per capita inferior a um salário mínimo vigente no período de coleta de dados no estado de São Paulo ${ }^{(75)}$. O achado corrobora com pesquisa realizada na Região Sudeste do país, que encontrou relação entre a prevalência da epilepsia ativa e indivíduos de classes econômicas desfavorecidas ${ }^{(80)}$.

A escolaridade da amostra foi, em média, de 9,8 anos; no entanto, $22 \%$ dos participantes não completaram o ensino médio e somente $46,1 \%$ estavam inseridos no mercado de trabalho, como empregados ou autônomos. O percentual de aposentados $(22,2 \%)$, afastados com auxíliodoença $(9,8 \%)$ e desempregados $(16,5 \%)$ foi alto, tendo em vista a idade dos incluídos no estudo.

O diagnóstico de epilepsia e a recorrência de crises podem ter impacto na função cognitiva e em atividades de vida diária do indivíduo. A disfunção cognitiva é um dos maiores problemas do paciente e, entre os déficits cognitivos, os mais comuns são declínio intelectual, velocidade diminuída para compreensão, aumento do tempo de reação, déficits de atenção e de memória ${ }^{(81)}$.

$\mathrm{Na}$ literatura científica, descreve-se que $25 \%$ dos pacientes com diagnóstico de epilepsia têm deficiência de aprendizado, enquanto metade dos pacientes com dificuldades de aprendizado tem epilepsia ${ }^{(81,82)}$.

Como doença que causa alteração transitória de função, a epilepsia tem como consequência algumas incapacidades que causam limitações e restrições para a realização de algumas atividades específicas. A incapacidade do paciente com epilepsia deve ser analisada com cautela quanto a gravidade, duração das alterações e profissão desempenhada, para que não ofereça risco ao próprio paciente e a terceiros ${ }^{(83)}$. 
Gomes (2009), em revisão narrativa sobre a inserção de indivíduos com epilepsia no mercado de trabalho, encontrou estudos em hospitais universitários que mostraram que a baixa escolaridade e habilitação resultaram no insucesso profissional de pessoas com epilepsia ${ }^{(83,84)}$.

Valores médios de escolaridade similares aos desta investigação foram encontrados em estudo que avaliou limitações no desempenho ocupacional de indivíduos com epilepsia em hospital universitário no sul do Brasil. Neste, destacaram-se das demais variáveis as dificuldades de manutenção do emprego, frequentar cursos e sair de casa sozinho. Essas limitações tiveram impacto significativo na qualidade de vida dos pacientes $^{(85)}$.

Embora presentes no cotidiano, as dificuldades psicossociais enfrentadas por pacientes com epilepsia nem sempre são consequência da frequência e gravidade de crises que estes apresentam; comumente, são resultados da discriminação e de conceitos errôneos sobre a doença ${ }^{(81,82)}$. Segundo a Organização Mundial da Saúde, o estigma social que envolve a epilepsia em todo o mundo é muitas vezes mais difícil de superar que as crises epilépticas $^{(1)}$.

O isolamento social é comum em indivíduos com epilepsia como consequência de inúmeros fatores, como medo de apresentar crises em público, reduzidas oportunidades para interação social devido à dificuldade de conseguir e manter um vínculo ocupacional e excesso de proteção familiar na realização de atividades ${ }^{(81)}$.

$\mathrm{Na}$ amostra analisada, a metade dos pacientes não tinha vínculo conjugal na época das entrevistas. As dificuldades psicossociais enfrentadas pelos indivíduos com epilepsia podem interferir na construção e manutenção de relacionamentos e ter efeito sobre a convivência com os membros da família. Estresse, conflitos conjugais, restrições na vida social, baixa autoestima e psicopatologias associadas são relatados em estudos por familiares de pessoas com epilepsia ${ }^{(81)}$.

Ademais, o preconceito em relação à doença pode agravar esse quadro. Segundo nota descritiva da OMS de outubro de 2012, no Reino 
Unido, a lei que proibia os indivíduos com epilepsia de se casarem foi revogada em 1970; na China e na Índia, a epilepsia é uma das razões para proibição ou anulação de casamentos ${ }^{(86)}$.

O suporte social da família favorece o comportamento de autocuidado e melhora a motivação de cuidado à saúde ${ }^{(87)}$. Em famílias nas quais havia dinâmica de acolhimento de integrantes com epilepsia, observou-se maior adesão ao tratamento pelos pacientes ${ }^{(88)}$.

Entre os participantes do presente estudo, predominaram os indivíduos que relataram "ter sempre" ou "quase sempre" apoio familiar para o tratamento. O principal efeito do suporte familiar é a satisfação com o apoio recebido no tratamento da doença crônica da pessoa que o recebe, pois essa percepção torna o indivíduo mais resistente para enfrentar as adversidades ambientais e traz consequências positivas para seu bem$\operatorname{estar}^{(87)}$.

A classificação do tipo de crise em estudos depende da acurácia da história do paciente, da disponibilidade de recursos médicos e da faixa etária em que a crise foi classificada. Em revisão de prevalência da epilepsia, observou-se que metade dos estudos classificou a maioria dos casos como epilepsia com crises generalizadas; porém, espera-se que, em áreas com recursos médicos adequados e populações limitadas à faixa etária adulta, seja encontrada maior frequência de indivíduos com crises do tipo focal ${ }^{(76)}$, assim como na amostra desta investigação, que teve $75,6 \%$ dos participantes com crises do tipo focal sintomática.

A epilepsia do tipo focal sintomática pode ser etiologicamente associada à esclerose hipocampal, anomalidade estrutural em que o paciente apresenta a síndrome de epilepsia mesial temporal ${ }^{(89)}$. Na presente investigação, 39,1\% dos pacientes apresentaram esclerose mesial temporal . Revisão de estudos ${ }^{(81)}$ que buscou identificar efeitos cognitivos e psicossociais da epilepsia descreve que pessoas com crises repetidas por esclerose mesial temporal podem ter algumas funções cognitivas comprometidas, como as funções de aprendizado, capacidade de resolução 
de problemas e memória ${ }^{(90,91)}$, em virtude da recorrência de crises, que acarretam danos e perdas de neurônios do hipocampo ${ }^{(92)}$.

Indivíduos com esclerose mesial temporal tendem a apresentar crises epilépticas após a primeira década de vida, com histórico inicial de crises febris que comumente respondem a tratamento inicial com DAEs. Há, porém, refratariedade durante o período da adolescência ou mais tardiamente $^{(89)}$.

A classificação precisa do tipo de crise e da síndrome epiléptica, assim como as análises da frequência de crises e de efeitos adversos ao tratamento com DAEs, devem ser consideradas no manejo medicamentoso da epilepsia ${ }^{(21)}$

A maioria dos indivíduos diagnosticados com epilepsia alcança o controle de crises, com ausência de eventos adversos, por meio de monoterapia. Sabe-se, porém, que uma pequena parcela de indivíduos pode necessitar da adição ou substituição de alguma DAE para alcançar esses $\operatorname{objetivos}^{(21)}$.

Contrapondo-se a essas observações, na atual pesquisa, 68,2\% dos participantes tinham em seu regime terapêutico duas a quatro medicações, ao passo que $31,8 \%$ dos pacientes faziam uso da monoterapia. Somente $39,5 \%$ da amostra percebia que suas crises estavam controladas e 26 $(28,9 \%)$ não apresentaram crises nos últimos 30 dias que antecederam a primeira avaliação.

A politerapia com DAEs é um recurso frequente no tratamento medicamentoso da epilepsia nos casos de refratariedade no controle das crises $^{(72,73,93)}$. Por conseguinte, os achados desta investigação são coerentes com as características do local do estudo; serviço terciário para onde são encaminhados casos complexos, com difícil controle das crises ou refratários ao tratamento.

Investigação em 11 centros de referência de tratamento terciário na Itália também avaliou o perfil de prescrições de DAEs de pacientes com epilepsia e encontrou alta prevalência de politerapia: $75 \%$ dos casos 
avaliados recebiam uma combinação de DAEs e um terço deles fazia uso de três ou mais drogas ${ }^{(94)}$.

Estudo recente, realizado em hospital na França, que visou avaliar o uso de DAEs em 44 pacientes com epilepsia focal refratária evidenciou a politerapia na amostra, com valor mediano de duas DAEs ${ }^{(53)}$.

Recente estudo realizado na Região Sudeste do Brasil também encontrou que as DAEs mais prescritas foram a carbamazepina, o clobazam e a lamotrigina, visto que, na prática clínica, os regimes terapêuticos são condizentes com as diretrizes vigentes do tratamento da epilepsia, porém são fortemente influenciados pela dispensação das DAEs no Sistema Único de Saúde (SUS) e local de estudo ${ }^{(93)}$.

Em geral, os participantes da amostra deste estudo não tiveram dificuldades na aquisição das DAEs, e a indisponibilidade das drogas não foi fator de destaque para a não adesão observada na avaliação inicial.

O ICTME teve média de 18,8 pontos $(\mathrm{dp}=9,8)$, variação de $5-48$, pontuação alta perante resultados de outros estudos. A análise de 320 indivíduos com epilepsia em acompanhamento ambulatorial encontrou valor médio do ICTME de 11,10 pontos, com variação de 1-48 pontos ${ }^{(95)}$. Pesquisa recente, com amostra de 385 pacientes em acompanhamento no mesmo serviço da atual investigação, apresentou pontuação média do ICTME de 14,7 pontos $(\mathrm{dp}=8,0)$, mínimo de dois e máximo de $44^{(72)}$.

Essas diferenças de pontuação do ICTME entre a amostra analisada e resultados já relatados podem estar relacionadas à inclusão, nesta investigação, somente de pacientes com média e baixa adesão. Em análise de regressão logística, a probabilidade de não adesão foi $6 \%$ maior a cada aumento de um ponto no $\operatorname{ICTME}^{(19)}$.

A falha na adesão ao tratamento medicamentoso pode ser resultado de comportamento não intencional e/ou intencional da pessoa com epilepsia. A má adesão ao tratamento de origem não intencional é definida por descuido ou esquecimento, falta de acesso aos medicamentos em uso, interrupções da rotina e/ou falta de lembretes para tomada dos remédios 
para o paciente. A não adesão intencional depende da decisão da pessoa com epilepsia em não tomar ou alterar seu esquema terapêutico propositalmente, de acordo com suas necessidades e percepções ${ }^{(41)}$.

Dos 91 pacientes incluídos nesta investigação, a grande maioria $(84,6 \%)$ foi categorizada com comportamento de média adesão pelo teste de Morisky e a resposta afirmativa à primeira questão - "Algumas vezes esqueço de tomar o medicamento" - foi a mais frequente, dada por $82,4 \%$ dos participantes.

Pesquisadores chineses, que avaliaram a adesão por meio do teste de Morisky, encontraram distribuição próxima à desta investigação de pacientes com média adesão, 70,2\%, e também observaram maior frequência de respostas afirmativas na primeira questão do teste $(39,4 \%)$, seguidas pelas que denotam comportamento intencional de parar de tomar o medicamento devido à melhora dos sintomas $(30,4 \%)^{(41)}$.

Nesse mesmo estudo, quando pacientes eram questionados sobre os motivos pelos quais deixavam de tomar seus medicamentos, aproximadamente metade dos 131 entrevistados responderam que a falta de adesão deveu-se ao esquecimento, enquanto a outra metade respondeu que ela decorreu dos longos períodos de ausência de crises ${ }^{(41)}$.

Autores americanos também identificaram o esquecimento como o principal fator responsável pela não adesão e, em uma de suas investigações, levantaram que as estratégias de lembretes de tomada de medicação são um recurso, segundo os pacientes, com potencial para favorecer a adesão ${ }^{(57,96)}$.

Nos resultados da presente investigação, a porcentagem de indivíduos que referiram esquecer-se de tomar medicamentos diminuiu mais de $50 \%$ após as intervenções, sendo o lembrete de tomada dos medicamentos por alarme de celular um dos recursos aplicados.

O autorrelato pelo teste de Morisky foi utilizado juntamente com a frequência de crises nos últimos 30 dias e a dosagem sérica das DAEs para mensurar a adesão medicamentosa, porém as análises de associação das medidas mostram que não houve relação entre os resultados. 
Pesquisa brasileira que comparou as três medidas estudadas também não encontrou correlação entre presença de crises, dosagem sérica de DAEs e autorrelato de adesão, porém a amostra do estudo foi de apenas 24 pacientes $^{(32)}$.

A frequência de crises é um marcador clínico importante no tratamento do indivíduo com epilepsia, utilizado como medida indireta de adesão ao tratamento. A importância do uso regular das DAEs para o controle das crises está na base do uso da frequência de crises na mensuração da adesão. Sabe-se que a não adesão ao tratamento medicamentoso aumenta em $21 \%$ o risco de desenvolver crises entre pacientes que iniciam o uso de DAEs ${ }^{(12,24)}$.

Hovinga et al. (2008) identificaram, em pacientes com epilepsia categorizados como aderentes ao tratamento, maior frequência de indivíduos sem crises. Verificaram também associação estatisticamente significativa entre não adesão e ausência de controle de crises. Este achado foi condizente ao descrito em amostra de pacientes do mesmo local do estudo atual, visto que os resultados evidenciaram que indivíduos com controle das crises tiveram menor probabilidade de não adesão perante os demais ${ }^{(96)}$.

Correlação moderada entre frequência de crises e alterações na adesão foi descrita recentemente em estudo realizado em região rural da China $(\mathrm{r}=0,4 ; \mathrm{p}=0,05)$. Nesta investigação, porém, não foram excluídos das análises indivíduos com alta adesão e a medida por autorrelato foi realizada por meio de uma escala de Lickert de seis itens ${ }^{(59)}$.

$\mathrm{Na}$ Inglaterra, a análise de 59 pacientes mostrou que indivíduos considerados com epilepsia não controlada tiveram maior frequência de média e baixa adesão e também apresentaram maior frequência de crises. Entretanto, não houve correlação siginificativa entre valores absolutos de frequência de crises e escore do teste de Morisky, assim como na atual investigação ${ }^{(14)}$.

Estudo realizado na China com 131 pacientes, que analisou indivíduos com média e baixa adesão, segundo teste de Morisky, não encontrou diferença estatisticamente significante em relação à periodicidade 
das crises - semanal, mensal e anual - nos grupos categorizados com média e baixa adesão $(\mathrm{p}<0,586)^{(41)}$.

Em relação à frequência de crises, verificou-se na presente amostra que, em média, os pacientes apresentaram 4,9 crises e que a maioria $(62,6 \%)$ apresentou até duas crises no período inicial. Observou-se ainda grande variação de valores, de zero até 100 crises, e 28,6\% dos casos sem crise nos últimos 30 dias que antecederam a intervenção.

Em geral, na maioria dos pacientes, as crises são controladas com o uso de DAEs, mas 25 a 30\% dos pacientes ainda apresentam crises apesar de fazerem uso de um regime terapêutico adequado e aderir ao tratamento. Alguns podem também apresentar efeitos adversos intoleráveis ao uso de medicamentos, devido a interações medicamentosas e maior suscetibilidade a essas respostas $^{(97)}$.

Pesquisa que avaliou a frequência de crises e adesão em cerca de 18 mil pacientes com epilepsia de um banco de dados americano de planos de saúde encontrou $77,7 \%$ dos casos sem crises no último semestre ${ }^{(24)}$. Em estudo inglês, com 1.652 indivíduos, observou-se variação de zero a 100 crises e metade da amostra não teve crises nos últimos seis meses ${ }^{(98)}$.

Ausência de crises por esse período foi observada somente em $21 \%$ dos casos de uma amostra de 385 pacientes atendidos entre julho de 2009 e fevereiro de 2010 no ambulatório onde foi realizado o atual estudo ${ }^{(19,20)}$. A menor frequência de casos com controle de crises pode ser relacionada às características deste serviço e sua clientela. Em indivíduos com crises epilépticas refratárias ao tratamento, como a deste estudo, atingir a ausência de crises por longos períodos é um objetivo difícil a ser alcançado; portanto, para amostras com alta frequência de pacientes com esta característica, o uso da frequência de crises como medida de adesão ao tratamento tem importante limitação e os resultados devem ser interpretados com cautela.

A dosagem sérica é um indicador no tratamento com DAEs que aperfeiçoa o regime terapêutico, na falta de uma resposta clínica ou fisiológica clara às drogas, evitando a administração excessiva ou reduzida de DAEs. Para muitas DAEs, o valor da concentração sérica indica se seu 
efeito está sendo terapêutico ou tóxico ${ }^{(97)}$. De mais a mais, a dosagem sérica é utilizada na medida de adesão ao tratamento e a variabilidade do nível plasmático de uma DAE pode ser um indicativo da má adesão do paciente ao seu regime terapêutico ${ }^{(29)}$.

$\mathrm{Na}$ presente investigação, ao realizar a dosagem sérica de DAEs, observou-se que somente cerca de $42 \%$ dos participantes apresentaram valores inferiores ao considerado terapêutico, embora todos tivessem autorrelato de média ou baixa adesão pelo teste de Morisky. Além disso, os valores padronizados da dosagem sérica não diferiram nos grupos de média e baixa adesão e a dosagem sérica inferior ao nível terapêutico foi independente da presença de crises.

A análise da dosagem sérica de DAEs de 86 indivíduos acompanhados em um hospital na Holanda mostrou que os pacientes que compareceram ao serviço de emergência nos 15 dias que antecederam a entrevista, devido a crises epilépticas, apresentaram maior frequência de crises e menor nível plasmático de DAEs quando comparados com os demais. Identificou-se, porém, que ambos os grupos apresentaram baixa adesão, pela avaliação da aquisição de drogas no serviço de farmácia ${ }^{(47)}$.

Paschal et al.(2014), em revisão sobre medidas de adesão em pacientes com epilepsia, afirmaram que a avaliação do nível plasmático de DAEs é efetiva quando é utilizada para monitorizar pacientes em casos extremos de baixa adesão, não tendo acurácia suficiente para pacientes que apresentam pequenas variações nos níveis plasmáticos ${ }^{(29)}$.

Gomes, Filho e Noé (1998) observaram que a avaliação do nível sérico isolado, exceto em casos de adesão extremamente baixa, não é suficiente para o reconhecimento da ingestão inadequada de DAEs. Segundo os autores, a dosagem sérica não é uma medida exata em pacientes com média e alta adesão, pois as variações dos níveis plasmáticos encontradas podem ser decorrentes de alterações nas rotinas do paciente, como mudança na ingestão de alimentos e líquidos, uso de outras drogas, entre outras ${ }^{(32)}$.

A variabilidade do nível plasmático também é influenciada pelo tipo de DAE em estudo ${ }^{(29)}$. O conhecimento das propriedades farmacocinéticas 
de DAEs é essencial para interpretar essa variabilidade e um parâmetro que deve ser considerado é a meia-vida das drogas, quando se avalia as flutuações dos níveis plasmáticos ${ }^{(99)}$.

Drogas com curto período de meia-vida, como a carbamazepina e o ácido valproico, necessitam de múltiplas doses diárias para manutenção da dosagem sérica em níveis terapêuticos ${ }^{(99)}$; em consequência, podem ser mais sensíveis a falhas na adesão. O fenobarbital, por sua vez, atinge concentração plasmática máxima 9 a 10 horas após a ingesta oral de uma dose, e sua meia-vida é longa, de 2 a 6 dias $^{(100)}$.

A fenitoína não apresenta farmacocinética linear, uma vez que progressivamente acarreta a saturação de enzimas hepáticas responsáveis pelo seu metabolismo. Como resultado, pequenos aumentos na dosagem de fenitoína podem aumentar o nível plasmático acima dos níveis terapêuticos, causando a toxicidade clínica ${ }^{(99)}$.

$\mathrm{Na}$ presente investigação, o nível sérico da carbamazepina esteve, com maior frequência, abaixo do nível terapêutico em relação às demais drogas. A dosagem sérica realizada em maior frequência foi da carbamazepina (60,7\%), seguida pelo ácido valproico, dosado em 21,3\% dos pacientes. Todas as drogas dosadas tiveram casos de nível plasmático inferior aos níveis terapêuticos e o fenobarbital foi a única droga em que não se observou níveis plasmáticos acima do nível terapêutico.

A análise dos níveis plasmáticos de DAEs de 264 pacientes internados também identificou indivíduos com níveis plasmáticos acima dos intervalos terapêuticos, sugerindo que outros fatores, afora a ingestão excessiva dos medicamentos, estiveram associados aos níveis elevados observados $^{(54)}$.

Além das propriedades isoladas das DAEs, o uso concomitante dessas drogas também ocasiona alterações na dosagem sérica, já que esses medicamentos apresentam importantes interações farmacocinéticas e farmacodinâmicas ${ }^{(99,101)}$. Características individuais dos usuários das DAEs também interagem na farmacocinética dessas drogas, como predisposição genética, idade, fisiologia, doenças e interações medicamentosas. Assim, 
pacientes que recebem a mesma dose podem apresentar grande variação de concentração plasmática de DAEs ${ }^{(99)}$.

A análise de níveis terapêuticos é mais apropriada em indivíduos saudáveis e deve ser realizada com cautela na presença de outras doenças ou eventos fisiológicos em que a capacidade de ligação das drogas com as proteínas plasmáticas esteja reduzida, como em doenças hepáticas, renais e gastrointestinais, ou em casos de gestação ou idade avançada ${ }^{(102)}$. Na amostra desta pesquisa, apesar da exclusão de pacientes que tomavam medicação para outras doenças crônicas e de não haver indivíduos com idade avançada, não foram coletados dados suficientes que garantam a ausência dessas condições clínicas ou fisiológicas.

Embora seja considerada "padrão ouro" por alguns pesquisadores, a dosagem sérica como medida de adesão apresenta, segundo a literatura científica, duas restrições importantes em seu uso: falha na identificação de comportamentos intermediários de adesão e uso mais apropriado em populações saudáveis. Como comentado anteriormente, a adesão não é um fenômeno binário e a maioria dos estudos mostra que a classificação em média adesão é bem mais frequente entre indivíduos com epilepsia que a categorização em baixa. Além disto, a maior prevalência de epilepsia ativa está acima de 65 anos, faixa etária em que as comorbidades são frequentes.

Revisão sistemática realizada em 2013 concluiu que ainda não há medida de adesão que possa ser considerada "padrão-ouro" e que futuras investigações devem buscar superar as limitações existentes ${ }^{(30)}$. A falta de convergência das medidas utilizadas na atual pesquisa acrescenta a essa observação uma grande fragilidade a três medidas acessíveis e recomendadas na literatura científica ${ }^{(30)}$, indicando que, provavelmente, somente alternativas metodológicas complexas, específicas a grupos de pacientes, poderão aumentar a acurácia à mensuração e, desse modo, oferecer segurança aos pesquisadores que analisam os efeitos de intervenções para ampliar a adesão de pacientes.

Estudos das intervenções para aumento da adesão à terapia com DAEs têm utilizado diferentes formas de mensuração de seus efeitos, sendo 
frequente entre eles a associação de medidas e o uso do teste de Morisky, da frequência de crises e da dosagem sérica das DAEs ${ }^{(50,51)}$. Entretanto, outras medidas de adesão também são utilizadas, como a mensuração da aquisição das DAEs em serviços de farmácia, MEMs, além de outros questionários de autorrelato de adesão ou que identificam condições relacionadas a esse comportamento. Todas, porém, apresentam limitações na estimativa da medida, deixando questionamentos quanto à exatidão dos resultados observados $^{(68)}$.

Conjuntamente à variedade de formas de medidas, os estudos utilizam métodos de recrutamento e critérios de elegibilidade diversos e aplicam diferentes intervenções, o que dificulta a comparação dos resultados. A associação de intervenções é frequente e diversificada e o tamanho das amostras bastante variado.

Nos estudos, são aplicadas até quatro intervenções associadas. Em geral, há somente um grupo de intervenção confrontado com o controle. O intervalo entre a intervenção e a avaliação do seu efeito é de um mês a um ano e o tamanho das amostras é de 22 a 581 pacientes $^{(33-35,48,50-52,59,68)}$.

Em revisão sistemática realizada em 2011 pela Cochrane ${ }^{(68)}$, identificou-se entre os estudos de intervenção para melhorar a adesão que a alocação dos pacientes nos grupos de forma randomizada foi esporádica $^{(34,48)}$. Além do mais, todos incluíram na amostra pacientes com ou sem alteração na adesão ao tratamento ${ }^{(33-35,48,49,68)}$.

Além dessas características metodológicas, evidenciou-se nesta revisão que poucas publicações apresentaram análise da adesão no período inicial, anterior à aplicação das intervenções, e nenhuma delas, apesar de descrever características demográficas da amostra total do estudo, realiza a descrição das características dos pacientes que completaram o seguimento após as intervenções ${ }^{(33-35,48,49,68)}$.

Todavia, as pesquisas mais recentes realizaram a alocação dos pacientes nos grupos de forma randomizada, utilizaram níveis de cegamento e descreveram e compararam grupos e participantes das fases inicial e final do estudo ${ }^{(50,51,59)}$. Na atual investigação, além desses quesitos, realizou-se a 
mensuração da adesão pré-intervenção e a categorização no teste de Morisky em baixa ou média adesão foi critério de inclusão na amostra.

Esse critério, no entanto, trouxe à pesquisadora inquietações éticas que redundaram no manejo de todos os pacientes selecionados em três grupos de intervenção. A instrução complementar foi considerada essencial e aplicada a todos os pacientes, de forma isolada no grupo Intervenção 1, associada ao lembrete de tomada dos medicamentos por alarme de celular no grupo Intervenção 2 e à caixa organizadora de medicamentos no grupo Intervenção 3.

Depois de realizadas as intervenções, 62 pacientes retornaram para reavaliação da adesão, completando as fases de seguimento do estudo. No final, os grupos Intervenção 1, 2 e 3 totalizaram 18 (29\%), 20 (32,3\%) e 24 $(38,7 \%)$ integrantes, respectivamente. Esses grupos, quando comparados em relação a características associadas à adesão, mostraram similaridade.

Estudos têm identificado características relacionadas ao paciente, à doença, ao tratamento e à assistência a saúde associadas ao comportamento de adesão ao regime terapêutico. Entre as características individuais do paciente, observam-se idade, sexo, condições socioeconômicas, raça, nível educacional, crenças e presença de comorbidades. Em relação aos fatores relacionados à doença, destacam-se a gravidade e frequência de crises epilépticas. Quanto às características do tratamento, evidenciam-se a complexidade terapêutica e a presença de efeitos adversos. Entre os fatores relacionados à assistência, estão o relacionamento médico-paciente e a acessibilidade aos serviços de saúde ${ }^{(12,19,57,103)}$.

A análise das perdas, isto é, dos pacientes que não completaram sua participação no estudo, foi realizada considerando-se fatores associados e as medidas de adesão terapêuticas resultantes da avaliação inicial. Houve similaridade entre pacientes que não completaram sua participação no estudo e aqueles que finalizaram o seguimento em relação a quase todos os fatores associados à adesão. Não obstante, verificou-se que, em média, os que completaram sua participação na pesquisa eram mais velhos. Em investigação anterior, verificou-se que a não adesão é menos frequente nos 
mais velhos e o aumento de um ano de idade diminui a probabilidade de não adesão em $3 \%{ }^{(19,20)}$. Apesar dessa evidência, os valores da adesão inicialmente aferidos foram similares entre os que completaram ou não sua participação neste estudo.

Nas análises antes e depois dos 62 indivíduos que completaram o seguimento deste estudo, observaram-se várias indicações de efeitos benéficos das intervenções na adesão à terapia com DAEs que merecem destaque. Em relação aos resultados no teste de Morisky, observou-se maior pontuação em $85,5 \%$ dos integrantes da amostra, $67,7 \%$ alcançaram melhor categoria e somente um apresentou diminuição na pontuação, sem, no entanto, modificar sua categorização no teste. No final do estudo, nenhum paciente referiu baixa adesão e o percentual de participantes com média adesão, que no início era de $83,9 \%$ da amostra, reduziu quase à metade $(43,6 \%)$.

Estudo de uma intervenção realizada na Malásia em 2013, que utilizou mensagens eletrônicas em celulares para informações complementares e como lembrete de tomada de medicamentos e consultas médicas, verificou, pelo autorrelato com o teste de Morisky, que o grupo de intervenção teve aumento estatisticamente significativo da adesão $(\mathrm{p}<0,001)$, ao passo que, no grupo controle, não se evidenciou essa diferença ${ }^{(51)}$.

Recentemente, outra publicação divulgou resultados sobre a aplicação de uma intervenção educacional para melhorar a adesão de pessoas com epilepsia em uma região rural do Quênia desprovida de recursos suficientes para manejo da doença. Após 1 ano, o seguimento de 581 pacientes foi concluído e verificou-se aumento da adesão pela avaliação do teste de Morisky nos grupos de intervenção e controle $(\mathrm{p}<0,001$, em ambos) $)^{(50)}$.

O número médio de frequência de crises no último mês passou de $5,3(\mathrm{dp}=14,7)$ para $2(\mathrm{dp}=4,1)$ e reduziu após a intervenção em $51,6 \%$ da amostra. A ausência de crises foi referida por 19 pacientes na primeira avaliação, aumentado para 28 após intervenção. Em contrapartida, o 
aumento da frequência de crises da fase inicial para a final foi observado em $21 \%$ da amostra.

Outras investigações também apresentaram efeito benéfico de intervenções na frequência de crises. Peterson, McLean e Millingen (1984), ao aplicarem uma intervenção educacional, encontraram no grupo experimental redução estatisticamente significativa do número de crises, passando, em média, de 6 para 2,5 crises $(\mathrm{p}<0,01)$. A aplicação de educação intensiva, livre acesso a consultas, cartão de registro de ocorrências e uso de instrução impressa a cada aquisição das DAEs em 183 pacientes resultou em diminuição da frequência de crises em mais de $50 \%$ dos casos. Esta redução alcançou o nível de significância estabelecido $(\mathrm{p}<0,001)^{(59)}$.

Hegelson et al. (1990), por outro lado, ao avaliar o efeito de um programa psicoeducativo (SEE), não encontraram diferença na frequência de crises entre o período inicial e o final, tanto no grupo controle quanto no grupo de intervenção. No Quênia, o uso da intervenção educacional mostrou que tanto o grupo experimental quanto o grupo controle apresentaram redução estatisticamente significativa na frequência de crises $^{(35)}$.

No tempo final do presente estudo houve aumento dos valores da dosagem sérica em $62,9 \%$ dos casos e $73,7 \%$ dos pacientes tinham dosagem sérica superior ao nível mínimo terapêutico. Entretanto, no começo do estudo, somente $22(38,6 \%)$ dos integrantes que completaram seu seguimento apresentaram dosagem sérica em níveis inferiores aos desejáveis e a manutenção de valores dos níveis plasmáticos desses pacientes também foi um resultado favorável às intervenções. Em nove casos $(15,8 \%)$, a elevação da dosagem sérica representou mudança do nível abaixo do terapêutico para o superior, porém dois participantes (3,5\%) tiveram queda no nível da dosagem sérica, passando a apresentar valores inferiores ao recomendado no seu tratamento.

Frequência expressiva $(48,7 \%)$ de pacientes que alcançaram níveis terapêuticos já na avaliação inicial foi observada em estudo queniano que não excluiu inicialmente indivíduos categorizados em alta adesão. Nessa pesquisa, a dosagem sérica a níveis detectáveis se elevou após aplicação de 
intervenção educacional de $36 \%$ para $81 \%$; porém, no grupo controle, observou-se aumento de $38 \%$ para $74 \%{ }^{(50)}$.

Peterson, McLean e Millingen (1984), ao utilizarem uma combinação de estratégias para aumentar a adesão (instrução complementar, caixa organizadora de medicamentos e lembretes enviados por correio), observaram aumento do valor plasmático das DAEs no grupo submetido a esse conjunto de intervenções $(p<0,07)(34)$. Esse grupo também apresentou maior frequência de dosagem sérica em níveis terapêuticos, em relação ao controle, na fase final da pesquisa. Hegelson et al., em 1990, encontraram, com aplicação de terapia psicoeducacional (programa SEE), aumento da dosagem sérica em $70 \%$ dos pacientes ${ }^{(35)}$.

Ainda que uma parcela das intervenções para elevar a adesão à terapia com DAEs tenha evidenciado seu efeito, os estudos não compararam diferentes intervenções com um ou mais componentes. Na literatura científica, apenas um estudo de pacientes com epilepsia analisou o efeito de três diferentes intervenções. No caso, instrução escrita sobre o uso das DAEs entregue pessoalmente $(n=16)$, instrução verbal em entrevista presencial $(n=15)$ e instrução verbal por contato telefônico $(n=19)$. Os autores descreveram que nenhum efeito foi observado na dosagem sérica após quatro semanas e, por conseguinte, a comparação entre grupos não foi realizada ${ }^{(33)}$.

As análises deste estudo evidenciaram que as três intervenções proporcionaram melhora na adesão, significativa e similar, segundo escore e categoria do teste de Morisky. Portanto, pelo autorrelato, todos os grupos apresentaram melhora na adesão, independentemente da intervenção aplicada. Quando medidas objetivas de adesão foram utilizadas - número de crises mensais e valor da dosagem sérica das DAEs - observou-se, após intervenção, melhora estatisticamente significativa somente no grupo 2, em que se aplicou instrução complementar associada com lembrete de tomada dos medicamentos por alarme de celular. No entanto, essa diferença não se manteve entre os grupos quando o efeito clínico desejado com as intervenções foi considerado. 
A aplicação dos achados da presente pesquisa deve ser realizada de forma cautelosa, pois algumas limitações e fatores no desenvolvimento do estudo podem ter interferido na análise nos resultados. Entre as limitações, destacam-se as restrições nas medidas de adesão aplicadas e a ausência de um grupo controle, o que pode ter dificultado evidenciar diferenças perante as intervenções realizadas.

A grande variabilidade das frequências de crises mensais observadas (zero a 100) e o pequeno percentual $(38,6 \%)$ de pacientes que não haviam atingido os níveis plasmáticos da DAEs na avaliação anterior à intervenção realizada foram fatores que requereram análises não paramétricas nas medidas objetivas utilizadas.

A comunicação entre pacientes, cuidadores e profissionais envolvidos na assistência ambulatorial nos períodos anterior e posterior à entrevista pode ter influenciado a resposta dos pacientes participantes nas entrevistas inicial e final, assim como a disponibilidade dos coletadores e da pesquisadora do estudo em auxiliar e esclarecer dúvidas na tomada de DAEs, juntamente com agendamento para reavaliação da adesão, talvez tenha sensibilizado pacientes e cuidadores, ocasionando a maior atenção no uso de seus medicamentos.

A valorização e orientação da adesão terapêutica, o acompanhamento do comportamento do paciente por meio de entrevista e coleta de exames laboratoriais, além do contato telefônico, são fatores que podem ter beneficiado a adesão de todos os pacientes que finalizaram o seguimento da pesquisa. 


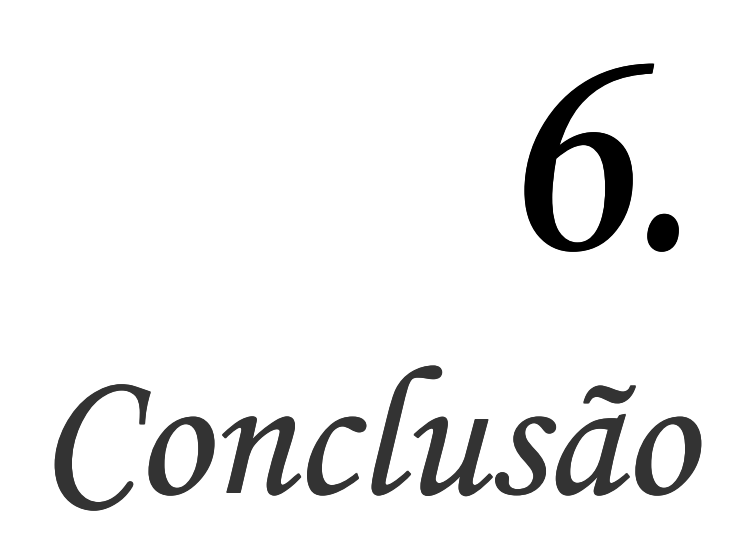




\section{CONCLUSÃO}

A casuística do estudo foi composta de 91 pacientes com diagnóstico de epilepsia, atendidos no ambulatório de neurologia do HCFMUSP. A análise da amostra mostrou que 50,5\% dos pacientes eram do sexo feminino, com idade média de 37,8 anos. A maioria dos pacientes completou o ensino médio $(42,8 \%)$ ou cursou ensino superior $(7,7 \%$ incompleto e $9,9 \%$ completo), porém somente $46,1 \%$ dos participantes estavam inseridos no mercado de trabalho, como empregados ou autônomos, no período das avaliações.

A média de tempo pelo qual os indivíduos conheciam o diagnóstico de sua doença foi 21,9 anos e a duração do tratamento com DAEs atingiu, em média, 20,7 anos. O tipo de crise mais frequente foi a focal sintomática (75,6\%); desses participantes, 49,3\% apresentavam diagnóstico de lesão localizada em lobo temporal, isolada (42\%) ou associada a outra lesão extratemporal $(7,3 \%)$. A esclerose mesial temporal foi diagnosticada em $39,1 \%$ dos participantes com lesão focal.

O ICTME médio foi de 18,8, desvio padrão de 9,8, e houve predomínio de pacientes que tomavam dois ou três medicamentos $(66 \%)$. A DAE mais prescrita foi a carbamazepina $(63,7 \%)$, seguida por clobazam $(39,6 \%)$ e lamotrigina $(37,4 \%)$.

A grande maioria dos pacientes adquiria medicamentos por meio da farmácia do hospital local do estudo $(75,8 \%)$ e cerca de $10 \%$ ficavam sem tomar os fármacos em caso de falta.

A percepção da maioria dos pacientes $(59,4 \%)$ indicava que suas crises nem sempre estavam controladas ou não eram controladas e que o apoio de familiares estava sempre presente no tratamento da doença $(68,1 \%)$.

O comportamento da grande maioria dos participantes $(84,6 \%)$ na primeira avaliação foi categorizado como de média adesão pela avaliação do 
teste de Morisky. Ainda que todos apresentassem média ou baixa adesão segundo esse teste, $28,9 \%$ relataram não apresentar crises nos últimos 30 dias antes da primeira avaliação. Além disso, somente em 37 (42\% dos participantes) observou-se dosagem sérica inferior ao nível terapêutico na dosagem inicial.

O coeficiente de correlação das medidas de adesão foi baixo (teste de Morisky, frequência de crises mensais e dosagem sérica padronizada) e não houve correlação estatisticamente significativa entre elas. De mais a mais, não houve associação estatisticamente significativa entre as categorias do teste de Morisky e as variáveis: número de crises, valor padronizado da dosagem sérica, presença de crises e de dosagem sérica inferior ao nível terapêutico. Ademais, a presença de crises foi independente de dosagem sérica inferior ao nível terapêutico.

Nas avaliações após intervenções, $67,7 \%$ dos participantes alcançaram melhor categoria no teste de Morisky (média ou alta adesão) e nenhum paciente referiu baixa adesão ao tratamento medicamentoso. Observou-se também maior pontuação no teste de Morisky em 85,5\% dos que completaram sua participação no estudo.

A frequência de crises nos últimos 30 dias reduziu após a intervenção em 51,6\% da amostra. Em contrapartida, observou-se aumento da frequência de crises da fase inicial para a final em $21 \%$ da amostra. Dezessete pacientes $(27,4 \%)$ mantiveram a frequência de crises; no entanto, $13(21 \%)$ já apresentavam ausência de crises na primeira avaliação.

Ainda que em 62,9\% dos casos fosse observado aumento dos valores da dosagem sérica entre a primeira e a segunda avaliação, somente em 9 casos $(15,8 \%)$ essa elevação representou a mudança de nível abaixo do terapêutico para superior. Não obstante, entre os que participaram até o final do estudo, 38,6\% a apresentaram dosagem sérica em níveis inferiores aos desejáveis na avaliação inicial. A manutenção dos valores da dosagem sérica de 57,9\% dos pacientes acima do nível terapêutico mínimo também foi um resultado favorável às intervenções. Dois participantes tiveram queda 
no nível da dosagem sérica, passando a apresentar nível abaixo do recomendado ao seu tratamento.

A comparação do efeito das três intervenções evidenciou que os três grupos apresentaram melhora na adesão, significativa e similar, segundo escore e categoria do teste de Morisky. Quando a frequência de crises e a dosagem sérica foram as medidas de adesão utilizadas, observou-se após intervenção melhora estatisticamente significativa no número de crises mensais e no valor da dosagem sérica das DAEs somente no grupo submetido à instrução complementar associada com lembrete de tomada dos medicamentos por alarme de celular. No entanto, essa diferença no desempenho dessa intervenção não se manteve quando se considerou o efeito desejado com as intervenções: em relação à frequência de crises, diminuí-las em pelo menos $30 \%$ ou apresentar ausência de crise na fase final; quanto à dosagem sérica, aumentá-la para níveis terapêuticos ou mantê-la quando atingiu esses níveis. 
Referências 


\section{REFERÊNCIAS}

1 Prilipko, L.; Saxena, S.; Boer, Hanekke. Atlas: epilepsy care in the world. Geneva: World Health Organization, 2005.91p.

2 Li, L.; Fernandes, P.; Noronha A.L.A; et. al. Demonstration project on epilepsy in Brazil: outcome assessment. Arquivos de neuropsiquatr, v. 65, n. Supl 1, p. 58-62, 2007.

3 Mbuba, C.K.; Ngugi, A.K.; Newton, C. R. et.al. The epilepsy treatment gap in developing countries: a systematic review of the magnitude, causes, and intervention strategies. Epilepsia, v. 49, n. 9, p. 1491-1503, 2008.

4 Hesdorffer, D.C.; Logroscino, G.; Benn E.K.T. et al. Estimating risk for developing epilepsy: A populationbased study in Rochester, Minnesota. Neurology, v. 76, n. 1, p. 23-27, 2011.

5 Neto, J.G.; Marchetti, R.L. Aspectos epidemiológicos e relevância dos transtornos mentais associados à epilepsia. Rev Bras Psiquiatr., v. 27, n. 4, p. 323328, 2005.

6 Fisher, R.S.; Emde Boas, W. Van; et al. Epileptic seizures and epilepsy: definitions proposed by the International League Against Epilepsy (ILAE) and the International Bureau for Epilepsy (IBE). Epilepsia, v. 46, n. 4, p. 470-472, 2005.

7 Fisher, R.S.; Acevedo, C.; Arzimanoglou, A. et al. ILAE official report: a practical clinical definition of epilepsy. Epilepsia, v. 55, n. 4, p. 475-482, 2014.

8 Betting, L.; Kobayashi, E.; Montenegro, MA.;et.al. Tratamento de epilepsia: consenso dos especialistas brasileiros. Arq Neuropsiquiatr, v. 61, n. 4, p. 10451070, 2003.

9 Porto, L.A.; Siqueira, J. de S.; Seixas, L. N. et al. O papel dos canais iônicos nas epilepsias e considerações sobre as drogas antiepilépticas: uma 
breve revisão. J Epilepsy Clin Neurophysiol, v. 13, n. 4, p. 169-175, 2007.

10 Schmidt, D. Drug treatment of epilepsy: options and limitations. Epilepsy Behav, v. 15, n. 1, p. 56-65, 2009.

11 Mcdonald, H.P.; Garg, A.X.; Haynes, R. B.Interventions to Enhance Patient Adherence: scientific review. JAMA, v. 288, n. 22, p. 2868-79, 2002.

12 Faught, E. Adherence to antiepilepsy drug therapy. Epilepsy Behav, v. 25, n. 3, p. 297-302, 2012.

13 Elliott, J.; Shneker, B. Patient, caregiver, and health care practitioner knowledge of, beliefs about, and attitudes toward epilepsy. Epilepsy Behav, v. 12, p. 547-556, 2008.

14 Jones, R.M.; Butler, J.A.; Thomas, V.A. et al. Adherence to treatment in patients with epilepsy: associations with seizure control and illness beliefs. Seizure, v. 15, n. 7, p. 504-508, 2006.

15 Sabaté, E. Adherence to long-term therapies. Geneva: World Health Organization, 2003.1-194p.

16 Haynes, R.; Ackloo, E.; et al. Interventions for enhancing medication adherence (review). Cochrane Database of Systematic Reviews, n. 2, 2008.

17 Leite, S.N.;Vasconcellos, M. da P.C. Adesão à terapêutica medicamentosa: elementos para a discussão de conceitos e pressupostos adotados na literatura. Ciência \& Saúde Coletiva, 8(3) , 775-782, 2003.

18 Dunbar-Jacob, J.; Mortimer-Stephens, M.K. Treatment adherence in chronic disease. Journal of clinical epidemiology, v. 54 Suppl 1, n. July, p. S57$60,2001$.

19 Ferrari, C.M.M.; Sousa, R.M.C.; Castro LHM. Factors associated with treatment non-adherence in patients with epilepsy in Brazil. Seizure, v. 22, n. 5, p. 384389, 2013. 
20 Ferrari, C.M.M. Adesão ao tratamento e qualidade de vida de indivíduos com epilepsia em tratamento ambulatorial. 2011. Tese (Doutorado) - Escola de Enfermagem, Universidade de São Paulo, São Paulo.

21 Sander, J.W. The Use of Antiepileptic Drugs: principles and practice. Epilepsia, v. 45, p. 28-34, 2004.

22 Hitiris, N.; Mohanraj, R.; et al. Mortality in epilepsy. Epilepsy Behav, v. 10, n. 3, p. 363-76, 2007.

23 Tomson, T.; Beghi, E.; et al. Medical risks in epilepsy: a review with focus on physical injuries, mortality, traffic accidents and their prevention. Epilepsy research, v. 60 , n. 1 , p. 1-16, 2004.

24 Manjunath, R.; Davis, K.L.; et al. Association of antiepileptic drug nonadherence with risk of seizures in adults with epilepsy. Epilepsy Behav, v. 14, n. 2, p. 372-378, 2009.

25 Beghi, E.; Cornaggia, C.; et al. Morbidity and accidents in patients with epilepsy: Results of a European cohort study. Epilepsia, v. 43, n. 9, p. 1076-1083, 2002.

26 Lucena, I. De; Ferreira, M. Mortalidade por epilepsia no Brasil , 1980-2003 Mortality from epilepsy in Brazil , 1980-2003. Ciência \& Saúde Coletiva, v. 14, n. 1, p. 89-94, 2009.

27 Faught, E.; Duh, M.S.; et al. Nonadherence to antiepileptic drugs and increased mortality: Findings from the RANSOM Study. Neurology, v. 71, n. 20, p. 1572-1578, 2008.

28 Smithson, W.H.; Hukins, D.; et al. Developing a method to identify medicines non-adherence in a community sample of adults with epilepsy. Epilepsy Behav, v. 24, n. 1, p. 49-53, 2012.

29 Paschal, A.M.; Hawley, S.R.; et al. Measures of adherence to epilepsy treatment: review of present practices and recommendations for future directions. Epilepsia, v. 49, n. 7, p. 1115-1122, 2008.

30 Jeffery, R. An evaluation of measurement od adherence and patient recruitment methods in patient 
adherence to adherence to medication research. 2013. Dissertação. (Mestrado) - McMaster University, Hamilton.

31 Garfield, S.; Clifford, S.; et al. Suitability of measures of self-reported medication adherence for routine clinical use: a systematic review. BMC Medical Research Methodology, v. 11, p. 149, 2011.

32 Gomes, M.D.M.; Maia Filho, H.D.S.; Noé, R. A. M. Anti-epileptic drug intake adherence. The value of the blood drug level measurement and the clinical approach. Arq Neuropsiquiatr, v. 56, n. 4, p. 708-13, 1998.

33 Pryse-Phillips, W.; Jardine, F.; Bursey, F. Compliance with drug therapy by epileptic patients. Epilepsia, v. 23, p. 269-274, 1982.

34 Peterson, G.; McLean, S.; Millingen, K.S. A randomised trial of strategies to improve patient compliance with anticonvulsant therapy. Epilepsia, $\mathrm{v}$. 25, n. 4, p. 412-417, 1984.

35 Helgeson, D.; Mittan, R.; et al. Sepulveda Epilepsy Education: the efficacy of a psychoeducational treatment program in treating medical and psychosocial aspects of epilepsy. Epilepsia, v. 31, n. 1 , p. 75-82, 1990.

36 Ben-Menachem, E.; Sander, J.W., Privitera, M., Gilliam, F., E. Measuring outcomes of treatment with antiepileptic drugs in clinical trials. Epilepsy Behav, v. 18, n. 1-2, p. 24-30, 2010.

37 Olivieri, N.F.; Matsui, D.; et al. Compliance assessed by the Medication Event Monitoring System. Archives of disease in childhood, v. 66, n. 12, p. 1399-402, 1991.

38 Morisky, D.E.; Green, L.W.; Levine, D. M. Concurrent and predictive validity of a self-reported measure of medication adherence. Medical care, v. 24, n. 1, p. 67-74, 1986.

39 Sweileh, W.M.; Ihbesheh, M.S.; et al. Self-reported medication adherence and treatment satisfaction in patients with epilepsy. Epilepsy Behav, v. 21, n. 3, p. 301-305, 2011. 
40 Nakhutina, L.; Gonzalez, J.S.; et al. Adherence to antiepileptic drugs and beliefs about medication among predominantly ethnic minority patients with epilepsy. Epilepsy Behav, v. 22, n. 3, p. 584-586, 2011.

41 Tang, F.; Zhu, G.; et al. Self-reported adherence in patients with epilepsy who missed their medications and reasons for nonadherence in China. Epilepsy Behav, v. 27, n. 1, p. 85-89, 2013.

42 Ungari, A.Q. (2008). Adherence to medicine treatment in high blood pressure patients followed at the Family Health Centers in the city of Ribeirão Preto, SP. 2007. Dissertação (Mestrado) - Faculdade de Medicina de Ribeirão Preto, Universidade de São Paulo. Ribeirão Preto, 2007.

43 Borges, J.; Moreira, T.; et al. Utilização de questionários validados para mensurar a adesão ao tratamento da hipertensão arterial: uma revisão integrativa. Rev Esc Enferm USP, v. 46, n. 2, p. 487494, 2012.

44 Schimitt Júnior, A.S.; Lindner, S.; et al. Assessment of adherence in elderly patients in primary care. Rev Assoc Med Bras, v. 59, n. 6, p. 614-621, 2013.

45 Remondi, F.; Aparecido, M.; Souza, R. K. T. Não adesão ao tratamento medicamentoso contínuo: prevalência e determinantes em adultos de 40 anos e mais. Cad Saude Pública, v. 30, n. 1, p. 126-136, 2014.

46 Gonzalez, J.S.; Schneider, H.E.; et al. Validity of medication adherence self-reports in adults with type 2 diabetes. Diabetes care, v. 36, n. 4, p. 831-7, 2013.

47 Handoko, K.B.; Zwart-van Rijkom, J.E.; et al. Drug treatment-related factors of inadequate seizure control. Epilepsy Behav, v. 13, n. 3, p. 545-548, 2008.

48 Brown, I.; Sheeran, P.; Reuber, M. Enhancing antiepileptic drug adherence: a randomized controlled trial. Epilepsy Behav, v. 16, n. 4, p. 634-639, 2009. 
49 DiIorio, C.; Reisinger, E.L.; et al. A telephone-based self-management program for people with epilepsy. Epilepsy Behav, v. 14, n. 1, p. 232-6, 2009.

50 Ibinda, F.; Mbuba, C.K.; et al. Evaluation of Kilifi epilepsy education programme: a randomized controlled trial. Epilepsia, v. 55, n. 2, p. 344-352, 2014.

51 Lua, P.L.; Neni, W.S. A randomised controlled trial of an SMS-based mobile epilepsy education system. J Telemed Telecare, v. 19, n. 1, p. 23-28, 2013.

52 Aliasgharpour, M.; Dehgahn Nayeri, N.; et al. Effects of an educational program on self-management in patients with epilepsy. Seizure, v. 22, n. 1, p. 48-52, 2013.

53 Carpentier, N.; Jonas, J.; et al. Direct evidence of nonadherence to antiepileptic medication in refractory focal epilepsy. Epilepsia, v. 54, n. 1, p. e20-3, 2013.

54 Landmark, C.J.; Rytter, E.; Johannessen, S.I. Clinical use of antiepileptic drugs at a referral centre for epilepsy. Seizure, v. 16, n. 4, p. 356-364, 2007.

55 Guerreiro, C.A.M.; Ramos, M.C.; Annes, M. Dosagens Séricas Repetidas de Enticonvulsivantes em Pacientes Epilépticas. Arq Neuropsiquiatr, v. 51, n. 1, p. 36-49, 1993.

56 Specht, U.; Elsner, H.; et al. Postictal serum levels of antiepileptic drugs for detection of noncompliance. Epilepsy Behav, v. 4, n. 5, p. 487-495, 2003.

57 Paschal, A.M.; Rush, S.E.; Sadler, T. Factors associated with medication adherence in patients with epilepsy and recommendations for improvement. Epilepsy Behav, v. 31, p. 346-350, 2014.

58 Garber, M.C.; Nau, D.P.; et al. The Concordance of Self-Report With Other Measures of Medication Adherence. Medical Care, v. 42, n. 7, p. 649-652, 2004.

$59 \mathrm{Li}, \mathrm{J} . ; \mathrm{Si}, \mathrm{Y} . ;$ et al. Enhancing medical compliance of patients with convulsive epilepsy in rural community: a randomized intervention trial. Epilepsia, v. 54, n. 11, p. 1988-1996, 2013. 
60 Heinrich, C.; Kuiper, R.A. Using Handheld Devices to Promote Medication Adherence in Chronic Illness. JNP, v. 8, n. 4, p. 288-293, 2012.

61 Cohen-Mansfield, J.; Creedon, M.A.; et al. Electronic Memory Aids for Community-Dwelling Elderly Persons: Attitudes, Preferences, and Potential Utilization. Journal of Applied Gerontology, v. 24, n. 1, p. 3-20, 2005.

62 Sterns, A. Curriculum design and program to train older adults to use personal digital assistants.Gerontologist, v. 45, n. 6, p. 828-834, 2005.

$63 \mathrm{Wu}$, A.W.; Snyder, C.F.; et al. A randomized trial of the impact of a programmable medication reminder device on quality of life in patients with AIDS. AIDS patient care and STDs, v. 20, n. 11, p. 773-81, 2006.

64 Lawrence, D.B.; Allison, W.; et al. Improving medication adherence with a targeted, technologydriven disease management intervention. Disease management, v. 11, n. 3, p. 141-4, 2008.

65 Saccol, A.Z.; Reinhard, N. Tecnologias de informação móveis, sem fio e ubíquas: definições, estado-da-arte e oportunidades de pesquisa. Revista de Administração Contemporânea, v. 11, n. 4, 175-98, 2007.

66 Zedler, B.K.; Kakad, P.; et al. Does packaging with a calendar feature improve adherence to selfadministered medication for long-term use? A systematic review. Clinical Therapeutics, v. 33, n. 1, p. 62-73, 2011.

67 Petersen, M.L.; Wang, Y.; et al. Pillbox organizers are associated with improved adherence to HIV antiretroviral therapy and viral suppression: a marginal structural model analysis. Clinical infectious Diseases, v. 45, n. 7, p. 908-15, 2007.

68 Al-Aqeel, S.; Al-Sabhan, J. Strategies for improving adherence to antiepileptic drug treatment in patients with epilepsy. Cochrane Database Systematic Reviews, n. 1, 2011. 
69 ReBEC - Registro Brasileiro de Ensaios Clínicos[Internet]: Rio de Janeiro (RJ): Escola de Enfermagem da Universidade de São Paulo, Cristina Helena Costanti Settervall; 2014 -Identifier RBR$943 \mathrm{kwq}$. Adesão terapêutica medicamentosa de pacientes com epilepsia; Disponível em: http://www.ensaiosclinicos.gov.br/rg/RBR-943kw. Acesso em 26 jun. 2014

70 Urbaniak, G.; Plous, S. Research Randomizer (version 4.0)[Programa de Computador]. Disponível em: http://www.randomizer.org/. Acesso em: 22 jun. 2013.

71 Divisão de Laboratório Central do Hospital das Clínicas da Faculdade de Medicina da Universidade de São Paulo (HCFMUSP). Manual de Exames. Disponível em: http://dlc.edm.org.br/portal/index.php/manualde-exames. Acesso em: 07 abr. 2012.

72 Ferrari, C.M.M.; Castro, L.H.M.; et al. Validity and reliability of the Portuguese version of the Epilepsy Medication Treatment Complexity Index for Brazil. Epilepsy Behav, v. 21, n. 4, p. 467-72, 2011.

73 Dilorio, C.; Yeager, K.; et al. The epilepsy medication and treatment complexity index: reliability and validity testing. Journal of Neuroscience Nursing, v. 35 , n. 3, p. 155-166, 2003.

74 R Core Team (2014). R: A language and environment for statistical computing. R Foundation for Statistical Computing, Vienna, Austria. Disponível em: http://www.R-project.org/. Acesso em: 1 maio 2014.

75 BRASIL. Decreto no 8.166, de 23 de dezembro de 2013. Regulamenta a Lei no 12.382 , de 25 de fevereiro de 2011, que dispõe sobre o valor do salário mínimo e a sua política de valorização de longo prazo. Brasília, Diário Oficial da União, 24 dez 2013.

76 Banerjee, P.N.; Filippi, D.; Hauser, A.W. The descriptive epidemiology of epilepsy-a review. Epilepsy Research, v. 85, n. 1, p. 31-45, 2009.

77 Das, K.; Banerjee, M.; et al. Evaluation of socioeconomic factors causing discontinuation of epilepsy treatment resulting in seizure recurrence: A study in 
an urban epilepsy clinic in India. Seizure, v. 16, n. 7, p. 601-607, 2007.

78 Lima-Costa, M.F.; Barreto, S.M.; Giatti, L. Condições de saúde, capacidade funcional, uso de serviços de saúde e gastos com medicamentos da população idosa brasileira: um estudo descritivo baseado na Pesquisa Nacional por Amostra de Domicílios. Cad Saúde Pública, v. 19, p. 735-743, 2003.

79 Annegers, J.F.; Dubinsky, S.; et al. The incidence of epilepsy and unprovoked seizures in multiethnic, urban health maintenance organizations. Epilepsia, v. 40, n. 4, p. 502-6, 1999.

80 Noronha, A.; Borges, M.; et al. Prevalence and pattern of epilepsy treatment in different socioeconomic classes in Brazil. Epilepsia, v. 48, n. 5, p. 880-885, 2007.

81 McCagh, J.; Fisk, J.E.; Baker, G.A. Epilepsy, psychosocial and cognitive functioning. Epilepsy Research, v. 86, n. 1, p. 1-14, 2009.

82 Boer, H.M. de; Mula, M.; Sander, J.W. The global burden and stigma of epilepsy. Epilepsy Behav, v. 12, n. 4 , p. $540-546,2008$.

83 Gomes, M. da M. Epilepsia e incapacidade laborativa. J Epilepsy Clin Neurophysiol, v. 15, p. 130-134, 2009.

84 Salgado, P.C.B.; Souza, E.A.P. de S. Impacto da Epilepsia no Trabalho: avaliação da qualidade de vida. Arq Neuropsiquiatr, v. 60, n. 2-B, p. 442-445, 2002.

85 Nickel, R.; Silvado, C.E.; et al. Quality of life issues and occupational performance of persons with epilepsy. Arq Neuropsiquiatr, v. 70, n. 2, p. 140-144, 2012.

86 World Health Organization (2012). Epilepsy: Fact sheet N॰999 October 2012. N॰999. Disponível em: http://www.who.int/mediacentre/factsheets/fs999/e/. Acesso em: 5 jun. 2014. 
87 Alonso, N.B.; Muszkat, R.S.A.; et al. Suporte familiar nas epilepsias. J Epilepsy Clin Neurophysiology, v. 16, n. 4, p. 170-173, 2010.

88 Bressi, C.; Cornaggia, C.M.; et al. Epilepsy and family expressed emotion: results of a prospective study. Seizure, v. 16, n. 5, p. 417-23, 2007.

89 Engel, J.J. Introduction to temporal lobe epilepsy. Epilepsy Research., v. 26, n. 1, p. 141-150, 1996.

90 Hermann, B.P.; Seidenberg, M.; et al. Neuropsychological characteristics of the syndrome of mesial temporal lobe epilepsy. Archives of neurology, v. 54, n. 4, p. 369-376, 1997.

91 Hermann, B.; Seidenberg, M.; et al. The neurodevelopmental impact of childhood-onset temporal lobe epilepsy on brain structure and function. Epilepsia, v. 43, n. 9, p. 1062-71, 2002.

92 Alessio, A.; Bonilha, L.; et al. Memory and language impairments and their relationships to hippocampal and perirhinal cortex damage in patients with medial temporal lobe epilepsy. Epilepsy Behav, v. 8, p. 593600, 2006.

93 Freitas-Lima, P.; Baldoni Ade, O.; et al. Drug utilization profile in adult patients with refractory epilepsy at a tertiary referral center. Arq Neuropsiquiatr, v. 71, n. 11, p. 856-861, 2013.

94 Malerba, A.; Ciampa, C.; et al. Patterns of prescription of antiepileptic drugs in patients with refractory epilepsy at tertiary referral centres in Italy. Epilepsy Research, v. 91, n. 2-3, p. 273-282, 2010.

95 Yeager, K.A.; DiIorio, C.; et al. The complexity of treatments for persons with epilepsy. Epilepsy Behav, v. 7, n. 4, p. 679-686, 2005.

96 Hovinga, C.A.; Asato, M.R.; et al. Association of nonadherence to antiepileptic drugs and seizures, quality of life, and productivity: survey of patients with epilepsy and physicians. Epilepsy Behav, v. 13, n. 2, p. 316-322, 2008. 
97 Neels, H.M.; Sierens, A.C.; et al. Therapeutic drug monitoring of old and newer anti-epileptic drugs. Clin Chem Lab Med, v. 42, n. 11, p. 1228-1255, 2004.

98 Moran, N.F.; Poole, K.; et al. Epilepsy in the United Kingdom: seizure frequency and severity, antiepileptic drug utilization and impact on life in 1652 people with epilepsy. Seizure, v. 13, n. 6, p. 425433, 2004.

99 Perucca, E. An introduction to antiepileptic drugs. Epilepsia, v. 46 Suppl 4, p. 31-7, 2005.

100 Varona, J.; Escribano, E.; et al. Fenobarbital: farmacocinética, toxicología y monitorización por el Laboratorio. Rev Diagn Biol, v. 50, n. 1, p. 13-16, 2001.

101 Patsalos, P.N.; Perucca, E. Review Clinically important drug interactions in epilepsy: general features and interactions between antiepileptic drugs. Lancet Neurology, v. 44, n. 0, p. 347-356, 2003.

102 Eadie, M.J. Therapeutic drug monitoring: antiepileptic drugs. $\mathrm{Br}$ J Clin Pharmacol, v. 46, n. 3, p. 185-193, 1998.

103 Bautista, R.E.; Rundle-Gonzalez, V. Effects of antiepileptic drug characteristics on medication adherence. Epilepsy Behav, v. 23, n. 4, p. 437-441, 2012. 


\section{Apêndices}




\title{
APÊNDICES
}

\section{Apêndice A - Termo de Consentimento Livre e Esclarecido}

\author{
Convidamos o (a) senhor(a) para participar do estudo adesão terapêutica \\ medicamentosa de pacientes com epilepsia.
}

O objetivo do presente estudo é conhecer o efeito do uso de dois diferentes recursos para melhorar a adesão terapêutica de pacientes com epilepsia.

Nosso intuito é testar duas estratégias que podem melhorar a adesão ao tratamento de pacientes com essa doença, sendo de grande importância a sua participação.

O (a) senhor(a) está sendo convidado(a) para responder questões em relação a sua doença, medicações prescritas pelo médico durante a consulta e como você faz uso de suas medicações.

A baixa adesão ao tratamento medicamentoso é provavelmente a causa mais importante da epilepsia não controlada e da maior morbimortalidade em pacientes com esta condição clínica frente à população em geral. Intervenções para melhorar a adesão medicamentosa do paciente com epilepsia, especialmente as que envolvem o paciente no tratamento, são essenciais para controle da doença e redução de suas consequências.

Além das entrevistas será solicitada sua permissão para coletar o seu sangue, para um exame que avalia a concentração de medicações para epilepsia. Será necessária a sua participação em três encontros no ambulatório de epilepsia do Hospital das Clínicas da Faculdade de Medicina. Em cada encontro o(a) senhor(a) será entrevistado(a) e será realizada uma nova coleta de sangue. Os encontros serão hoje, daqui a cerca de um mês e daqui a seis meses.

Se o $\mathrm{Sr}$ (a) concordar em participar do estudo é garantida sua liberdade de deixar de participar da pesquisa em qualquer momento, sem nenhum prejuízo ao seu tratamento no hospital. Todas as informações obtidas serão analisadas em conjunto com as obtidas com outros pacientes, não será divulgada em nenhum momento sua identificação. Os pesquisadores se comprometem a utilizar dados e materiais somente para a pesquisa. Não haverá gastos pessoais em qualquer fase do estudo, mas também sua participação não envolve nenhuma compensação financeira. $\mathrm{O} \mathrm{Sr}(\mathrm{a})$ tem direito de conhecer os resultados desta pesquisa em qualquer momento, mesmo antes do seu término (resultados parciais).

Em qualquer etapa do estudo, o $\operatorname{Sr}($ a) poderá conversar com a pesquisadora para esclarecimento de dúvidas, a enfermeira Cristina Helena Costanti Settervall, que realizará as entrevistas, poderá ser encontrada no telefone (XX) XXXXXXXX.. Ela estará presente no ambulatório de epilepsia, no prédio dos ambulatórios do HCFMUSP, às sextasfeiras no horário de atendimento.

Este projeto foi analisado aprovado pelo Comitê de Ética em Pesquisa da Escola de Enfermagem da Universidade de São Paulo, e-mail: edipesq@usp.br, telefone (11) 3061-7548. Informamos também que este Termo de Consentimento Livre e Esclarecido tem duas vias, uma via do pesquisador e a segunda via ficará com o(a) sr(a).

Fui suficientemente esclarecido(a) pela enfermeira Cristina Helena Costanti Settervall em relação ao projeto: "Estudo comparativo de recursos auxiliares para adesão terapêutica medicamentosa de pacientes com epilepsia".

Ficaram claros para mim o propósito do estudo, os procedimentos a serem realizados, seus desconfortos e riscos, as garantias de confidencialidade e de esclarecimentos permanentes. Ficou claro também que minha participação é isenta de despesas e que tenho garantia de acesso a tratamento hospitalar quando necessário, independentemente de minha participação na pesquisa. Concordo voluntariamente em participar deste estudo e por isso assino este termo.

\section{Assinatura do paciente}

Declaro que obtive de forma apropriada e voluntária o Consentimento Livre e Esclarecido deste paciente. 
Apêndice B - Diário de medicação

\begin{tabular}{|l|l|l|l|l|l|}
\hline Nome: & Diário de Medicacão & & Data: \\
Enfermeiro:
\end{tabular}




\section{Apêndice C - Instruções para Elaboração do Diário de Medicação junto do Paciente}

A elaboração de um diário de medicação consiste na atividade de reescrever a prescrição das DAEs recebida pelo paciente em consulta médica. A prescrição médica será escrita, com a colaboração do paciente, em forma de uma tabela, que permite separar e ordenar as medicações que compõem o regime terapêutico, a quantidade de comprimidos a serem tomados e o período indicado para tomada de medicação.

Primeiramente serão preenchidos os dados de identificação do paciente com as informações registradas em prontuário.

Para elaboração do diário de medicação junto do paciente, o pesquisador deverá ter acesso à prescrição médica e solicitar ao paciente descrever como compreendeu o regime terapêutico proposto durante a consulta médica.

Será solicitada também ao paciente a descrição de como faz uso das DAEs e como adéqua o regime terapêutico às atividades diárias, de forma que não se esqueça de tomar a medicação nos horários indicados.

Após o levantamento destas informações, o investigador junto do paciente irá preencher a tabela do Diário de Medicação (Apêndice B).

A primeira medicação incluída na tabela do diário de medicação deve ser inserida pelo investigador, mas enquanto este preenche as informações da DAE na tabela, deve orientar concomitantemente o paciente em relação ao que significa cada informação do diário de medicação.

A segunda e as demais DAEs deverão ser inseridas pelo paciente, com auxílio do investigador. Neste momento, a pesquisador deve estimular o paciente a associar a tomada de medicação com horários de atividades diárias e solicitar que este preencha com uma caneta a tabela com estas informações, de forma que fiquem claras para sua compreensão.

Após o término do preenchimento da tabela do diário de medicação, será solicitado ao paciente que repita o nome, a quantidade, a instrução e os horários de tomada de todas as medicações, até que este consiga dizer sozinho o esquema terapêutico.

$\mathrm{O}$ diário de medicação será de uso pessoal do paciente. $\mathrm{O}$ investigador ao final da construção da tabela orientará o paciente a levar o diário de medicação e deixá-lo exposto em locais de preferência do paciente, desde que este local the permita lembrar do esquema medicamentoso da prescrição médica. 


\section{Apêndice D - Instrumento para seleção dos participantes da pesquisa}

Nome:

RGHC:

Número Prontuário Ambulatório:

DATA DA COLETA:

Instrumento para Avaliação da Adesão - Teste de Morisky

1.Você alguma vez esquece de tomar seu medicamento?

Sim ( ) Não ( )

2.Você às vezes é descuidado para tomar seu medicamento?

Sim ( ) Não ( )

3.Quando você se sente melhor às vezes você para de tomar seu medicamento?

Sim ( ) Não ( )

4.Às vezes se você se sente pior quando toma o

medicamento, você para de tomá-lo?

Sim ( ) Não ( )

( ) Baixa adesão (três ou quatro questões afirmativas)

( ) Média adesão (uma ou duas questões afirmativas)

( ) Alta adesão (quatro questões negativas)

\section{Cheklist dos Critérios de Participação}

1.Diagnóstico de epilepsia há mais de um ano

$\operatorname{Sim}($ ) Não ( )

2.Idade maior ou igual a 18 anos

$\operatorname{Sim}($ ) Não ( )

3.Escolaridade mínima de quatro anos

$\operatorname{Sim}($ ) Não ( )

4.Independente na vida diária

$\operatorname{Sim}($ ) Não ( )

5.Ausência de deficiência mental e psíquica

prévia

Sim ( ) Não ( )

6.Faz uso dos recursos auxiliares testados neste estudo

$\operatorname{Sim}($ ) Não ( )

7.Possui um aparelho celular

Sim ( ) Não ( )

8.Outras doenças crônicas

Sim ( ) Não ( )

9.Aumento ou retirada de DAEs diária ou semanalmente

Sim ( ) Não ( )

\section{ATENDE TODOS OS CRITÉRIOS DE PARTICIPAÇÃO \\ Sim ( ) Não ( )}




\section{Apêndice E - Formulário para Entrevista(20)}

Nome:

Número Prontuário Ambulatório:

DATA DA COLETA:
RGHC:

GRUPO: Telefone para contato:

\section{Identificacão}

1 Idade:

2 Sexo:
( ) Masculino
( ) Feminino

3. Vínculo conjugal

Você vive em companhia de cônjuge ou companheiro?

Sim ( ) Não ( )

Caso não, já viveu anteriormente?

Sim ( ) Não ( )

1.4. Qual sua cor da pele?

$$
\begin{aligned}
& \text { Branca ( ) } \\
& \text { Parda ( ) } \\
& \text { Amarela ( ) } \\
& \text { Preta/negra ( ) } \\
& \text { Outra ( ) Especifique: }
\end{aligned}
$$

\section{$\underline{\text { Dados Socioeconômicos }}$}

1. Escolaridade

Completei até série do ensino

2. Situação ocupacional
( ) empregado
( ) empregador
( ) autônomo
( ) afastado (auxílio-doença)
( ) aposentado
( ) desempregado

- Instrumento Adaptado: Ferrari CMM. Adesão ao tratamento e qualidade de vida de indivíduos com epilepsia em tratamento ambulatorial. [Tese]. Escola de Enfermagem da Universidade de São Paulo. São Paulo, 2011. 


\section{Ocupação:}

(escrever como o entervistado se qualifica: se ajudante ou auxiliar definir " $d o$ que”, especificar o setor econômico; se aposentado, descrever a ocupação em que atuou por mais tempo)

\section{Renda per capita familiar}

1. Qual os ganhos das pessoas que moram com você, qual a renda somada de todos da família no último mês? (incluir todas as possíveis fontes)

$\mathrm{R} \$$

( ) Não sabe

( ) Não quer informar

2. Quantas pessoas dependem desta renda

\section{Variáveis Relacionadas à Doença}

1. Há quanto tempo o $\operatorname{Sr}(\mathbf{a})$ sabe que tem epilepsia? (quando foi informado pela primeira vez) anos.

2. Quanto tempo faz que o $\operatorname{Sr}(a)$ toma medicamentos para epilepsia?

Anos

3. Frequência das crises nos últimos 30 dias:

4. Data da última crise: 1

\section{Percepção do controle de crises}

( ) Controlada

( ) Nem sempre controlada (menos frequente e ou menos grave)

( ) Não controlada

Variáveis Relacionadas ao Apoio Familiar

1. Você tem algum familiar e/ou algum amigo que auxilia no tratamento?
( ) $\operatorname{Sim}$
( ) Não

2. Caso SIM, qual a frequência?
( ) Sempre
( ) Quase sempre( ) Raramente 


\section{Variáveis Relacionadas ao Acesso a DAEs}

1. Quanto aos medicamentos, normalmente, você:
( ) Retira na farmácia do HC
( ) Recebe medicação em casa
( ) Outro. Especifique:

2. Consegue todos os medicamentos prescritos?

( ) Sim, consegue todos os medicamentos prescritos.

( ) Não, porém consegue parte dos medicamentos prescritos.

( ) Não consegue os medicamentos prescritos.

3. E quando não consegue a medicação?

( ) Fica sem tomar

( ) Compra a medicação

( ) Outro. Especifique:

\section{Dosagem Plasmática}

\begin{tabular}{|l|l|l|l|}
\hline DAE & $\begin{array}{c}\text { Realização da } \\
\text { coleta }\end{array}$ & $\begin{array}{c}\text { Concentração } \\
\text { plasmática }\end{array}$ & Data da Coleta \\
\hline & & & \\
\hline & & & \\
\hline & & & \\
\hline
\end{tabular}




\section{Apêndice F - Instrumento para Acompanhamento}

Nome:

Número Prontuário Ambulatório:

Data:
RGHC:

GRUPO:

FASE:

\section{Instrumento para Avaliação da Adesão - Teste de Morisky}

1.Você alguma vez esquece de tomar seu medicamento? $\operatorname{Sim}()$ Não ( )

2.Você às vezes é descuidado para tomar seu medicamento?

3.Quando você se sente melhor às vezes você para de tomar seu medicamento?

4.Às vezes se você se sente pior quando toma o medicamento, você para de tomá-lo?

( ) Baixa adesão (três ou quatro questões afirmativas)

( ) Média adesão (uma ou duas questões afirmativas)

( ) Alta adesão (quatro questões negativas)

\section{$\underline{\text { Acesso às DAEs }}$}

1. Conseguiu receber todos os medicamentos prescritos gratuitamente desde o último encontro?

( ) Conseguiu todos os medicamentos prescritos

( ) Conseguiu parte dos medicamentos prescritos

( ) Não conseguiu os medicamentos prescritos

\section{Listar DAEs que não recebeu:}

3. Motivo de não conseguir adquirir todas as medicações:

( ) Não recebeu todas as medicações em casa.

( ) Não recebeu medicações na farmácia do HC.

( ) Outro. Descreva: 
4. Se não conseguiu receber a medicação

( ) Ficou sem tomar

( ) Comprou a medicação

( ) Outro. Especifique:

\section{Controle de Crise}

1. Frequência das crises nos últimos 30 dias:

2. Data da última crise:

3. Percepção do controle de crises

( ) Controlada

( ) Nem sempre controlada (menos frequente e ou menos grave)

( ) Não controlada

\section{Dosagem Plasmática}

\begin{tabular}{|l|l|l|l|}
\hline DAE & $\begin{array}{c}\text { Realização da } \\
\text { coleta }\end{array}$ & $\begin{array}{c}\text { Concentração } \\
\text { plasmática }\end{array}$ & Data da coleta \\
\hline & & & \\
\hline & & & \\
\hline & & & \\
\hline
\end{tabular}


Apêndice G: BoxPlot da frequência de crises nos últimos 30 dias que antecederam a avaliação inicial. São Paulo, 2013-2014.

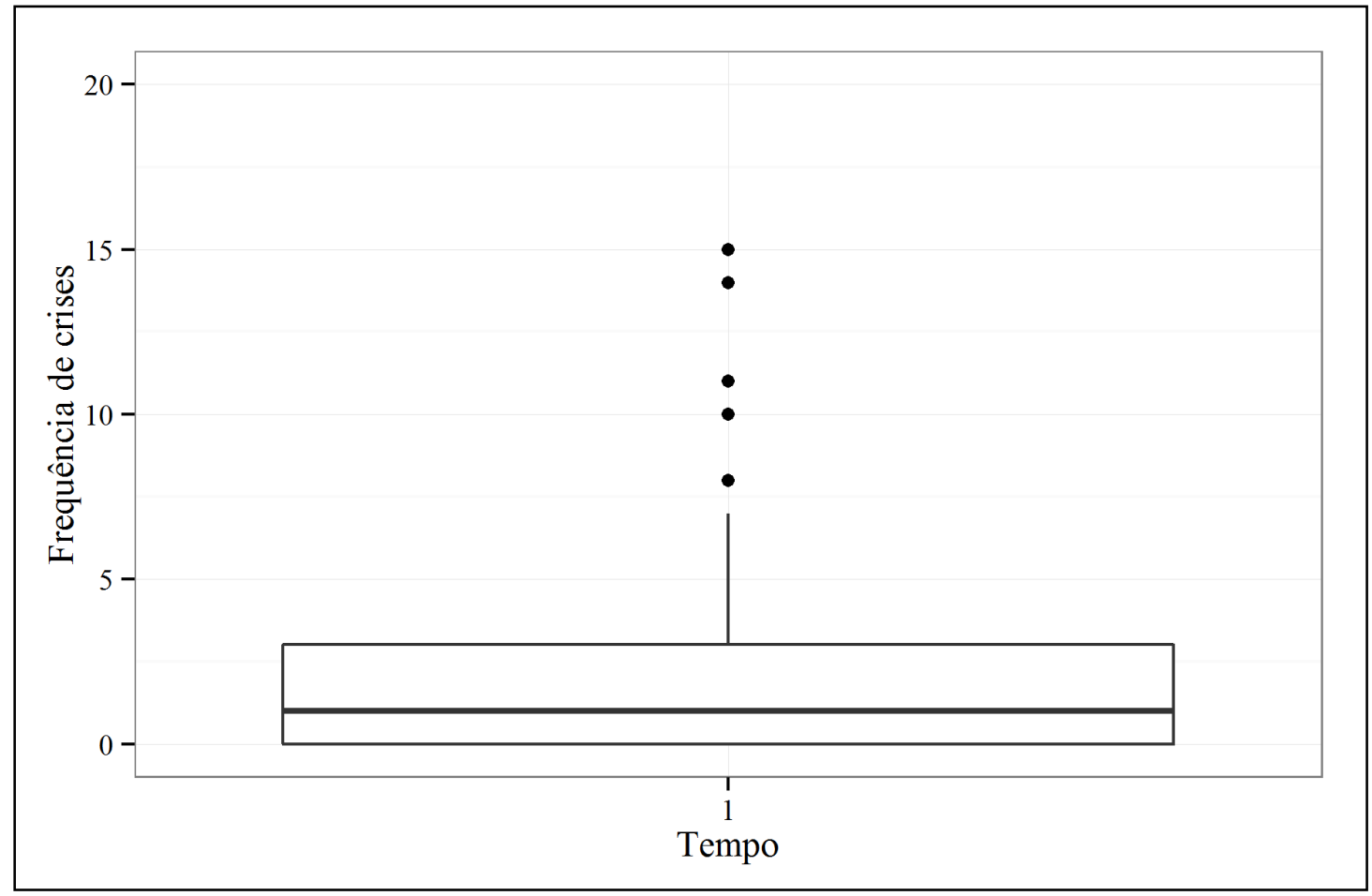


Anexos 


\begin{abstract}
ANEXOS
Anexo 1 - Instruções para aplicação dos instrumentos ICTME e Morisky $^{(20)}$

\section{EMTCI}

O instrumento deve ser aplicado por um entrevistador treinado e na presença do paciente. É utilizada uma folha para cada medicamento. O questionário apresenta quatro seções que se referem a informações gerais sobre o medicamento; freqüência da administração; instruções especiais e ações para administração.

$\mathrm{O}$ entrevistador deverá discutir cada item com o paciente, a fim de obter as informações necessárias para as quatro seções do instrumento.
\end{abstract}

\title{
$1^{\text {a }}$ Seção: Informações gerais sobre a medicação.
}

Colocar o nome genérico do medicamento; quantidade em relação ao número total de medicamentos prescritos; número de comprimidos tomado por dia e a dosagem.

\section{$2^{a}$ Seção: Frequência com que toma a medicação:}

Esta seção refere-se à quantidade de vezes e/ou horários das medicações. São possíveis dezesseis horários diferentes correspondentes a períodos tradicionalmente prescritos; por exemplo, duas vezes ao dia, a cada 4 horas, antes de dormir etc.

Cada horário tem uma pontuação específica e o valor está ao lado da alternativa assinalada. A opção selecionada deve estar relacionada somente ao intervalo ou horários e não ao número de comprimidos. Por exemplo, nos casos dos pacientes que tomam um comprimido ao dia ou dois ou mais comprimidos ao dia, a opção de escolha será relacionada à frequência de ingestão do medicamento que, nesse caso, é diária ou todas as manhãs, conforme resposta do paciente. Portanto, 1 ponto será atribuído segundo o questionário ou, se a opção for 1 comprimido 4 vezes ao dia, o valor dessa resposta será 4 .

\section{$3^{\text {a }}$ Seção: Instruções especiais}

Essas instruções são frequentemente solicitadas ao paciente epiléptico. Elas incluem diferentes doses da mesma medicação no mesmo dia ou em dias alternados, tomar em horários diferentes de outras medicações etc.

Atribuir um ponto para cada opção selecionada ou zero se nenhuma opção for selecionada.

\section{4 a Seção: Ações de administração}

Nesta seção estão listadas 13 ações diferentes; por exemplo, tomar a medicação com a comida, dividir o comprimido ao meio, misturar com a comida.

Colocar entre parênteses o número de vezes ao dia em que a ação é realizada.

Calcular o valor total desta seção somando os valores entre os parentes e do índice, somando todos os valores das três últimas seções. Pacientes que necessitam de várias medicações, portanto com mais de um medicamento prescrito em seu regime terapêutico, deverão ter os escores totais de todas as drogas prescritas somados, obtendo-se assim um único escore que indicará a complexidade de seu tratamento.

\section{TESTE DE MORISKY ${ }^{(27)}$}

O questionário de Morisky consiste em quatro perguntas, com respostas dicotômicas (sim e não). Assinale nos parênteses a resposta do paciente, some as repostas afirmativas e assinale a classificação da adesão terapêutica do respondente, conforme instruções no próprio instrumento.

Ferrari CMM. Adesão ao tratamento e qualidade de vida de indivíduos com epilepsia em tratamento ambulatorial. [Tese]. Escola de Enfermagem da Universidade de São Paulo. São Paulo, 2011. 


\section{Anexo 2 - Índice de Complexidade do Tratamento Medicamentoso em Epilepsia (ICTME)}

Identificação do Entrevistador:

Identificação do Paciente:

REGISTRO NO HC:

Instruções para o uso:

Registro no ambulatório:

Preencha uma folha separada para cada medicamento ou tratamento que você esteja tomando ou usando atualmente para o controle da sua epilepsia.

Informação Geral do Medicamento

a)Nome do medicamento/tratamento

b)Quantidade de medicamento/tratamento medicamentos/tratamentos.

c)Quantos comprimidos deste medicamento você toma todos os dias?

d)Como este medicamento é tomado? (Favor anotar a quantidade em $\mathrm{mg}$ )

\section{Frequência de Administração}

Com que frequência você toma ou usa este medicamento/tratamento? Indique quais opções se aplicam:

( ) diariamente (1)

( ) todas as manhãs (1)

( ) a cada 4 horas (6)

( ) a cada 6 horas (4)

( ) todas as noites/antes de dormir (1)

( ) $2 \mathrm{x}$ dia (2)

( ) $3 \mathrm{x}$ dia (3)

( ) $4 \mathrm{x}$ dia (4)

( ) dia sim, dia não (2)

( ) após as refeições/antes de dormir (4)

( ) antes das refeições/antes de dormir (4)

Outro. Especificar:

( )a cada 8 horas (3)

( )a cada 12 horas (2)

( )magneto se necessário, somente se ocorrer ataque epiléptico (1)

( ) medicamento quando necessário, somente se ocorrer ataque epiléptico (1)

Some os números de todas as respostas assinaladas para a pontuação total da frequência:

\section{Instruções Especiais}

Você segue instruções especiais sobre como tomar esse medicamento para o ataque epiléptico/usar esse tratamento?

Indique quais opções que se aplicam:

( ) Dosagem diferente no mesmo dia.

( ) Em horário diferente ao dos antiácidos

( ) Antes de levantar

( ) A dose pode mudar se eu tiver um ataque epiléptico

( ) A dose pode mudar dependendo do período menstrual

( )Em horários diferentes dos outros medicamentos

( )Passar o magneto sobre o gerador um número específico de vezes no início das crises

( ) Doses diárias alternadas

( ) Outra instrução especial: Especificar:

Some o número de respostas marcadas para a pontuação total de instruções especiais:

(Se nenhuma, coloque 0)

\section{Ações de administração:}

Você precisa fazer algo especial para ajudá-lo(a) a tomar este medicamento/tratamento?

Coloque o número de vezes ao dia que você faz isto entre os parênteses.

(__ t toma com alimentos

(__ quebra o comprimido na metade ou em pedacinhos

(__ creme/pomada

) comprimidos esmagados

) toma mais de um comprimido quando toma uma dose

) outras instruções especiais. Especifique:

Some todos os números nos parênteses para o total das ações na administração:

(Se nenhuma, marque 0)

)toma de estômago vazio )abre as cápsulas

)deve levar o medicamento/tratamento em todos os momentos

)sublingual (derrete sob a língua)

) mistura na comida (p. ex., pudins)

)administra por via retal

\section{) toma comprimidos com diferentes $\mathrm{mg}$ ao \\ tomar uma dose}

(Se nenhuma, marque 0 )

Ferrari CMM. Adesão ao tratamento e qualidade de vida de indivíduos com epilepsia em tratamento ambulatorial. [Tese]. Escola de Enfermagem da Universidade de São Paulo. São Paulo, 2011. 


\section{Anexo 3 - Comitê de Ética em Pesquisa da Escola de Enfermagem da Universidade de São Paulo (EEUSP)}

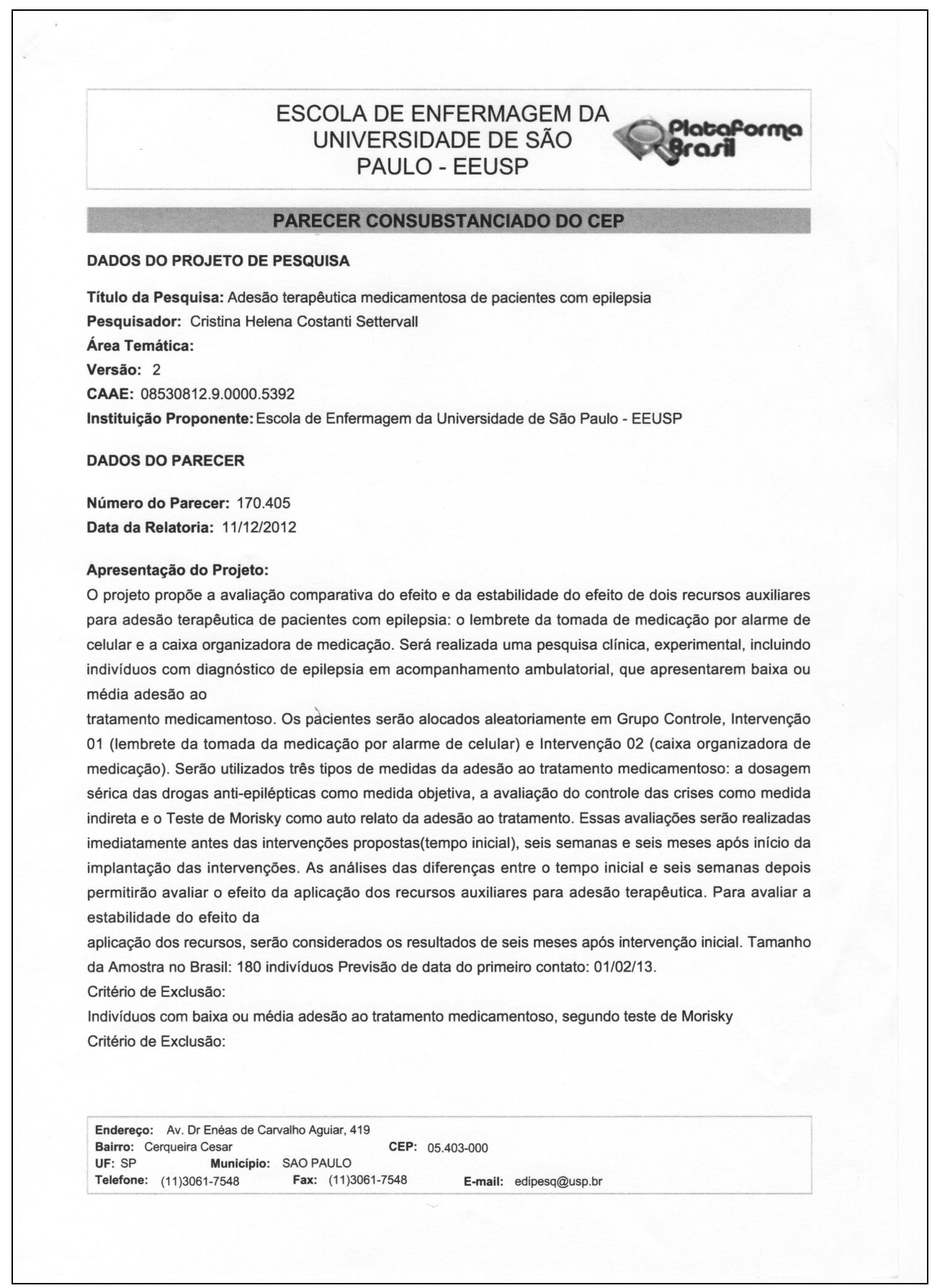


Cristina Helena Costanti Settervall

ESCOLA DE ENFERMAGEM DA UNIVERSIDADE DE SÃO PAULO - EEUSP

Serão excluídos da amostra pacientes com prescrição médica de aumento ou retirada de doses de DAES diariamente ou semanalmente, aqueles que já fazem uso dos recursos auxiliares testados neste estudo para melhorar adesão e os com outras doenças crônicas em tratamento medicamentoso contínuo.

Os dados serão armazenados em banco de dados computadorizado e provas estatísticas serão aplicadas, conforme orientação de especialista da área.

Objetivo da Pesquisa:

Comparar o efeito e a estabilidade do efeito da aplicação dos seguintes recursos auxiliares para adesão terapêutica de pacientes com epilepsia em acompanhamento ambulatorial: lembrete da tomada da medicação por alarme de celular e caixa organizadora de medicação.

Avaliação dos Riscos e Benefícios:

Riscos: intercorrências decorrentes da punção venosa.

A pesquisadora garantiu que as possiveis intercorrências serão atendidas no hospital que é campo de pesquisa.

Beneficios:

Os resultados da pesquisa podem possibilitar o aumento da adesão terapêutica dos pacientes no tratamento.

Comentários e Considerações sobre a Pesquisa:

O projeto não apresenta óbices éticos

Considerações sobre os Termos̀ de apresentação obrigatória:

O Termo de Consentimento Livre e Esclarecido está de acordo com as recomendações preconizadas pela Resolução 196/96

Recomendações:

Ajustes no TCLE

Conclusões ou Pendências e Lista de Inadequações:

Este CEP considerou o projeto aprovado, por não apresentar questões que comprometem a ética do estudo, mesmo com a necessidade de ajustes no TCLE.

Situação do Parecer:

Aprovado

Necessita Apreciação da CONEP:

Não

Considerações Finais a critério do CEP:

A aprovação do Comitê de Ética em Pesquisa da EEUSP não substitui a autorização da instituição coparticipante antes do início da pesquisa.

Endereço: Av. Dr Enéas de Carvalho Aguiar, 419 Bairro: Cerqueira Cesar
UF: SP

Telefone: (11)3061-7548 Fax: (11)3061-7548 E-mail: edipesq@usp.br 


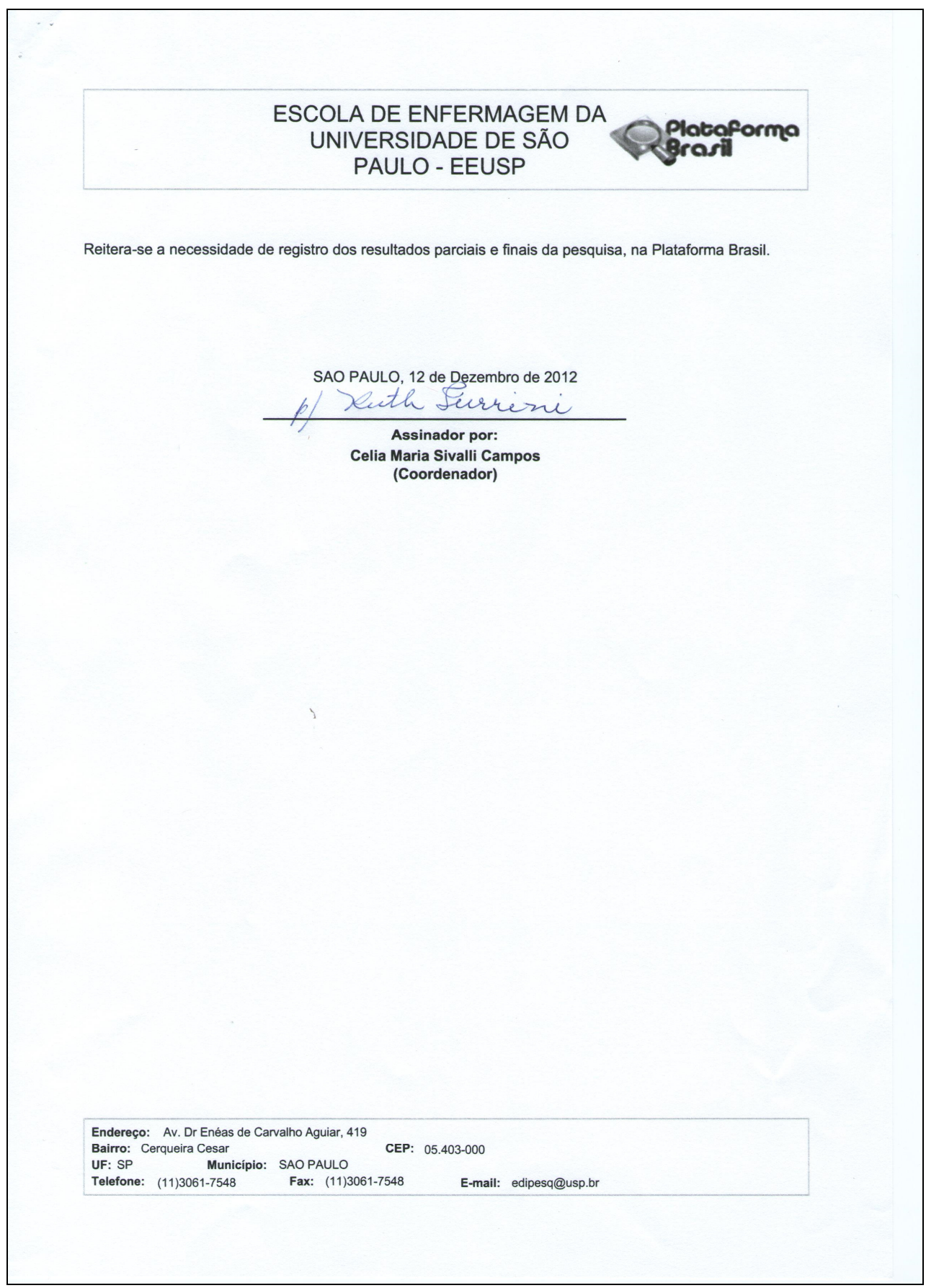


Anexo 4 - Comissão de Ética para Análise de Projetos de Pesquisa (CAPPesq) do HCFMUSP

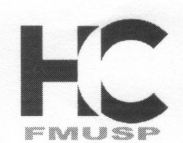

\section{Hospital das Clínicas da FMUSP}

Comissão de Ética para Análise de Projetos de Pesquisa - CAPPesq

PROJETO DE PESQUISA

Elaborado pela Instituição Coparticipante

Título: Adesão terapêutica medicamentosa de pacientes com epilepsia

Pesquisador Responsável: Cristina Helena Costanti Versão: 2

Settervall

CAAE: 08530812.9 .0000 .5392

Instituição: Escola de Enfermagem da Universidade de São Paulo - EEUSP

\section{DADOS DO PARECER}

Número do Parecer: 172.864

Data da Relatoria: $14 / 12 / 2012$

Apresentação do Projeto: Trata-se de estudo que tem como instituição proponente a Escola de Enfermagem da Universidade de São Paulo-EEUSP

Objetivo da Pesquisa: Comparar o efeito e a estabilidade do efeito da aplicação dos seguintes recursos auxiliares para adesão terapêutica de pacientes com epilepsia em acompanhamento ambulatorial: lembrete da tomada da medicação por alarme de celular e caixa organizadora de medicação.

Avaliação dos Riscos e Benefícios: Adequados já analisados pelo CEP da Instituição Proponente

Comentários e Considerações sobre a Pesquisa: Nenhum

\section{Considerações sobre os Termos de apresentação obrigatória: Adequados}

Conclusões ou Pendências e Lista de Inadequações: 0 estudo será realizado no ambulatório de Eplepsia do HCFMUSP do departamento de neurologia do HCFMUSP tendo sido anexada carta de concordância do responsável - Dr. Luiz Henrique Martins Castro

Situação do Parecer: Aprovado

Necessita Apreciação da CONEP: Não.

São Paulo, 14 de Dezembro de 2012

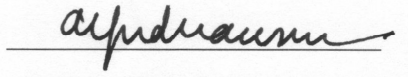

PROF. DR. ALFREDO JOSÉ MANSUR Coordenador

Comissão de Ética para Análise de Projetos de Pesquisa - CAPPesq

Rua Dr. Ovídio Pires de Campos, 225 - Prédio da Administração - 50 andar CEP 05403-010 - São Paulo - SP.

5511 2661-7585 - 5511 2661-6442 ramais: 16, 17, 18 | marcia.carvalho@hc.fm.usp.br 